INSTITUTO DE PESQUISAS ENERGÉTICAS E NUCLEARES

Autarquia associada à Universidade de São Paulo

\begin{abstract}
DETERMINAÇÃO DE POTÊNCIA DE DIFERENTES PREPARAÇÕES DE FOLICULOTROFINA, LUTEOTROFINA E TIREOTROFINA: COMPARAÇÃO ENTRE A QUANTIFICAÇÃO POR CROMATOGRAFIA LÍQUIDA EM FASE REVERSA E POR BIOENSAIO IN VIVO
\end{abstract}

BEATRIZ ELANE DE ALMEIDA

Tese apresentada como parte dos requisitos para obtenção do Grau de Doutor em Ciências na Área de Tecnologia Nuclear - Aplicações.

Orientadora:

Profa. Dra. Maria Teresa C. P. Ribela

Versão Corrigida

Versão Original disponível no IPEN

SÃo PAULO

2013 
Alos meus pais Eroilia e Dedro, ao mou noivo EEmerson, aos seus pais Geni e Sosk e a toda minha familia e amigos, pelo constante amor $e$ apoio. QEm especial aos meus afithados Xarina $e$ Euan, pela docura de seus othares. 


\section{Agradecimentos}

A Deus, por Seu amor incondicional.

À Dra. Maria Teresa de Carvalho Pinto Ribela, pela orientação e confiança, mais uma vez o meu reconhecimento e gratidão.

Ao Dr. Paolo Bartolini, pela atenção e contribuição neste trabalho.

Ao amigo Johnny, por todo ensinamento e companheirismo.

À Dra. Cibele N. Peroni, Dra. Kayo Okazaki e Dr. Carlos R. J. Soares, pelo incentivo e colaboração.

Às amigas, Arlete, Cláudia, Dani, Ednéia, Eliana, Eliza, Fernanda, Flávia, Geiza, Gi, Giuliana, Ivete, Juliana, Karina, Keli, Larissa, Marina, Mariana, Márcia, Miriam, Natália, Neide, Patrícia, Regina, Renata, Rosa, Rosângela, Rute, Susana, Taís, Thais, e Tamara, pelo incentivo, ajuda e pelas boas risadas. Valeu meninas!

Aos amigos, Bruno, Flávio, Herbert, José Maria, Junqueira, Marcos, Nélio, Perez, Roberto, Rodrigo, Patrick, Vicent companheiros sempre prontos a ajudar.

A todos os colegas do Centro de Biotecnologia, que direta e/ou indiretamente contribuíram para elaboração deste trabalho.

Ao Instituto de Pesquisas Energéticas e Nucleares, pela oportunidade de executar este trabalho e pelo apoio financeiro. 
"Viver é como andar de bicicleta:

É preciso estar em constante movimento para manter o equilíbrio."

(Albert Einstein) 


\title{
DETERMINAÇÃO DE POTÊNCIA DE DIFERENTES PREPARAÇÕES DE FOLICULOTROFINA, LUTEOTROFINA E TIREOTROFINA: COMPARAÇÃO ENTRE A QUANTIFICAÇÃO POR CROMATOGRAFIA LÍQUIDA EM FASE REVERSA E POR BIOENSAIO IN VIVO
}

\author{
Beatriz Elane de Almeida
}

\begin{abstract}
RESUMO
Com a intenção de estabelecer métodos físico-químicos como uma alternativa ao bioensaio in vivo para determinação de atividade biológica, o conteúdo de hFSH, hTSH e hLH de diferentes preparações, nativas e recombinantes, foi determinado por cromatografia líquida de alta eficiência em fase reversa (RP-HPLC) e comparado ao dado obtido pelo clássico bioensaio in vivo em camundongos ou ratos (BA). Para estes hormônios foi encontrada uma relação linear entre os dois métodos: $\mathrm{hFSH} B A_{U I}=0,9925 \mathrm{RP}-\mathrm{HPLC} \mathrm{C}_{U I}-1,3165$, $r=0,9371, p<0,001, n=24 ; \quad h T S H \quad B A_{\mu g}=0,9790 R P-H P L C_{\mu g}-0,052$, $r=0,8725, p<0,001, n=14 ; h L H ~ B A_{U I}=0,8771$ RP-HPLC $U I+12,41 ; r=0,9786$, $p<0,01, n=5$. Para outras nove preparações de hFSH e onze preparações de hTSH foi determinada a diferença média ( $\overline{\mathrm{d}}$ ) entre a bioatividade predita pela RPHPLC através destas equações e da média das bioatividades obtidas com os dois métodos. Para o hLH não foi possível determinar esta diferença em virtude das poucas amostras disponíveis. No caso do $h F S H, \bar{d} \pm D P=-2,11 \pm 3,49 \%$ sendo a precisão de $1,16 \%$ e no caso do $\mathrm{hTSH}, \overline{\mathrm{d}} \pm \mathrm{DP}=-2,01 \pm 5,56 \%$ com precisão de $1,68 \%$. Amostras parcialmente alteradas apresentaram diferentes graus de atividade de hFSH, hTSH e hLH que puderam ser preditas por RP-HPLC com uma aceitável concordância com os bioensaios in vivo. Estes resultados demonstraram que o emprego de um ensaio físico-químico sem o uso de animais, tal como a RP-HPLC, é uma alternativa viável ao uso do bioensaio in vivo para a determinação da potência de hFSH e hTSH, reduzindo assim o número de animais em geral utilizados para assegurar a qualidade e eficácia de um produto farmacêutico.
\end{abstract}




\title{
POTENCY DETERMINATION OF FOLLITROPIN, LUTROPIN AND THYROTROPIN: A COMPARISON BETWEEN THE QUANTIFICATION BY REVERSED-PHASE HIGH-PERFORMANCE LIQUID CHROMATOGRAPHY AND IN VIVO BIOASSAY
}

\author{
Beatriz Elane de Almeida
}

\begin{abstract}
With the intention of setting up physico-chemical methods as an alternative to in vivo bioassay for determining biological activity, the hFSH, hTSH and $\mathrm{hLH}$ content of native and recombinant preparations was determined by reversed-phase high-performance liquid chromatography (RP-HPLC) and compared with the data obtained by the classical mouse or rat in vivo bioassays (BA). A linear relationship between the two methods was found for these hormones: hFSH BA $A_{I U}=0.9925$ RP-HPLC $C_{I U}-1.3165, r=0.9371, p<0.001, n=$ 24; $\mathrm{hTSH} \mathrm{BA}_{\mu g}=0.9790 \mathrm{RP}^{-H P L C}{ }_{\mu g}-0.052, \mathrm{r}=0.8725, \mathrm{p}<0.001, \mathrm{n}=14 ; \mathrm{hLH}$ $B A_{I U}=0.8771$ RP-HPLC $I U+12.41, r=0.9786, p<0.01, n=5$. For nine other $\mathrm{hFSH}$ and eleven hTSH preparations, the mean difference $(\overline{\mathrm{d}})$ between the bioactivity predicted from RP-HPLC data via these equations and the mean of the bioactivities obtained with the two methods was as follows. For hLH this difference could not be estimated due to lack of different samples. In the case of hFSH, $\overline{\mathrm{d}} \pm \mathrm{SD}=-2.11 \pm 3.49 \%$ with a precision of $1.16 \%$ and in the case of hTSH, $\overline{\mathrm{d}} \pm \mathrm{SD}=-2.01 \pm 5.56 \%$, with precision of $1.68 \%$. Partly-degraded hFSH, hTSH and hLH samples presented different activity degrees that could be predicted by RP-HPLC, with an acceptable agreement with the in vivo bioassays. These results demonstrate that the employment of a non-animal physico-chemical assay, such as RP-HPLC, is a viable alternative to the use of an in vivo bioassay for $\mathrm{hFSH}$ and $\mathrm{hTSH}$ potency determination, thus reducing the number of animals currently used for assuring quality and efficacy of a pharmaceutical product.
\end{abstract}




\section{SUMÁRIO}

Página

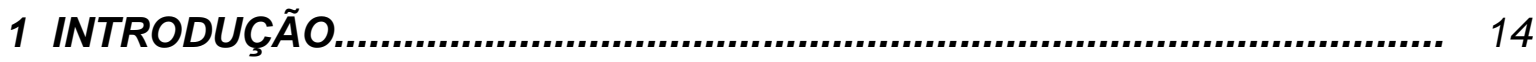

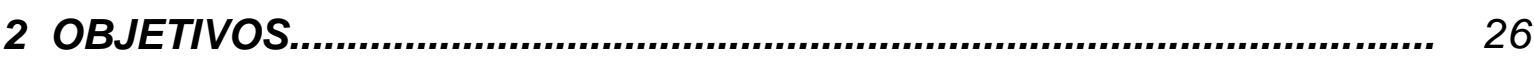

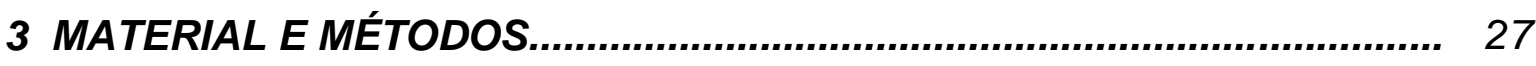

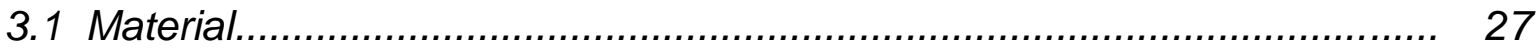

3.1.1 Preparações hormonais............................................................ 27

3.1.2 Preparações hormonais potencialmente alteradas................................ 28

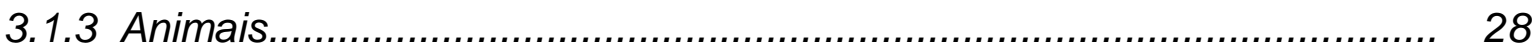

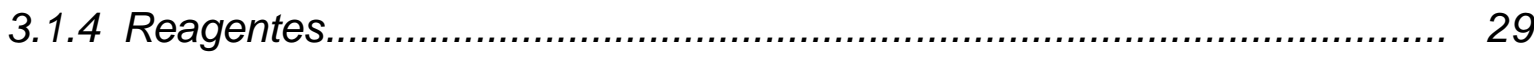

3.1.5 Equipamentos e acessórios principais............................................... 29

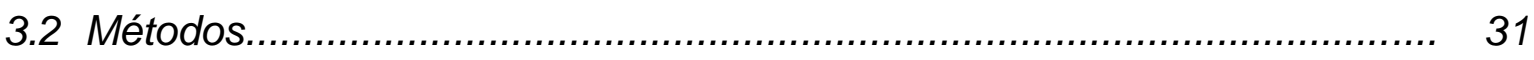

3.2.1 Cromatografia líquida de alta eficiência em fase reversa (RP-HPLC)...... 31

3.2.2 HPLC de exclusão molecular (HPSEC)................................................ 32

3.2.3 Ensaio biológico...................................................................... 33

3.2.3.a Ensaio biológico de preparações de hFSH........................................ 33

3.2.3.b Ensaio biológico de preparações de hTSH....................................... 33

3.2.3.c Ensaio biológico de preparações de $h L H$........................................... 34

3.3 Método Estatístico aplicado para validar a comparação entre dois métodos analíticos.......................................................................... 34

3.4 Parâmetros de uma separação cromatográfica......................................... 36

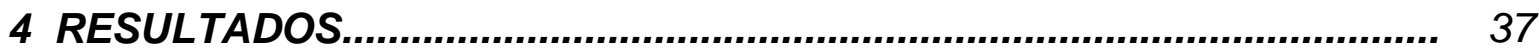

4.1 Determinação da potência de hFSH.................................................... 37

4.1. a Cromatografia líquida de alta eficiência em fase reversa (RP-HPLC)...... 37

4.1.b Ensaio Biológico...................................................................... 43

4.1.c Comparação entre as quantificações de hFSH por RP-HPLC e por 
Ensaio Biológico in vivo. 44

4.1.d Validação da RP-HPLC para quantificação de hFSH........................... 45

4.1.e Análise das preparações potencialmente alteradas de $h F S H$.................. 49

4.2 Determinação da potência de hTSH................................................. 53

4.2.a Comparação entre as determinações de hTSH por RP-HPLC e por Ensaio Biológico in vivo...................................................................... 53

4.2.b Validação da RP-HPLC para quantificação de hTSH............................. 57

4.2.c Análise das preparações potencialmente alteradas de $\mathrm{hTSH}$................. 61

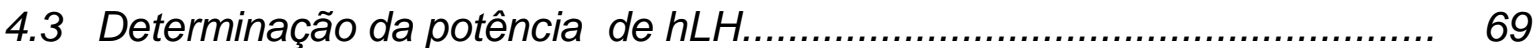

4.3.a Cromatografia líquida de alta eficiência em fase reversa (RP-HPLC).... 69

4.3.b Quantificação de amostras íntegras e potencialmente alteradas por RPHPLC e por Ensaio Biológico in vivo.................................................. 75

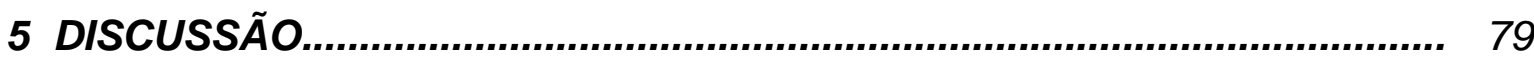

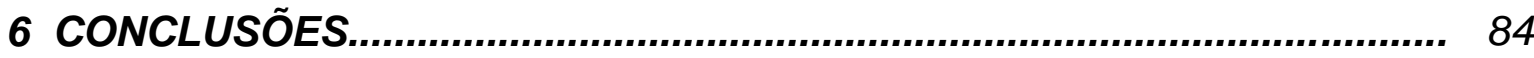

REFERÊNCIAS BIBLIOGRÁFICAS......................................................... 85 


\section{LISTA DE TABELAS}

Página

TABELA 1 - Características químicas dos hormônios glicoprotéicos hFSH, hLH e $h T S H$ (Ribela, 2006).

TABELA 2 - Condições experimentais empregadas na RP-HPLC para análise do $h F S H, h T S H$ e do $h L H$.

TABELA 3 - Condições experimentais empregadas na HPSEC para análise do $h F S H, h T S H$ e do $h L H$.

TABELA 4 - Determinação inter-dias do conteúdo de hFSH em preparações de diferentes origens, por RP-HPLC.

TABELA 5 - Determinação da potência do hFSH por ensaio biológico in vivo... 43 TABELA 6 - Comparação entre a quantificação de preparações de hFSH por Bioensaio in vivo e por RP-HPLC.

TABELA 7 - Comparação entre a atividade biológica do hFSH determinada por Bioensaio in vivo e predita pela equação por análise em RP-HPLC.

TABELA 8 - Parâmetros estatísticos, determinados de acordo com Bland e Altman, comparando o valor da bioatividade in vivo com aquela predita por $R P-H P L C$.

TABELA 9 - Comparação entre a quantificação por Bioensaio in vivo e por $R P-H P L C$ de preparações de $h F S H$ fora do prazo de validade.

TABELA 10 - Comparação entre a quantificação de preparações de hTSH por Bioensaio in vivo e por RP-HPLC.

TABELA 11 - Comparação entre a atividade biológica do hTSH determinada por Bioensaio in vivo e por análise em RP-HPLC.

TABELA 12 - Parâmetros estatísticos, determinados de acordo com Bland e 
Altman, comparando o valor da bioatividade in vivo com aquela predita por RP-HPLC

TABELA 13 - Comparação entre a atividade de preparações alteradas de hTSH por Bioensaio in vivo e por RP-HPLC

TABELA 14 - Condições estudadas para análise por RP-HPLC da preparação de $L H$

TABELA 15 - Condições experimentais a serem empregadas na RP-HPLC para análise de $h L H$.

TABELA 16 - Parâmetros de desempenho de separação HSA-LH em diferentes condições de RP-HPLC..

TABELA 17 - Parâmetros de qualidade da separação HSA-LH

TABELA 18 - Comparação entre a quantificação de preparações de $h L H$ íntegras e alteradas por Bioensaio in vivo e por RP-HPLC.

TABELA 19 - Comparação entre a atividade de preparações alteradas de $h L H$ por Bioensaio in vivo e por RP-HPLC. 


\section{LISTA DE FIGURAS}

Página

FIGURA 1: Esquema de validação de um método alternativo proposto pelo ECVAM (Leist, 2012)............................................................. 15

FIGURA 2: Uso de ensaio in vivo para controle de qualidade de produtos farmacêuticos (Metz, 2007).

FIGURA 3 - Sequência de aminoácidos da subunidade a dos hormônios glicoproteicos.

FIGURA 4 - Sequência de aminoácidos da subunidade $\beta$ dos hormônios glicoproteicos.

FIGURA 5 - Perfil em HPLC de $2 \mu \mathrm{g}$ do padrão de referência para ensaios biológicos hFSH recombinante (WHO 92/642). (A) RP-HPLC. (B) HPSEC.... 38 FIGURA 6 - Perfil em RP-HPLC de diferentes preparações de hFSH recombinante: rhFSH-A ; rhFSH-B

FIGURA 7 - Perfil em RP-HPLC de diferentes preparações de hFSH hipofisário: phFSH-C; phFSH-D.

FIGURA 8 - Perfil em RP-HPLC de diferentes preparações de hFSH urinário: uhFSH-E; uhFSH-F......

FIGURA 9 - Comparação entre a bioatividade predita e in vivo.

FIGURA 10 - Perfil em RP-HPLC de preparações de hFSH recombinante

(A) $r h F S H-M(B)$ rhFSH-N

FIGURA 11 - Perfil em RP-HPLC da preparação hFSH-O. (A) hFSH-O

(B) $h F S H-O$ submetida a aquecimento a $80 \stackrel{\circ}{ } \mathrm{C}$

FIGURA 12 - Perfil em RP-HPLC de $5 \mu \mathrm{g}$ do padrão de referência para ensaios biológicos hTSH recombinante (WHO 03/192). (A) RP-HPLC;

(B) HPSEC. 
FIGURA 13 - Perfil em RP-HPLC de preparações de hTSH. (A) preparação rhTSH-O; (B) preparação phTSH-A................................................. 56 FIGURA 14 - Comparação entre a bioatividade predita $e$ in vivo de preparações de $h T S H$..

FIGURA 15 - Perfil em RP-HPLC da preparação rhTSH-T. (A) rhTSH-T Controle (B) rhTSH-T fora do prazo de validade (C) rhTSH-T submetida a 5 ciclos de congelamento-descongelamento

FIGURA 16 - Perfil em RP-HPLC da preparação rhTSH-U. (A) rhTSH-U Controle (B) rhTSH-U submetida a aquecimento a $100^{\circ} \mathrm{C}$

FIGURA 17 - Perfil em RP-HPLC da preparação de hTSH recombinante $U$.

(A) rhTSH-U Controle (B) rhTSH-U submetida a aquecimento a $50^{\circ} \mathrm{C}$.

FIGURA 18 - Perfil em RP-HPLC da preparação de hTSH recombinante $U$.

(A) rhTSH-U Controle (B) rhTSH-U submetida a aquecimento a $65^{\circ} \mathrm{C}$.

FIGURA 19 - Perfil em HPSEC de $2 \mu g$ do padrão de referência para ensaios biológicos $h L H$ recombinante (WHO 96/602).

FIGURA 20 - Perfil em RP-HPLC do padrão de referência para ensaios biológicos $h L H$ recombinante (WHO 96/602) nas condições experimentais descritas por Almeida e colaboradores (2010)

FIGURA 21 - Perfil em RP-HPLC do padrão de referência para ensaios biológicos $h \mathrm{LH}$ recombinante (WHO 96/602). (A) condições experimentais descritas por Almeida e colaboradores (2010); (B) novas condições estabelecidas.

FIGURA 22 - Perfil em RP-HPLC da preparação rhLH-C. (A) rhLH-C Controle (B) rhLH-C após aquecimento a $70^{\circ} \mathrm{C}$.

FIGURA 23 - Perfil em RP-HPLC da preparação phLH-B. (A) phLH-B Controle (B) phLH-B após aquecimento a $70^{\circ} \mathrm{C}$ 


\section{LISTA DE ABREVIATURAS}

BP - Farmacopeia Britânica

CHO - Células de Ovário de Hamster Chinês

ECVAM - Centro Europeu de Validação de Métodos Alternativos

EDQM - European Directorate for the Quality of Medicines

$E P$ - Farmacopeia Europeia

EPO - Eritropoietina

FDA - Food and Drug Administration

FRTL-5 - Células de Tireóide de Rato

FSH - Foliculotrofina

G-CSF - Fator Estimulador de Colônia de Granulócito

GH - Hormônio de Crescimento

GnRH - Hormônio Liberador de Gonadotrofinas

RP-HPLC - Cromatografia Líquida de Alta Eficiência em Fase Reversa

HPSEC - Cromatografia Líquida de Alta Eficiência de Exclusão Molecular

HSA - Albumina de Soro Humano

JP - Farmacopeia Japonesa

LH - Luteotrofina

PTH - Hormônio Recombinante da Paratireóide

RIA - Radioimunoensaio

T3 - 3,3', 5-Triiodo-L-Tironina

T4 - Tiroxina

TRH - Hormônio Liberador daTireotrofina

TSH - Tireotrofina

USP - Farmacopeia Americana

WHO - World Health Organization 


\section{INTRODUÇÃO}

Um aspecto importante no controle de qualidade de hormônios utilizados terapeuticamente é a determinação da sua atividade biológica. Para esta finalidade, os modelos animais são amplamente utilizados. Os bioensaios in vivo fornecem uma medida adequada da bioatividade bem como da farmacocinética ou farmacodinâmica do hormônio, porém são em geral demorados, trabalhosos, caros, apresentam alto grau de variabilidade inerente aos organismos vivos e utilizam um grande número de animais para obter dados estatisticamente válidos. Em virtude da baixa precisão destes ensaios e da pressão ética e política sobre o uso de animais há, atualmente, uma forte tendência mundial de reduzir e/ou substituir os bioensaios in vivo para estimar a potência de produtos farmacêuticos. Diversas agências reguladoras tais como, "European Directorate for the Quality of Medicines" (EDQM), "Food and Drug Administration" (FDA) e "World Health Organization" (WHO), recomendam recorrer a um ensaio in vivo apenas naqueles casos em que não é disponível informação suficiente e que esta não pode ser obtida por outros testes (Madden, 2012).

Métodos alternativos ao uso de animais que atendam ao princípio dos "Três Rs" (Reduction, Refinement, Replacement), definido por Russel e Burch (1959), tem sido pesquisados (Miethe, 2002; Hendriksen; 2004; Fenwick, 2005; Fabre, 2008; Obora, 2009). Estes parâmetros são entendidos como: "Reduction", redução do número de animais ao mínimo; "Refinement", minimização do dano aos animais tanto na criação quanto nos procedimentos experimentais e "Replacement", substituição total dos modelos animais por modelos não-animais. 
Estes métodos devem ser validados segundo a orientação do ECVAM "Centro Europeu de Validação de Métodos Alternativos", que define a validação de um novo método alternativo como a avaliação da fidedignidade (reprodutibilidade e exatidão) e da capacidade preditiva do método alternativo (correlação com o método clássico) para um determinado fim (Figura 1) (Worth, 2004; Hartung, 2013).

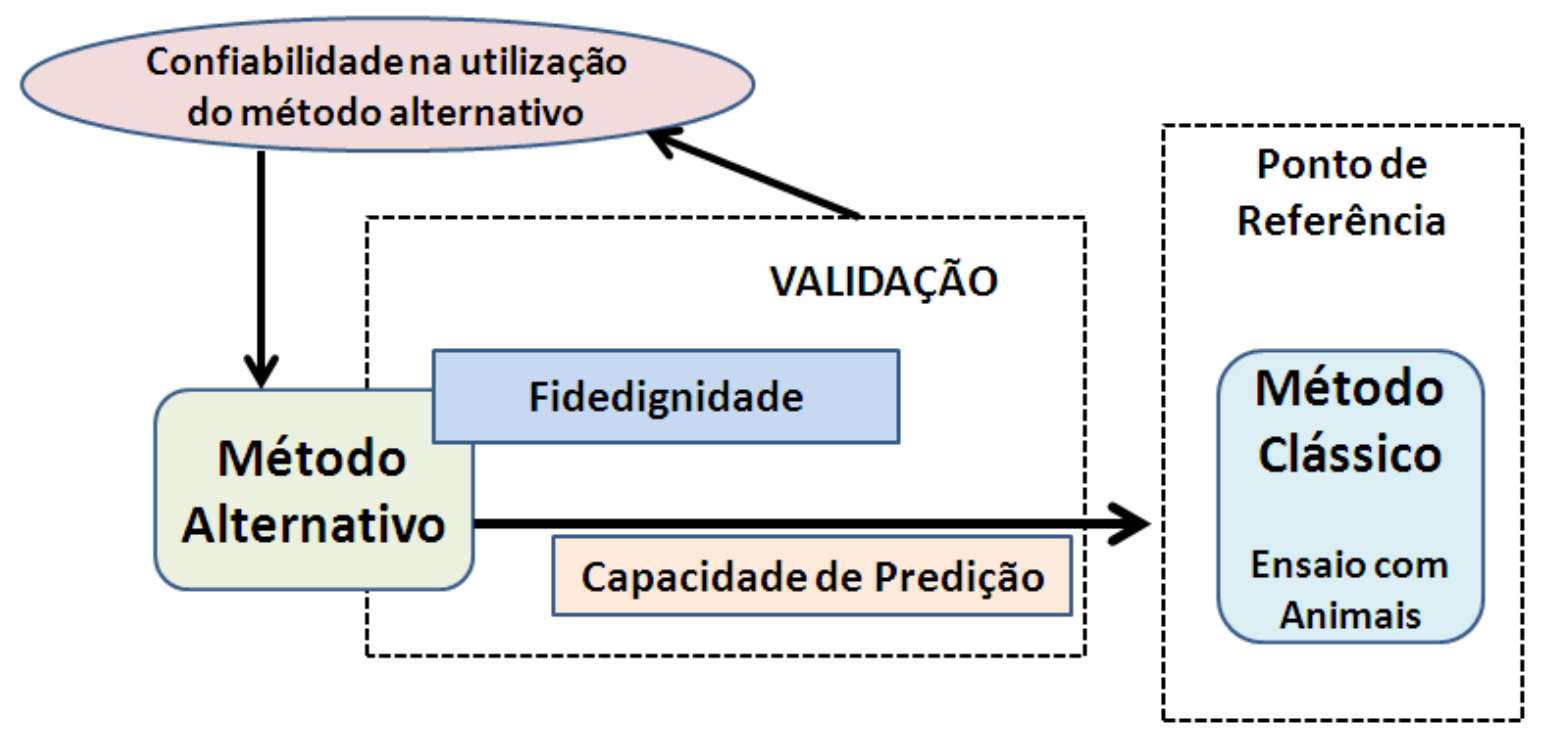

FIGURA 1: Esquema de validação de um método alternativo proposto pelo ECVAM (Leist, 2012)

Neste contexto, várias estratégias alternativas, incluindo os métodos físico-químicos, têm sido relatados na literatura como potenciais ensaios alternativos para a determinação, com maior precisão e exatidão, da atividade biológica de diferentes proteínas. Enquanto alguns defendem a possibilidade de equivalência, ou pelo menos complementaridade, entre métodos físico-químicos e métodos in vivo (Halder, 2002; Arora, 2011), outros acreditam que não é possível correlacionar um parâmetro derivado de uma medida sistêmica global com uma determinação mais específica de um analito (Spieser, 2008). Na nossa opinião, sistemas de qualidade para glicohormônios deveriam combinar ambos os enfoques, isto é, utilizar ensaios in vivo e ensaios alternativos, aplicados em diferentes etapas do processo de produção e controle de qualidade e, dessa forma, limitar e reduzir significativamente o uso de ensaios com animais. 
Para garantir uma alta qualidade do produto final que atenda as especificações para uso farmacêutico é pré-requisito monitorar a consistência da produção, o que deve ser feita através de métodos que estudem propriedades do produto como identidade, estrutura, pureza, sequência de aminoácidos e antigenicidade. Uma combinação de várias técnicas independentes pode fornecer a identidade do produto, que então poderá ser comparado a uma preparação de referência de potência comprovada (Hendriksen, 2009). Enquanto atualmente a proporção de animais utilizados na indústria farmacêutica no controle de qualidade de um biofármaco é muito grande, especialmente nas etapas finais do seu processo, no futuro a tendência é utilizar, seguindo a filosofia dos 3 Rs, um número bem menor de ensaios in vivo, sendo a maior proporção de animais utilizada nas etapas iniciais do desenvolvimento do fármaco (Figura 2) (Metz, 2007).

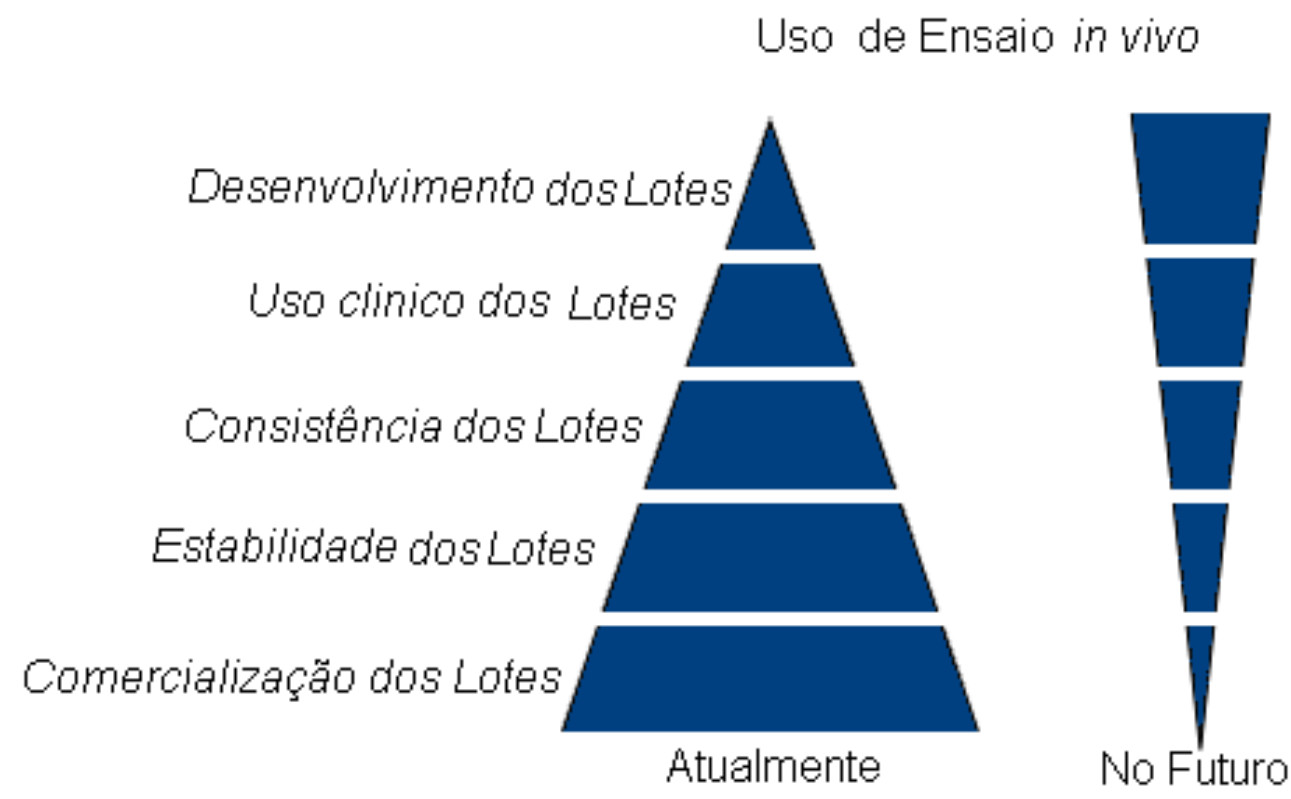

FIGURA 2: Uso de ensaio in vivo para controle de qualidade de produtos farmacêuticos (Metz, 2007)

Entre os vários ensaios desenvolvidos que evitam o uso de animais, a cromatografia líquida de alta eficiência de exclusão molecular (HPSEC) (Riggin, 1988; Bristow, 1992) mostrou-se uma alternativa adequada ao bioensaio in vivo realizado em camundongos anões ou hipofisectomizados, para a determinação da potência do hormônio de crescimento humano $(\mathrm{hGH})$, sendo inclusive este ensaio 
adotado pelas principais farmacopeias (Wilhelmi, 1973; Bellini, 1993; EP, 2011). Da mesma forma, um método de cromatografia líquida de alta eficiência em fase reversa (RP-HPLC) em combinação com HPSEC mostrou correlação significativa com os bioensaio in vivo para avaliar a potência do fator estimulador de colônia de granulócito humano recombinante (rhG-CSF) (Dalmora, 2006) e do hormônio recombinante da paratireóide (rhPTH) (Stamm, 2013).

A substituição de bioensaios por métodos físico-químicos no caso de glicoproteínas é particularmente difícil, principalmente levando em conta a complexidade destas moléculas e a heterogeneidade da sua glicosilação. RPHPLC, bem como HPSEC, foram propostos como uma possível alternativa para o bioensaio em camundongos normocitêmicos para a determinação da potência de eritropoietina humana recombinante (rhEPO) (Barth, 2007; Ferreto, 2009; Schutkoski, 2013). Utilizando métodos quantitativos de separação baseados em carga, tais como eletroforese capilar e focalização isoelétrica foi possível estimar a atividade in vivo do hormônio foliculotrofina (hFSH) puro. Uma correlação altamente significativa entre a distribuição de isoformas e a bioatividade in vivo foi demonstrada por Mulder e colaboradores $(1997,1999)$ e por Storring e Das (2002). Ainda com relação ao hFSH, a HPSEC, com uma variabilidade menor do que $2 \%$, foi também utilizada com sucesso como alternativa para bioensaios in vivo, especialmente durante a fase de produção deste hormônio, para controle da consistência entre diferentes lotes e para a definição do conteúdo das ampolas utilizadas na prática clínica (Driebergen, 2003; Bassett, 2005).

No presente trabalho focamos nossos estudos nos hormônios humanos glicoprotéicos hipofisários, hFSH, luteotrofina $(\mathrm{hLH})$ e tireotrofina (hTSH). Estes hormônios são produzidos e secretados pela glândula hipofisária anterior, em diferentes células, nos gonadotropos (FSH e LH) em resposta ao estímulo do hormônio liberador de gonadotrofinas $(\mathrm{GnRH})$ e nos tireotropos (TSH) em resposta ao estímulo do hormônio liberador da tireotrofina $(\mathrm{TRH})$ e inibido pelos hormônios da tireóide $\left(\mathrm{T}_{3}\right.$ e $\left.\mathrm{T}_{4}\right)$, em um clássico mecanismo de feedback negativo.

O hFSH está envolvido na regulação de várias funções reprodutivas incluindo a gametogênese, o crescimento folicular e a ovulação e, portanto, tem um papel fisiológico importante tanto no homem como na mulher (Loumaye, 1998) 
Com relação ao $\mathrm{LH}$, na literatura são reportadas várias funções: o hLH participa na regulação ovariana e testicular, tem um papel crítico na maturação folicular, na ovulação, no desenvolvimento e manutenção do corpo lúteo e intervem na síntese de esteróides, de fatores de crescimento e de citocinas (Rao, 2001; Perera-Marín, 2007).

Além do controle das funções tireoideanas, O TSH está também envolvido na diferenciação morfológica das células da tireóide, na produção e liberação de iodotironinas, na promoção do crescimento da glândula, além de atuar protegendo as células tireoideanas da apoptose e ocupar um papel fundamental na ontogenia (Szkudilinski, 2002).

Os hormônios glicoprotéicos hipofisários são heterodímeros formados por duas subunidades ( $\alpha$ e $\beta$ ), que são cadeias polipeptídicas com carboidratos acoplados a cada subunidade, em um ou mais sítios. Estudos relativos à síntese das subunidades sugerem que estes carboidratos facilitam a formação de pontes dissulfeto próprias durante o enovelamento (folding) das cadeias peptídicas e evitam proteólises e agregação das subunidades (Hartree, 1992; Galet, 2004). As pontes dissulfeto formadas são cinco na subunidade $\alpha$ e seis na subunidade $\beta$, sendo as posições de ligação das cisteínas nas duas subunidades, para cada hormônio, indicadas na Tabela 1. 
TABELA 1 - Características químicas dos hormônios glicoprotéicos hFSH, hLH e hTSH (Ribela, 2006)

\begin{tabular}{|c|c|c|c|c|c|}
\hline Hormônio & $\begin{array}{l}\text { Estrutura } \\
\text { Primária }\end{array}$ & $\begin{array}{l}\text { Aminoácido } \\
\text { N-Terminal }\end{array}$ & $\begin{array}{r}\text { Pontes } \\
\text { Cy }\end{array}$ & $\begin{array}{l}\text { ssulfeto } \\
\text { Cys }\end{array}$ & $\begin{array}{c}\text { Sítio de } \\
\text { Glicosilação }\end{array}$ \\
\hline hFSH & $\begin{array}{l}\alpha: 92 \text { aа } \\
\beta: 111 \text { aа }\end{array}$ & $\begin{array}{l}\alpha: \text { Ala } \\
\beta: \text { Asn }\end{array}$ & $\begin{array}{r}7-31 \\
10-60 \\
\alpha: 28-82 \\
32-84 \\
59-87\end{array}$ & $\begin{array}{c}3-51 \\
17-66 \\
\beta: 20-104 \\
28-82 \\
32-84 \\
87-94\end{array}$ & $\begin{array}{r}\alpha: \text { Asn } 52 \\
\text { Asn } 78 \\
\beta: \text { Asn } 7 \\
\quad \text { Asn } 24\end{array}$ \\
\hline $\mathrm{hLH}$ & $\begin{array}{l}\alpha: 92 \text { aа } \\
\beta: 121 \text { aа }\end{array}$ & $\begin{array}{l}\alpha: \text { Ala } \\
\beta: \text { Ser }\end{array}$ & $\begin{array}{r}7-31 \\
10-60 \\
\alpha: 28-82 \\
32-84 \\
59-87\end{array}$ & $\begin{array}{c}9-57 \\
23-72 \\
\beta: 26-110 \\
34-88 \\
38-90 \\
93-100\end{array}$ & $\begin{array}{r}\alpha: \text { Asn } 52 \\
\text { Asn } 78 \\
\beta: \text { Asn } 30\end{array}$ \\
\hline hTSH & $\begin{array}{l}\alpha: 92 \text { aа } \\
\beta: 118 \text { aа }\end{array}$ & $\begin{array}{l}\alpha: \text { Ala } \\
\beta: \text { Phe }\end{array}$ & $\begin{array}{r}7-31 \\
10-60 \\
\alpha: 28-82 \\
32-84 \\
59-87\end{array}$ & $\begin{array}{c}2-52 \\
17-67 \\
\beta: \\
19-105 \\
27-83 \\
31-85 \\
88-95\end{array}$ & $\begin{array}{r}\alpha: \text { Asn } 52 \\
\text { Asn } 78 \\
\beta \text { : Asn } 23\end{array}$ \\
\hline
\end{tabular}

As cadeias de carboidratos no hFSH recombinante constituem $28 \%$ de seu peso e introduzem considerável micro heterogeneidade (isohormônios) (Horsman, 2000). No hLH os carboidratos constituem $21 \%$ do seu peso total (Hara, 1978) e no hTSH 15 a 25\% (Skudlinski, 2000; 2002). As massas moleculares destes hormônios recombinantes são 28,5 kDa, 28,8 kDa e 29,6 kDa, respectivamente, para o hFSH, hLH e hTSH (Mendonça, 2005; Loureiro, 2006; Carvalho, 2009).

Os oligossacarídeos das subunidades $\beta$ destes hormônios têm um papel fundamental na depuração metabólica e, portanto, na atividade biológica in vivo dos hormônios. Os oligossacarídeos das subunidades a por sua vez, são essenciais na ação do hTSH durante a transdução de sinal pós-receptor, 
participam do "folding" da subunidade $\beta$ e da estabilização do heterodímero (Szkudlinski, 2002; Ulloa-Aguirre 2003; Bousfield, 2007).

As subunidades $\alpha$ dos três hormônios são glicosiladas na porção Cterminal da molécula, em dois sítios, na asparagina 52 e 78, enquanto as subunidades $\beta$ são glicosiladas na porção amino terminal, em uma ou duas posições, isto é, na asparagina 7 e 24 no hFSH $\beta$, na asparagina 30 no hLH $\beta$ e na asparagina 23 no hTSH $\beta$ (Tabela 1). Os oligossacarídeos de ligação $\mathrm{N}$ das cadeias a são do tipo complexo e consistem essencialmente de estruturas di- e triantenárias, mono- e disialiladas. Entretanto, existem diferenças na quantidade relativa destes componentes na cadeia $\alpha$. Por exemplo, na subunidade $\alpha \mathrm{FSH}$, os oligossacarídeos triantenários são bastante raros, enquanto no $\alpha \mathrm{LH}$ eles são tão abundantes quanto as estruturas biantenárias. Também foram observadas diferenças nas estruturas diantenárias e triantenárias fucosiladas: no aLH estas estruturas não são detectadas, enquanto no ahFSH elas aparecem (Amoresano, 1996).

A sequência de aminoácidos que compõe a subunidade $\alpha$ dos três hormônios glicoprotéicos é comum, enquanto aquela que forma a subunidade $\beta$ é específica de cada hormônio e responsável por conferir a função fisiológica específica (Figuras 3 e 4). A subunidade $\alpha$ dos três hormônios contém 92 aminoácidos e cinco pontes dissulfeto contribuindo para a sua estrutura terciária. Já as subunidades $\beta$ do hFSH, hTSH, e hLH contém respectivamente 111, 118 e 121 aminoácidos, sendo suas moléculas estabilizadas por seis ligações dissulfeto.

\begin{tabular}{|lllllllllll|}
\hline Ala & Pro & Asp & Va & Gln & Asp & Cys & Pro & Glu & Cys & 10 \\
Thr & Leu & Gln & Glu & Asn & Pro & Phe & Phe & Ser & Gln & 20 \\
Pro & Gly & Ala & Pro & Ile & Leu & Gln & Cys & Met & Gly & 30 \\
Cys & Cys & Phe & Ser & Arg & Ala & Tyr & Pro & Thr & Pro & 40 \\
Leu & Arg & Ser & Lys & Lys & Thr & Met & Leu & Val & Gln & 50 \\
Lys & Asn & Val & Thr & Ser & Glu & Ser & Thr & Cys & Cys & 60 \\
Val & Ala & Lys & Ser & Tyr & Asn & Arg & Val & Thr & Val & 70 \\
Met & Gly & Gly & Phe & Lys & Val & Glu & Asn & His & Thr & 80 \\
Ala & Cys & His & Cys & Ser & Thr & Cys & Tyr & Tyr & His & 90 \\
Lys & Ser & & & & & & & & & 92 \\
\hline
\end{tabular}

FIGURA 3 - Sequência de aminoácidos da subunidade a dos hormônios glicoproteicos 


\begin{tabular}{|c|c|c|c|c|c|c|c|c|c|c|}
\hline \multicolumn{11}{|c|}{ Subunidade beta do hFSH } \\
\hline Asn & Ser & Cys & Glu & Leu & Thr & Asn & lle & Thr & lle & 10 \\
\hline & lle & Glu & & Glu & Glu & Cys & $\operatorname{Arg}$ & & Cys & 20 \\
\hline & Ser & lle & Asn & Thr & Thr & Trp & Cys & Ala & G & 0 \\
\hline Tyr & Cys & Tyr & Thr & Arg & Asp & Leu & Val & Tyr & Lys & 0 \\
\hline$p$ & Pro & Ala & Arg & Pro & /s & Ile & Gln & /s & Ir & 50 \\
\hline & Thr & Pro & Lys & Glu & eu & Val & Tyr & & Thr & 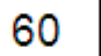 \\
\hline$v_{c}$ & $\operatorname{Arg}$ & Val & Pro & & & Ala & & & & 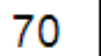 \\
\hline Asp & Ser & Leu & Tyr & $\mathrm{Tr}$ & $y r$ & Pro & Val & la & Thr & 0 \\
\hline r & Cys & $\mathrm{His}$ & Cys & Gly & & Cys & Asp & er & Asp & 90 \\
\hline Ser & Thr & Asp & Cys & $\mathrm{Thr}$ & al & Arg & $y$ & & Gly & 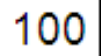 \\
\hline Pro & Ser & Tyr & Cys & Ser & he & & & & Lys & 110 \\
\hline Glu & & & & & & & & & & 111 \\
\hline \multicolumn{11}{|c|}{ Subunidade beta do hLH } \\
\hline Ser & Arg & Glu & Pro & Leu & $\mathrm{Arg}$ & ro & Trp & Cys & 10 & 10 \\
\hline$m$ & & Asn & Ala & lle & Leu & la & Val & n & Lys & 20 \\
\hline Glu & Gly & Cys & Pro & Val & Cys & Me & $\mathrm{T}$ & Val & Asn & 30 \\
\hline $1 \mathrm{n}$ & Th & lle & Cys & Ala & Gly & Tyr & Cys & Pro & Thr & 40 \\
\hline et & Met & Arg & Val & Leu & Gln & Ala & Val & Leu & FTo & 50 \\
\hline ro & Leu & Pro & Gln & Val & Val & Cys & Thr & Tyr & Arg & 60 \\
\hline $\mathrm{sp}$ & Val & Arg & Phe & Glu & Ser & 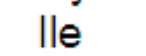 & Arg & Leu & Pro & 70 \\
\hline 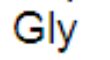 & Cys & Pro & Arg & Gly & Val & Asp & Pro & Val & Val & 80 \\
\hline $\mathrm{Se}$ & Phe & Pro & Val & Ala & Leu & Ser & Cys & Arg & Cys & 90 \\
\hline Gl & Pro & Cys & Arg & Arg & Ser & Th & Ser & Asp & Cys & 100 \\
\hline Gly & Gly & Pro & Lys & Asp & His & Pro & Leu & Thr & Cys & 11 \\
\hline Asp & His & Pro & Gln & Leu & Ser & Gly & Leu & Leu & Phe & 12 \\
\hline La & & & & & & & & & & 12 \\
\hline \multicolumn{11}{|c|}{ Subunidade beta do hTSH } \\
\hline he & Cys & Ile & Pro & Thr & Glu & Tyr & Thr & Met & His & 10 \\
\hline & Glu & Arg & Arg & Glu & Cys & Ala & Tyr & Cys & Leu & 20 \\
\hline & lle & Asn & Thr & & & Cys & Ala & sle & Tyr & 30 \\
\hline & Met & Thr & Arg & $A$ & lle & Asn & Gly & & Leu & 40 \\
\hline & $\mathrm{Le}$ & Pro & Lys & $\mathrm{T}$ & la & & Ser & G & Asp & 50 \\
\hline & Cys & Thr & Tyr & Arg & $s p$ & Phe & lle & Tyr & Arg & 60 \\
\hline & Val & Glu & Trp & Pro & Gly & Cys & Pro & Leu & His & 70 \\
\hline & Ala & Pro & Tyr & Phe & Ser & Tyr & Pro & Val & Ala & 80 \\
\hline Le & Ser & Cys & Lys & Cys & Gly & Lys & Cys & Asn & Thr & 90 \\
\hline & Tyr & Ser & As & & & & Si & & lle & 100 \\
\hline Lys & Thr & Asn & Tyr & Cys & Thr & Lys & Pro & Gln & Lys & 110 \\
\hline El & Tyr & Leu & Val & Gly & Phe & Ser & Val & & & 118 \\
\hline
\end{tabular}

FIGURA 4 - Sequência de aminoácidos da subunidade $\beta$ dos hormônios glicoprotéicos 
No hormônio intacto, as subunidades são unidas por ligações não covalentes e a associação delas é mandatória para a expressão da atividade biológica destes hormônios. Há evidências que a associação das subunidades $\alpha \mathrm{e}$ $\beta$ começa no retículo endoplasmático rugoso (Hartree, 1992).

A utilização destes hormônios como agentes terapêuticos tem sido amplamente descrita na literatura (Loumaye, 1998; Howles, 2000; Luster, 2006; Choi, 2007; Shoham, 2008; Zhao, 2011; De Leo, 2012; Bonnema, 2012; Lisi, 2013; Fraietta, 2013).

As principais estratégias utilizadas para a síntese e purificação destes hormônios recombinantes foram amplamente discutidas em revisão que aborda este assunto (Ribela, 2003; Muralidhar, 2008).

A avaliação meticulosa da segurança, eficácia e qualidade destes hormônios têm sido também reportada. Vários bioensaios são utilizados na caracterização biológica destes hormônios.

O ensaio utilizando modelo animal mais usado para estimar a biopotência in vivo do hFSH é o clássico bioensaio de Steelman e Pohley, que determina o aumento do peso do ovário de ratas, sob o estímulo do FSH (Steelman, 1953). Este foi o ensaio escolhido, no presente trabalho, para a quantificação de diferentes preparações de hFSH. Vários ensaios baseados em células também têm sido desenvolvidos para medir a atividade de FSH. Van Damme e colaboradores descreveram um bioensaio in vitro baseado na produção de estrogênio pelas células de Sertoli, enquanto Jia e colaboradores determinaram o FSH baseando-se na produção de estrogênio, pelas células da granulosa (Van Damme, 1979; Jia, 1986 A e B). Outro ensaio in vitro também usado baseia-se na produção de inibina pelas células de Sertoli ou por células granulosas, sob o estímulo de FSH (Groome, 1996). Ensaios baseados em receptores são também utilizados. Quando o FSH se liga ao seu receptor de membrana, o AMP cíclico aumenta através da interação com proteínas $G$ associadas à membrana. Este aumento pode ser quantificado usando genes repórter contendo em seu promotor elementos cAMP responsivos (Minegishi, 1991; Christin-Maitre, 1996). 
Para o hTSH o método in vivo mais antigo desenvolvido e amplamente utilizado é o bioensaio em camundongos, baseado na captação do ${ }^{131}$ | pela tireóide, seguida da medida do aumento subsequente da radioatividade na circulação, sob o estímulo de TSH (McKenzie,1958). Um bioensaio in vivo desenvolvido posteriormente, que não administra radioatividade, foi reportado na literatura (East-Palmer, 1995; Mattaliano, 1995), no qual T4 induzido pelo TSH é medido, mediante imunoensaio, após supressão do TSH endógeno pela administração de T3. Este tem sido o ensaio biológico adotado em nosso laboratório para estimar a atividade biológica das preparações de hTSH aqui sintetizadas (Peroni, 2002; Mendonça, 2005; Oliveira, 2007 e 2008; Damiani, 2009 e 2013) e será também utilizado no presente trabalho. Bioensaios in vitro baseados na elevação dos níveis de CAMP, em células de tireóide de rato (FRTL5) e em células de ovário de hamster chinês $(\mathrm{CHO})$ transfectadas com receptor de TSH ou em membranas de tireóide bovina e humana tem sido descritos para medir a atividade de hTSH (Canone, 1995; Szkudlinski, 2000; Sendak, 2002)

Para o hLH, o bioensaio in vivo em geral adotado na literatura (Van Hell, 1964) é o que estima o aumento do peso da vesícula seminal de ratos aos quais foi administrado o hLH. Este foi o ensaio escolhido, no presente trabalho, para a quantificação de diferentes preparações de hLH. Bioensaios in vitro baseados na produção de testosterona pelas células de Leydig de camundongos e ratos são também descritos na literatura para medir a atividade de LH (Van Damme, 1974; Dufau, 1974).

A HPLC tem se mostrado uma ferramenta bastante útil na análise qualitativa e quantitativa dos hormônios hipofisários humanos (Ribela, 2006; Carvalho, 2009). Características da técnica de HPLC, tais como automação, alta resolução, sensibilidade e reprodutibilidade fazem desta metodologia uma opção analítica bastante utilizada, especialmente na indústria farmacêutica, para a identificação e quantificação de impurezas presentes nos fármacos. As principais farmacopéias (USP, EP, BP, JP) recomendam extensivo uso da HPLC durante a validação dos processos de fabricação e controle de qualidade de fármacos, sendo determinante no desenvolvimento de novos produtos (Basak, 2007; Kovaleski, 2007; Ahuja, 2007; Zacharis, 2009; Staub, 2011; Li, 2012). 
Esta técnica também tem sido freqüentemente utilizada para a caracterização e controle de qualidade destes hormônios, sendo capaz de detectar e quantificar discretas modificações na estrutura molecular do produto analisado, tanto dos hormônios glicoproteicos (Oliveira, 2003; Mendonça, 2005; Loureiro, 2006; Ribela, 2006; Carvalho, 2009; Almeida,2010) como daqueles sem glicosilação (Bristow, 1992; Dalmora, 1997; Oliveira, 1999; Ueda, 2001; Soares, 2002; Jung, 2005; Ribela, 2006).

Um dos modos de HPLC mais utilizados nestas análises é o de fase reversa (RP-HPLC), que se baseia na ligação do soluto à fase estacionária mediada predominantemente por interações hidrofóbicas entre os resíduos de aminoácidos não polares dos peptídeos ou proteínas e dos ligantes imobilizados. Os solutos são eluídos por gradiente, em ordem crescente de hidrofobicidade molecular, adicionando-se solvente orgânico à fase móvel, em concentrações crescentes, ao longo de um período de tempo. A retenção das proteínas é fortemente dependente das pequenas variações da força do solvente, uma mudança muito pequena (<1\%) no teor do modificador orgânico podendo levar a uma significativa mudança na retenção da proteína.

A separação de uma proteína por RP-HPLC pode ser ajustada alterando a inclinação do gradiente, a temperatura de funcionamento, os aditivos, o $\mathrm{pH}$ ou os modificadores orgânicos. A melhor abordagem para melhorar a seletividade e, portanto, a resolução é alterar a natureza química ou a concentração do modificador orgânico (por exemplo, acetonitrila, metanol, ou isopropanol) (Fekete, 2012). Em virtude de sua versatilidade, flexibilidade e robustez, a RP-HPLC é um dos enfoques dominantes utilizados para análise de peptídeos e proteínas (Nikitas, 2009; Fekete, 2012). Esta foi a metodologia escolhida no presente trabalho para a quantificação de diferentes preparações de hFSH, hTSH e hLH.

Diferentes condições de eluição em RP-HPLC foram estabelecidas por diversos autores, nos últimos 30 anos, para 0 isolamento e a análise de subunidades e de formas heterodiméricas do TSH, FSH e LH (Ribela, 2006). Os trabalhos pioneiros de Bristow e colaboradores (1983), que descreveram pela primeira vez a detecção do hTSH heterodimérico por RP-HPLC, e de Parson e colaboradores (1984), que estabeleceram as condições de eluição para a análise 
das subunidades dissociadas destes hormônios, serviram de base para trabalhos posteriores em que foram estudados diferentes tipos de gradientes para detectar também as formas heterodiméricas de FSH e LH (Hiyama, 1990; Chlenov, 1993; Oliveira, 2003; Loureiro, 2006; Carvalho, 2009; Almeida, 2010).

Face ao exposto ao longo deste capítulo, fica claro o desafio que se apresenta com relação à utilização de ensaios com animais no controle de produtos farmacêuticos. Nesta direção, para contornar tal desafio e aprimorar 0 controle de qualidade de produtos biotecnológicos, o presente trabalho estabeleceu seus objetivos. 


\section{OBJETIVOS}

\section{Objetivo Geral}

$\checkmark \quad$ Avaliar estratégia de quantificação físico-química, alternativa ao bioensaio in vivo, para estimar a potência de diferentes preparações de foliculotrofina humana (hFSH), tireotrofina humana (hTSH) e luteotrofina humana $(\mathrm{hLH})$, visando sua aplicação na caracterização e controle de qualidade farmacêutica destes hormônios.

\section{Objetivos Específicos}

$\checkmark \quad$ Quantificar diferentes preparações íntegras e alteradas de hFSH, recombinantes e naturais, por RP-HPLC e comparar com a potência determinada pelo bioensaio in vivo baseado no aumento de peso do ovário de ratas.

$\checkmark \quad$ Quantificar diferentes preparações íntegras e alteradas de hTSH, recombinantes e naturais, por RP-HPLC e comparar com a potência determinada pelo bioensaio in vivo baseado no estímulo do T4 pelo TSH.

$\checkmark \quad$ Quantificar diferentes preparações íntegras e alteradas de hLH, recombinantes e naturais, por RP-HPLC e comparar com a potência determinada pelo bioensaio in vivo baseado no aumento de peso da vesícula seminal de ratos.

$\checkmark \quad$ Estabelecer e validar a correlação entre os métodos físico-químico e biológico de acordo com a estatística de Bland-Altman. 


\section{MATERIAL E MÉTODOS}

\subsection{Material}

\subsubsection{Preparações hormonais}

No estudo referente ao hFSH foram analisadas 15 preparações, sendo 8 preparações recombinantes, derivadas de Células de Ovário de Hamster Chinês (CHO), (rhFSH-A, rhFSH-B, rhFSH-J, rhFSH-K, rhFSH-L, rhFSH-M, rhFSH-N, rhFSH-O), 2 hipofisárias (phFSH-C, phFSH-D) e 5 preparações urinárias (uhFSH-E, uhFSH-F, uhFSH-G, uhFSH-H, uhFSH-I). Três Padrões Internacionais da Organização Mundial de Saúde (WHO) foram utilizados neste estudo: o Padrão Internacional de FSH recombinante humano para bioensaio (rhFSH-WHO 92/642 e rhFSH-WHO 08/282) e o Padrão Internacional de FSH hipofisário humano para bioensaio (phFSH-WHO 83/575).

No estudo referente ao $\mathrm{hTSH}$ foram analisadas 21 preparações, sendo 19 preparações recombinantes derivadas de $\mathrm{CHO}$ (rhTSH- C a U) e 2 hipofisárias (phTSH-A, phTSH-B). Neste estudo foi utilizado o Padrão Internacional de TSH recombinante humano para bioensaio (rhTSH-WHO 03/192).

No estudo referente ao hLH foram analisadas 3 preparações, sendo 1 preparação recombinante derivada de $\mathrm{CHO}$ ( $\mathrm{rhLH}-\mathrm{C}$ ) e 2 hipofisárias (phLH-A, phLH-B). Neste estudo o padrão utilizado foi o Padrão Internacional de $\mathrm{LH}$ recombinante humano para bioensaio (rhLH-WHO 96/602) e o Padrão Internacional de LH hipofisário humano para bioensaio (phLH-WHO 80/552). 
As preparações citadas foram obtidas de: Aker University Hospital (Oslo, Noruega), Dong-A Pharmaceutical Co. (Daegu, Coreia do Sul), Ferring $\mathrm{GmbH}$ (Kiel, Alemanha), Genzyme Corporation (Cambridge, EUA), Institut Biochimique S.A. (IBSA) (Lugano, Suíça), IPEN-CNEN (São Paulo,Brasil), National Hormone and Pituitary Program (Torrance, EUA) e N.V.Organon (Oss, Holanda). Os Padrões Internacionais foram obtidos do National Institute for Biological Standard and Control (NIBSC, South Mimms, Reino Unido).

\subsubsection{Preparações hormonais potencialmente alteradas}

- Fora do prazo de validade:

- rhFSH-M e rhFSH-N (10 meses após o vencimento)

- rhTSH-T (2 anos após o vencimento)

- Tratamento com ciclos de congelamento e descongelamento:

- rhTSH-T (5 ciclos)

- Tratamento térmico:

- rhFSH-O (80 ${ }^{\circ} \mathrm{C}$, durante 5 minutos)

- rhTSH-U (100 $\stackrel{\circ}{\mathrm{C}}$, durante 5 minutos)

- rhTSH-U (65 $\stackrel{\circ}{\mathrm{C}}$, durante 10 minutos)

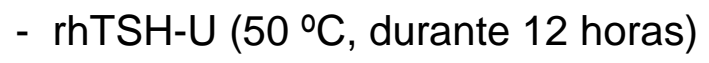

- phLH-B (70 ${ }^{\circ} \mathrm{C}$, durante 10 minutos)

- rhLH-C (70 ${ }^{\circ} \mathrm{C}$, durante 10 minutos)

\subsubsection{Animais}

Todos os ensaios utilizando animais foram conduzidos de acordo com a Legislação Nacional de Proteção do Bem-Estar Animal.

Foram utilizados:

- Camundongos machos da linhagem isogênica Balb-C, com peso de 22 $30 \mathrm{~g}$, oriundos do Biotério de Criação e Manutenção de Animais de Laboratório do IPEN/CNEN - SP. 
- Ratos machos e ratas fêmeas Sprague-Dawley oriundos do Biotério de Criação e Manutenção de Animais de Laboratório da UFSM-RS.

\subsubsection{Reagentes}

- $\quad$ Acetonitrila, grau HPLC, Mallinckrodt (Phillipsburg, EUA).

- $\quad$ Ácido acético glacial p.a., Labsynth (São Paulo, Brasil).

- $\quad$ Cloreto de Sódio p.a., Merck (Darmstadt, Alemanha).

- $\quad$ Fosfato de amônio bibásico p. a., Labsynth (São Paulo, Brasil).

- $\quad$ Fosfato de sódio monobásico p.a., Merck (Darmstadt, Alemanha).

- $\quad$ Fosfato de sódio bibásico p.a., Merck (Darmstadt, Alemanha).

- $\quad$ Hidróxido de amônio p.a., Merck (Darmstadt, Alemanha).

- $\quad$ Metanol, grau HPLC, Mallinckrodt (Philipsburg, EUA)

- $\quad$ Sal de sódio de 3,3',5-triiodo-L-tironina ( $\left.T_{3}\right)$, Sigma (St. Louis, MO, EUA).

- $\quad$ Sistema de radioimunoensaio para dosagem de tiroxina total $\left(\mathrm{T}_{4}\right), R I A$ Coat-A-Count $\Theta$ Total $T_{4}$, Diagnostic Products Corporation (DPC) (Los Angeles, CA, EUA).

\subsubsection{Equipamentos e acessórios principais}

- $\quad$ Agitador magnético, modelo 258, Fanem (São Paulo, Brasil).

- Agitador rotatório (tipo vortex), modelo AP-56, Phoenix (Araraquara, Brasil).

- $\quad$ Aparelho de cromatografia líquida de alta eficiência (HPLC), modelo SCL10A, acoplado a um detector de UV SPD-10AV e um programa de computador Class VP, Shimadzu (MD, EUA).

- Autoclave horizontal, modelo Speedclave 12L, Odontobrás (São Paulo, Brasil).

- $\quad$ Autoclave vertical, modelo 103, Fabbe-Primar (São Paulo, Brasil).

- $\quad$ Balança analítica, modelo H20T, Mettler (Zurich, Suíça).

- $\quad$ Balança analítica, modelo P1000N, Mettler (Zurich, Suíça). 
- $\quad$ Balança analítica, modelo M5AS, Mettler (Zurich, Suíça).

- $\quad$ Bomba de vácuo, modelo Nevoni, NSR (Barueri, Brasil).

- Coluna de aço inoxidável utilizada em cromatografia líquida de alta eficiência (HPLC) de exclusão molecular TSK G 2000 SW $(60 \mathrm{~cm}$ X 7,5mm D.I.), tamanho das partículas $10 \mu \mathrm{m}$ e poros de $125 \AA$, acoplada a uma pré-coluna SW (7,5cm X 7,5mm D.I.), Tosohaas (Montgomeryville, EUA).

- Coluna de aço inoxidável utilizada em cromatografia líquida de alta eficiência (HPLC) de fase reversa $\mathrm{C}_{4}$ Grace Vydac, 214 TP $54(25 \mathrm{~cm} \mathrm{X}$ 4,6mm D.I.), tamanho das partículas $5 \mu \mathrm{m}$, diâmetro dos poros de $300 \AA$, acoplada à pré-coluna 214 FSK $54(5 \mu \mathrm{m}, 1,0 \mathrm{~cm}$ X 4,6mm D.I.), Grace Vydac Separations Group (Hesperia, EUA).

- Destilador de água, modelo 016, Fabbe-Primar (São Paulo, Brasil).

- $\quad$ Freezer $-20^{\circ} \mathrm{C}$, modelo 0651, Prosdócimo (São Paulo, Brasil).

- Freezer $-40^{\circ} \mathrm{C}$, modelo AB 240, Metalfrio (São Paulo, Brasil).

- $\quad$ Freezer $-80^{\circ} \mathrm{C}$, modelo 8425, Forma Scientific (Marietta, EUA).

- Medidor digital de pH, modelo 420A, Thermo Electron Corporation (Bervely, EUA).

- Membrana de celulose para diálise, modelo D9277-100 FT, Sigma Aldrich ( Saint Louis, EUA).

- Membrana filtrante, modelo GVWP 04700, Millipore (São Paulo, Brasil)

- $\quad$ Microtubos estéreis, Eppendorf (São Paulo, Brasil)

- Microtubos de homo-polímero, de 1,5mL, Axygen (Union City, CA, EUA).

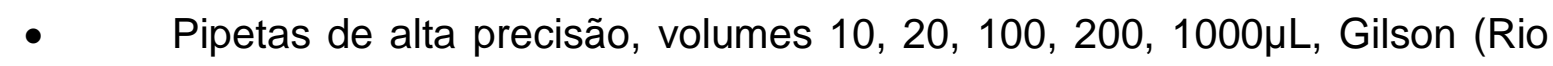
de Janeiro, Brasil).

- $\quad$ Pipeta Pasteur de vidro, Corning (New York, EUA).

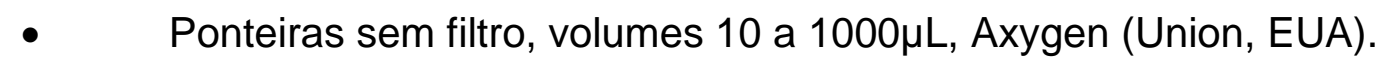

- Refrigerador duplex, modelo 320 Clean, Brastemp (São Paulo, Brasil).

- Refrigerador com porta de vidro, modelo VE 730, Metalfrio (São Paulo, Brasil).

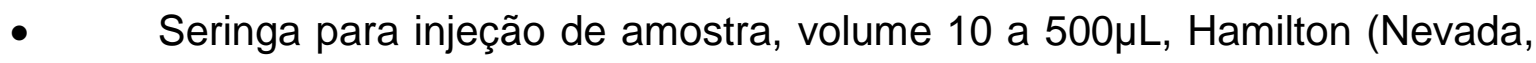
EUA)

- $\quad$ Sistema de purificação de água Milli-Q plus, Millipore (Bedford, EUA). 


\subsection{Métodos}

\subsubsection{Cromatografia líquida de alta eficiência em fase reversa (RP-HPLC)}

As análises por RP-HPLC dos hormônios $\mathrm{hFSH}$, hTSH e hLH foram realizadas nas condições experimentais mostradas na Tabela 2.

TABELA 2 - Condições experimentais empregadas na RP-HPLC para análise do hFSH, hTSH e do hLH

\begin{tabular}{ll}
\hline Características & Descrição \\
\hline Coluna & $\mathrm{C}_{4}$ Grace Vydac 214 TP $54(5 \mu \mathrm{m}, 25 \mathrm{~cm} \times$ 4,6mm D.I. $)$ \\
Pré-coluna & $\mathrm{C}_{4}$ Grace Vydac 214 FSK $54(5 \mu \mathrm{m}, 1 \mathrm{~cm} \mathrm{X} \mathrm{4,6mm} \mathrm{D.I.)}$
\end{tabular}

Temperatura da coluna $25^{\circ} \mathrm{C}$

Comprimento de onda $220 \mathrm{~nm}$

Sistema de detecção Absorbância em luz ultravioleta UV

Fluxo da fase móvel $\quad 0,5 \mathrm{~mL} / \mathrm{min}$

Fase Móvel

Solução A (FSH): Fosfato de Amônio 0,05M pH 8,6

Solução A (TSH e LH): Fosfato de Sódio $0,05 \mathrm{M} \mathrm{pH} \mathrm{7,0}$

Solução B: Acetonitrila

Gradiente Linear

Modo de eluição

FSH: $15-50 \%$ B

TSH: $12,5-50 \% \mathrm{~B}$

LH $1^{\circ}=27-42 \% B ; 2=42-65 \%$ B

Duração da corrida

FSH e TSH: 40 minutos

LH: $1^{\circ}=60$ minutos; $2^{\circ}=20$ minutos

Volume injetado

Alíquotas de $5-10 \mu \mathrm{L}$ de phFSH, phTSH e phLH

$20-100 \mu \mathrm{L}$ de rhFSH, uhFSH, rhTSH e r-hLH 


\subsubsection{HPLC de exclusão molecular (HPSEC)}

As análises por HPSEC dos hormônios hTSH, hFSH e hLH foram realizadas nas condições experimentais mostradas na Tabela 3.

TABELA 3 - Condições experimentais empregadas na HPSEC para análise do hFSH, hTSH e do hLH

\begin{tabular}{|c|c|}
\hline Características & Descrição \\
\hline Coluna & TSK G2000 SW (60cm X 7,5mm D.I.) \\
\hline Pré-coluna & TSK SW $(7,5 \mathrm{~cm} \times 7,5 \mathrm{~mm}$ D.I. $)$ \\
\hline Temperatura da coluna & Ambiente \\
\hline Comprimento de onda & $220 \mathrm{~nm}$ \\
\hline Sistema de detecção & Absorbância em luz ultravioleta UV \\
\hline Fluxo da fase móvel & $1,0 \mathrm{~mL} / \mathrm{min}$ \\
\hline \multirow{2}{*}{ Fase Móvel } & Fosfato de Sódio $0,05 \mathrm{M} \mathrm{pH} \mathrm{7,0}$ \\
\hline & Cloreto de Sódio 0,15 M \\
\hline Modo de eluição & Isocrático \\
\hline Duração da corrida & 30 minutos \\
\hline Volume injetado & Alíquotas de $20-100 \mu \mathrm{L}$ de rhTSH, rhFSH e rhLH \\
\hline
\end{tabular}




\subsubsection{Ensaio biológico}

\subsection{3.a Ensaio biológico de preparações de hFSH}

A atividade de $\mathrm{hFSH}$ foi determinada pelo método de Steelman e Pohley (1953). Resumidamente, 42 ratas fêmeas Sprague-Dawley entre 19 e 22 dias foram distribuidas em grupos de 6 animais por dose e o grupo controle e receberam, por via subcutânea, durante três dias, 0,5, 1 e $3 \mathrm{UI}$ de hFSH do padrão e da amostra, respectivamente. A autópsia foi realizada no quarto dia (72 horas após a primeira injeção). Os ovários foram retirados, dissecados livres de tecidos circundantes e pesados. A bioatividade in vivo de $\mathrm{hFSH}$ foi avaliada em comparação com o padrão de referência internacional de $\mathrm{hFSH}$ recombinante (WHO 96/642) ou com o padrão de referência internacional de hFSH hipofisário (phFSH-WHO 83/575). Estes ensaios foram realizados nos Laboratórios do Departamento de Farmácia Industrial da Universidade Federal de Santa Maria, em colaboração com o Dr. Sérgio Luiz Dalmora.

\subsection{3.b Ensaio biológico de preparações de hTSH}

A avaliação da atividade biológica das preparações de hTSH foi realizada por um ensaio in vivo, utilizando camundongos machos com peso variando entre $22-30 \mathrm{~g}$. O ensaio baseia-se na capacidade que $\mathrm{O}$ TSH tem de estimular a produção de tiroxina $\left(\mathrm{T}_{4}\right)$. Visando suprimir o TSH endógeno dos animais, foi administrada oralmente, durante 4-5 dias, uma solução de triiodotironina $\left(T_{3}\right), \mathrm{pH} 7,5$, com uma concentração final de $3 \mu \mathrm{g} / \mathrm{mL}$. Após a supressão do TSH endógeno, as amostras a serem analisadas foram

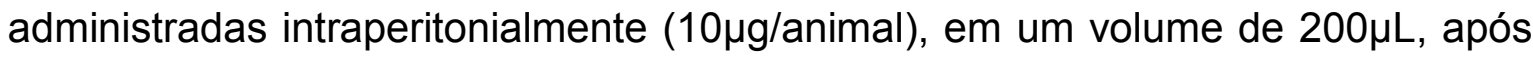
diluição em solução salina. Para cada preparação foram utilizados 10 animais, bem como para o controle (salina). Após 6 horas da administração das amostras, foi realizada a coleta de sangue, via plexo retro-orbital e o nível de $T_{4}$ circulante foi mensurado por radioimunoensaio (RIA). 


\subsection{3.c Ensaio biológico de preparações de hLH}

Para a atividade de $\mathrm{hLH}, 42$ ratos machos Sprague-Dawley entre $19 \mathrm{e}$ 22 dias foram distribuidas em grupos de 6 animais por dose e o grupo controle e receberam, por via subcutânea, durante três dias, 1, 2 e $4 \mathrm{UI}$ de hLH do padrão e da amostra, respectivamente. A autópsia foi realizada no quarto dia (72 horas após a primeira injeção). As vesículas seminais foram retiradas, dissecadas livres de tecidos circundantes e pesadas. A bioatividade in vivo de $\mathrm{hLH}$ foi avaliada em comparação com o padrão de referência internacional de hLH (WHO 96/602) ou o padrão de referência internacional de hLH hipofisário (phLH-WHO 80/552) (Van Hell, 1964). Estes ensaios foram realizados nos Laboratórios do Departamento de Farmácia Industrial da Universidade Federal de Santa Maria, em colaboração com o Dr. Sérgio Luiz Dalmora.

\subsection{Método Estatístico aplicado para validar a comparação entre dois métodos analíticos}

A comparação entre os dados obtidos por ensaio biológico e por RPHPLC das diferentes preparações de hFSH, hTSH e hLH, foi realizada por análise de regressão linear. $\mathrm{O}$ acordo entre os resultados obtidos por bioatividade in vivo estimada por RP-HPLC, a partir da equação estabelecida, e aquela estimada pelo Bioensaio in vivo foi avaliado seguindo a estatística de Bland e Altman (1986) que consiste de:

a) Calcular para cada preparação, a média entre os resultados do método proposto (bioatividade in vivo estimada por RP-HPLC, a partir da equação estabelecida) e o método tradicional (Bioensaio in vivo); esta média reflete o valor que mais se aproxima do valor real.

b) Calcular para cada preparação, a diferença (d) entre os resultados obtidos com os dois métodos, $(\mathrm{d}=$ resultado do método proposto - resultado da média entre o método proposto e o método tradicional). 
c) Plotar o valor da diferença d contra cada valor da média. Idealmente, os pontos variarão em torno de um valor médio de 0 .

d) Calcular o desvio padrão (DP) de d, e o limite de confiança de 95\%, (d + 2 DP) e (d - 2 DP), e traçar linhas horizontais no gráfico correspondente a estes valores, e também ao valor médio de $\mathrm{d}(\overline{\mathrm{d}})$.

e) $O$ intervalo de $(\overline{\mathrm{d}}-2 \mathrm{DP})$ a $(\overline{\mathrm{d}}+2 \mathrm{DP})$, indica o intervalo de $95 \%$ de confiança onde os valores de $\mathrm{d}$ podem estar.

f) Calcular o erro padrão da diferença média usando a fórmula:

$$
\sqrt{\mathrm{DP}^{2} / \mathrm{n}}
$$

Onde: $\mathrm{DP}=$ desvio padrão e $\mathrm{n}=\mathrm{o}$ número de valores de $\mathrm{d}$.

g) Calcular o erro padrão do desvio padrão usando a fórmula:

$$
\sqrt{3 \mathrm{DP}^{2} / \mathrm{n}}
$$

h) $O$ intervalo $\left(\overline{\mathrm{d}}+\mathrm{t} \sqrt{\mathrm{DP}^{2} / \mathrm{n}}\right)$ a $\left(\overline{\mathrm{d}}-\mathrm{t} \sqrt{\mathrm{DP}^{2} / \mathrm{n}}\right)$ indica a precisão que $\overline{\mathrm{d}}$ é determinado, onde $t=$ "t" Student's com $n-1$ graus de liberdade.

i) Calcular o intervalo de confiança (95\%) para o limite inferior (LI) de concordância (LI $\pm \mathrm{t} \sqrt{3 \mathrm{DP}^{2} / \mathrm{n}}$ ) e para o limite superior (LS) de concordância (LS \pm $\mathrm{t} \sqrt{3 \mathrm{DP} / \mathrm{n})}$.

Este procedimento permite analisar o grau de concordância entre dois métodos. 


\subsection{Parâmetros de uma separação cromatográfica}

Os parâmetros de eficiência de separação entre o LH e o excipiente (HSA) considerado neste estudo foram:

$\checkmark \quad$ Fator de resolução (Rf): determinado de acordo com a definição que considera assimetria do pico (Song, 2003). Em geral Rf $>1,5$ é indicativo de resolução completa, admitindo uma integração precisa dos picos individuais e sua quantificação.

$$
R f=\frac{2\left(t_{2}+w_{2}\right.}{2} \frac{2\left(1-1 / T f_{2}\right)-t_{1}-w_{1}}{w_{1}+w_{2}} \frac{\left.2\left(1-1 / T f_{1}\right)\right)}{2}
$$

Onde $t_{2}$ e $t_{1}$ são os tempos de retenção da $H S A$ e do $h L H$, respectivamente; $w_{2}$ e $w_{1}$ são as larguras dos picos de HSA e de $h L H$, medidas na linha de base e $\mathrm{Tf}_{2}$ e $\mathrm{Tf}_{1}$ são os fatores de assimetria dos picos de HSA e de hLH, respectivamente.

$\checkmark \quad$ Grau de assimetria do pico (tailing factor): determinado de acordo com a definição.

$$
T f=\underline{(a+b)}
$$

$2 a$

Onde $\mathrm{a}$ e $\mathrm{b}$ são as larguras dos picos dos lados esquerdo e direito, respectivamente, medidos na linha de base, com $w=a+b$. O pico é simétrico quando Tf é 1.

$\checkmark$ Índice de retenção relativo HSA-LH: determinado pelo tempo de retenção relativo $\left(\mathrm{t}_{\mathrm{RR}}\right)$.

$$
t_{R R}=\frac{\text { tempo de retenção da albumina }}{\text { tempo de retenção do } h L H}
$$




\section{RESULTADOS}

\subsection{Determinação de potência de hFSH}

\section{1.a Cromatografia líquida de alta eficiência em fase reversa (RP-HPLC)}

Considerando a falta de padrões oficiais para ensaios físico-químicos, foi utilizado para as determinações da potência do hFSH o padrão de referência internacional para ensaios biológicos rhFSH(WHO 92/642), que apresentou o perfil cromatográfico em RP-HPLC mostrado na Figura $5 \mathrm{~A}$. É importante ressaltar que este padrão de referência somente pôde ser utilizado para análise quantitativa em RP-HPLC, uma vez que o alto conteúdo de Albumina de Soro Humano (HSA) presente nesta amostra (200:1) não elui nas condições estabelecidas para esta metodologia. Entretanto, em cromatografia líquida de exclusão molecular (HPSEC), o pico do HSA elui sobrepondo-se ao pico do hFSH, o que inviabiliza a análise por esta técnica (Figura 5 B). 

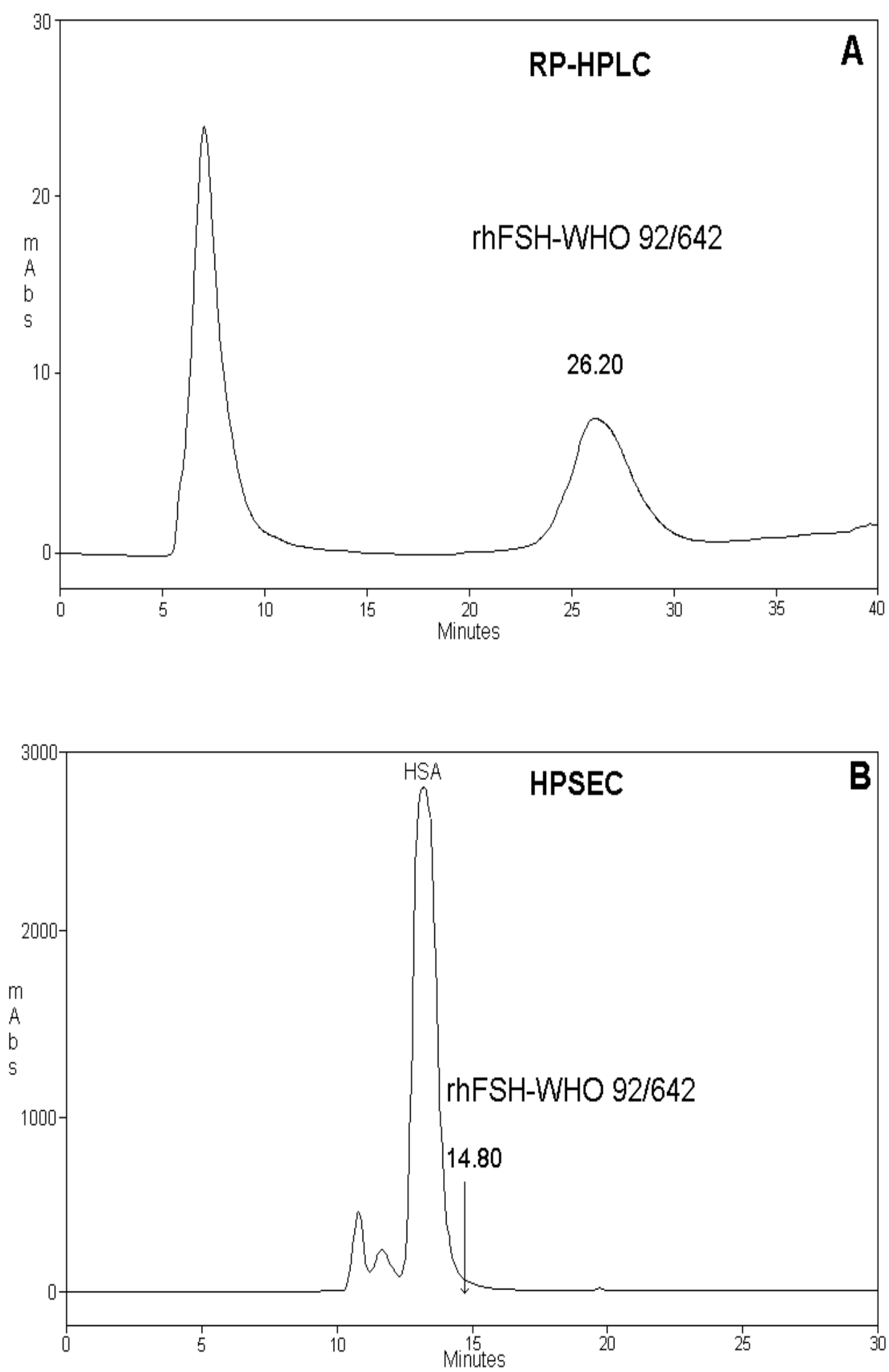

FIGURA 5 - Perfil em HPLC de $2 \mu \mathrm{g}$ do padrão de referência para ensaios biológicos hFSH recombinante (WHO 92/642). (A) RP-HPLC. (B) HPSEC. $O$ tempo de retenção da preparação de rhFSH sem HSA, analisada nas mesmas condições, é indicado pela seta. 
O conteúdo de hFSH em 6 preparações de diferentes origens, recombinante $(A$ e $B)$, hipofisária $(C$ e $D)$ e urinária $(E$ e $F)$ foi determinado utilizando a técnica descrita em nosso laboratório por Loureiro e colaboradores (2006) (Tabela 4). Uma variação inter-ampola e inter-dias $<6 \%$ foi observada para estas preparações.

TABELA 4 - Determinação inter-dias do conteúdo de hFSH em preparações de diferentes origens, por RP-HPLC

\begin{tabular}{ccc}
\hline Preparação & $\begin{array}{c}\text { Conteúdo de } \mathbf{F S H}^{\mathbf{a}} \\
(\mu \mathbf{g} / \mathbf{a m p o l a})\end{array}$ & $\begin{array}{c}\mathbf{D P R}^{\mathbf{b}} \\
(\%)\end{array}$ \\
\hline rhFSH-A & $5,5 \pm 0,32$ & 5,8 \\
rhFSH-B & $9,8 \pm 0,41$ & 4,2 \\
phFSH-C & $4,8 \pm 0,03$ & 1,7 \\
phFSH-D & $6,7 \pm 0,12$ & 1,6 \\
uhFSH-E & $5,2 \pm 0,30$ & 5,8 \\
uhFSH-F & $10,3 \pm 0,27$ & 2,6 \\
\hline
\end{tabular}

${ }^{a}$ Média \pm desvio padrão $(n=4)$

${ }^{\text {b}}$ Desvio padrão relativo, expresso como \% da média

Os perfis em RP-HPLC dos três grupos de preparações de hFSH são mostrados nas Figuras 6, 7 e 8. Foi encontrada uma diferença altamente significativa $(p<0,001)$ entre os tempos de retenção de $\mathrm{hFSH}$ recombinante $\left(\mathrm{t}_{\mathrm{R}}=\right.$ $26,42 \pm 0,23, n=8)$, hipofisário $\left(t_{R}=25,19 \pm 0,15, n=8\right)$ e urinário $\left(t_{R}=24,46 \pm\right.$ $0,22, n=8)$. Os picos com $t_{R}$ de $\sim 7$ minutos correspondem aos diferentes excipientes presentes nas preparações analisadas. 

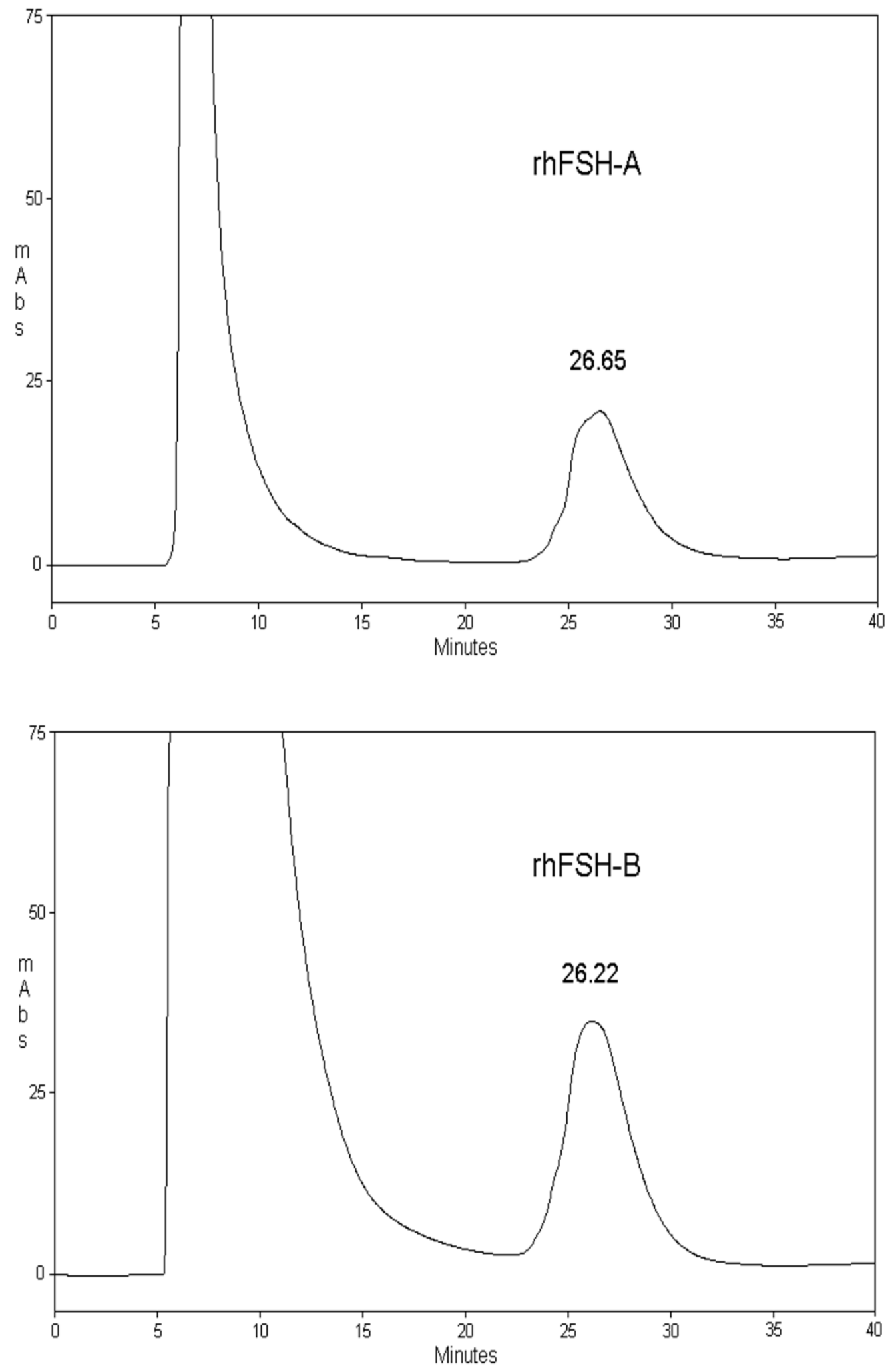

FIGURA 6 - Perfil em RP-HPLC de diferentes preparações de hFSH recombinante: rhFSH-A; rhFSH-B 

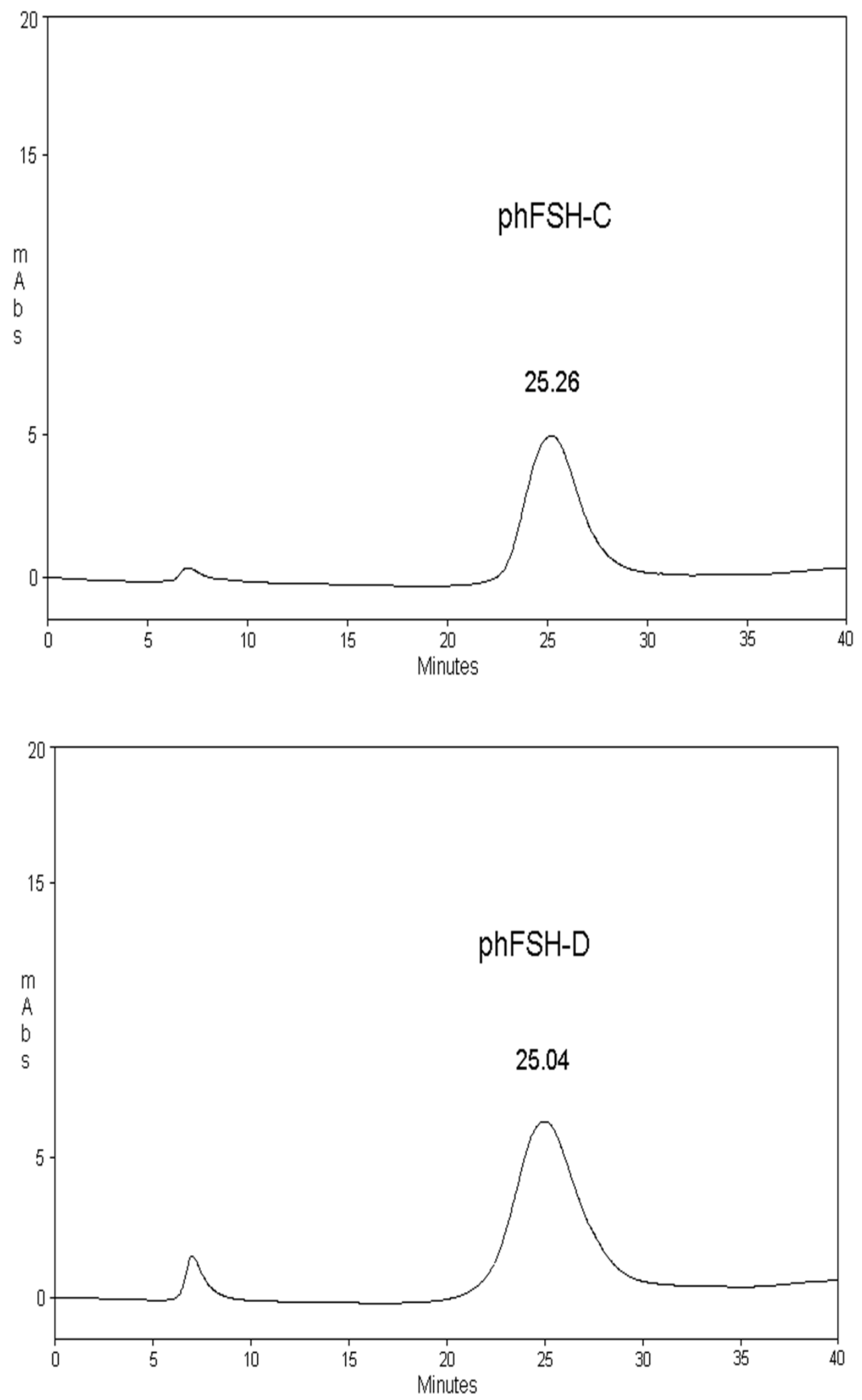

FIGURA 7 - Perfil em RP-HPLC de diferentes preparações de hFSH hipofisário: phFSH-C; phFSH-D 

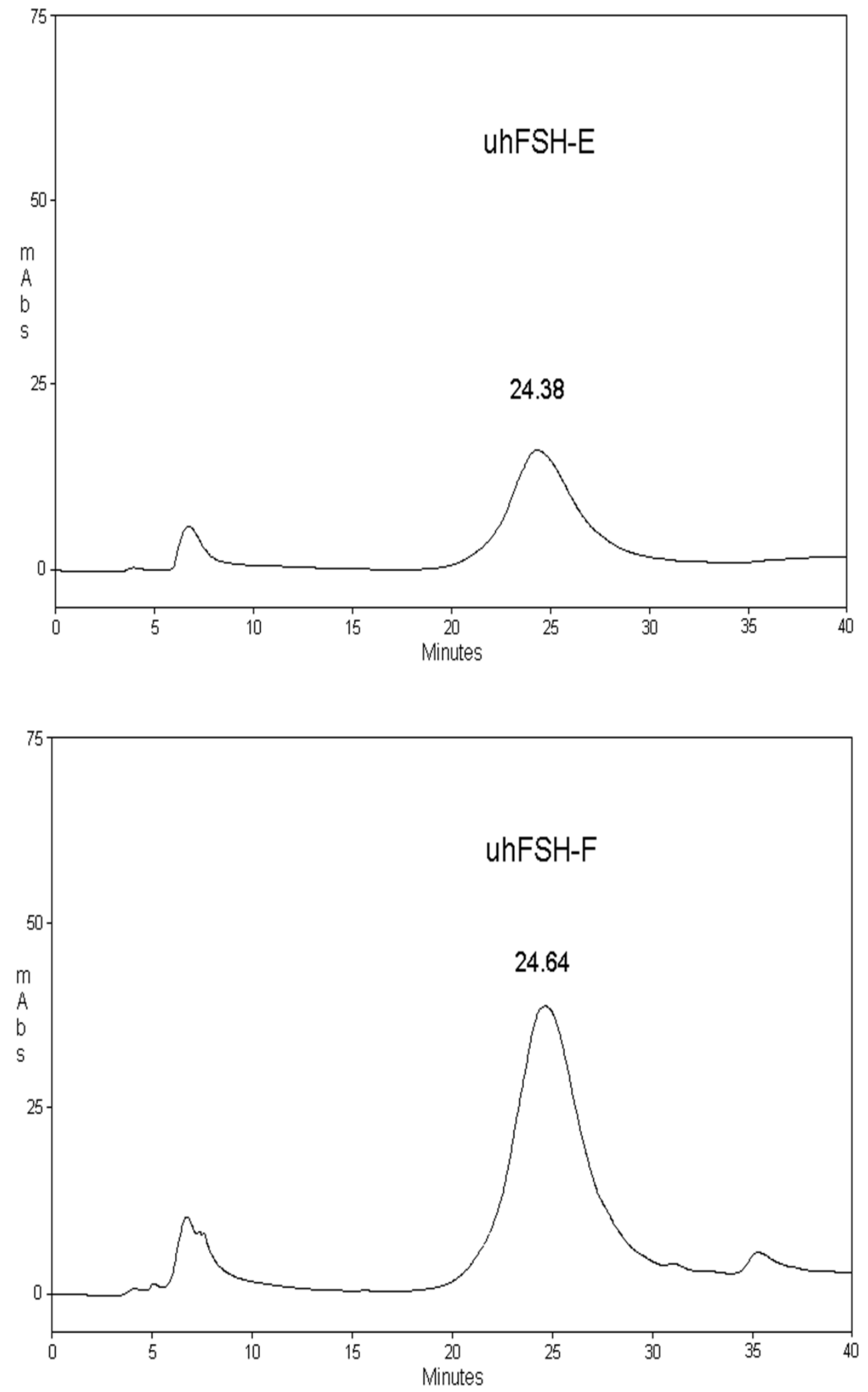

FIGURA 8 - Perfil em RP-HPLC de diferentes preparações de hFSH urinário: uhFSH-E; uhFSH-F 


\section{1.b Ensaio Biológico}

As estimativas de potência (Unidades Internacionais, Ul/ampola) de preparações de hFSH recombinante e urinária, através de ensaio biológico in vivo (Steelman, 1953), foram realizadas em relação ao padrão de referência internacional de hFSH recombinante (WHO 92/642), enquanto as preparações hipofisárias foram determinadas em relação ao padrão de referência internacional de hFSH hipofisário (WHO 83/575) (Tabela 5).

TABELA 5 - Determinação da potência do hFSH por ensaio biológico in vivo

\begin{tabular}{cc}
\hline Preparação & $\begin{array}{c}\text { Conteúdo de } \text { FSH }^{\mathbf{a}} \\
\text { (Ul/ampola) }\end{array}$ \\
\hline rhFSH-A & 77,0 \\
rhFSH-B & 117,2 \\
phFSH-C & 80,7 \\
phFSH-D & 116,9 \\
uhFSH-E & 76,1 \\
uhFSH-F & 161,7 \\
\hline $\begin{array}{l}{ }^{\text {Considerando } 13.800 ~ U l / m g ~ a ~ p o t e ̂ n c i a ~ d e ~ r h F S H(W H O ~ 92 / 642) ~ e ~} 19.184 \mathrm{UI} / \mathrm{mg} \text { a potência de } \\
\text { phFSH-WHO 83/575. }\end{array}$
\end{tabular}




\section{1.c Comparação entre as quantificações de hFSH por RP-HPLC e por Ensaio Biológico in vivo}

Para facilitar a comparação, o conteúdo de hFSH determinado pela RPHPLC em $\mu \mathrm{g}$ foi expresso em UI, devido a este sistema de unidade ser o mais utilizado na prática clínica (Tabela 6). Com base no bioensaio foi observada uma recuperação média com relação ao conteúdo nominal de hFSH de 108,3 \pm $11,63 \%$, enquanto com base na RP-HPLC, a recuperação média foi de $111,9 \pm 20,09 \%$. Uma relação linear foi encontrada quando a determinação da potência do hFSH pelo Bioensaio $\left(B_{U \mathrm{UI}}\right)$ foi comparada com a determinação pela RP-HPLC (RP-HPLC $\mathrm{CII}_{\mathrm{I}}$, com um coeficiente de correlação (r) altamente

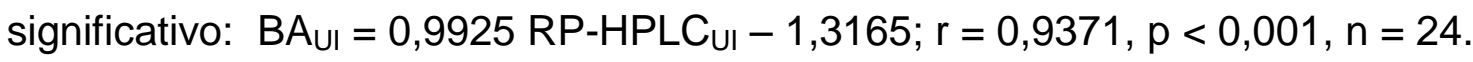

TABELA 6 - Comparação entre a quantificação de preparações de hFSH por Bioensaio in vivo e por RP-HPLC

\begin{tabular}{cccc}
\hline Preparação & $\begin{array}{c}\text { Conteúdo nominal de } \\
\text { hFSHa } \\
\text { (Ul/ampola) }\end{array}$ & $\begin{array}{c}\text { Determinação de hFSH } \\
\text { por Bioensaio in vivo } \\
\text { (Ul/ampola) }\end{array}$ & $\begin{array}{c}\text { Determinação de } \\
\text { hFSH por RP-HPLC } \\
\text { (Ul/ampola) }\end{array}$ \\
\hline rhFSH-A & 75 & 77,0 & 75,9 \\
rhFSH-B & 100 & 117,2 & 135,2 \\
phFSH-C & 85,6 & 80,7 & 92,1 \\
phFSH-D & 92,9 & 116,9 & 128,5 \\
uhFSH-E & 75 & 76,1 & 70,4 \\
uhFSH-F & 150 & 161,7 & 142,1 \\
\hline${ }^{a}$ Baseado no conteúdo declarado. & &
\end{tabular}




\section{1.d Validação da RP-HPLC para quantificação de hFSH}

Para avaliar o potencial da RP-HPLC de estimar com precisão a bioatividade in vivo, foi utilizada a análise estatística de Bland-Altman (1986). A bioatividade estimada por RP-HPLC, a partir da equação estabelecida, e aquela estimada pelo Bioensaio in vivo de nove amostras de hFSH que não tinham sido utilizadas para análise de correlação, sendo 3 delas potencialmente alteradas, foram analisadas e comparadas (Tabela 7). 
TABELA 7 - Comparação entre a atividade biológica do hFSH determinada por Bioensaio in vivo e predita pela equação

por análise em RP-HPLC

\begin{tabular}{|c|c|c|c|c|c|c|}
\hline Preparação & $\begin{array}{l}\text { Atividade } \\
\text { Biológica } \\
\text { determinada por } \\
\text { RP-HPLC } \\
\text { (Ul/ampola) }\end{array}$ & $\begin{array}{l}\text { Atividade Biológica } \\
\text { predita por } \\
\text { RP-HPLC } \\
\text { (1) } \\
\text { (Ul/ampola) }\end{array}$ & $\begin{array}{l}\text { Atividade Biológica } \\
\text { determinada por } \\
\text { Bioensaio in vivo } \\
\text { (2) } \\
\text { (Ul/ampola) }\end{array}$ & $\begin{array}{c}\text { Média } \\
\text { Atividade } \\
\text { Biológica } \\
\text { (1) e (2) } \\
\text { (Ul/ampola) }\end{array}$ & $\begin{array}{l}\text { Diferença entre } \\
\text { Atividade Biológica } \\
\text { predita e média } \\
\text { d } \\
\text { (UI) }\end{array}$ & $\begin{array}{l}\text { Diferença entre } \\
\text { Atividade Biológica } \\
\text { predita e média } \\
\text { d } \\
(\%)\end{array}$ \\
\hline uhFSH-G & 59,8 & 58,0 & 68,0 & 63,0 & $-5,0$ & $-7,9$ \\
\hline uhFSH-H & 167,0 & 164,2 & 150,3 & 157,3 & 6,9 & 4,4 \\
\hline uhFSH-I & 72,2 & 70,3 & 74,0 & 72,2 & $-1,9$ & $-2,6$ \\
\hline rhFSH-J & 118,5 & 116,4 & 119,0 & 117,7 & $-1,3$ & $-1,1$ \\
\hline rhFSH-K & 116,5 & 114,2 & 116,6 & 115,4 & $-1,2$ & $-1,0$ \\
\hline rhFSH-L & 118,1 & 116,1 & 115,8 & 116,0 & 0,1 & 0,09 \\
\hline rhFSH-M (10 meses após o vencimento) & 57,9 & 56,1 & 62,9 & 59,5 & $-3,4$ & $-5,7$ \\
\hline rhFSH-N (10 meses após o vencimento) & 118,4 & 116,2 & 123,9 & 120,1 & $-3,9$ & $-3,2$ \\
\hline rhFSH-O (80 $\left.{ }^{\circ} \mathrm{C}, 5 \mathrm{~min}\right)$ & 52,0 & 50,3 & 52,4 & 51,4 & $-0,8$ & $-2,1$ \\
\hline
\end{tabular}


Foi observada uma diferença percentual média $(\overline{\mathrm{d}})$, entre a bioatividade predita pela equação e a média das bioatividades obtidas pelos dois métodos de $-2,11 \pm 3,49 \%$, com limites de confiança de $95 \%(\bar{d} \pm 2 D P)$ de $-9,1$ a $+4,9 \%$ (Figura 9).

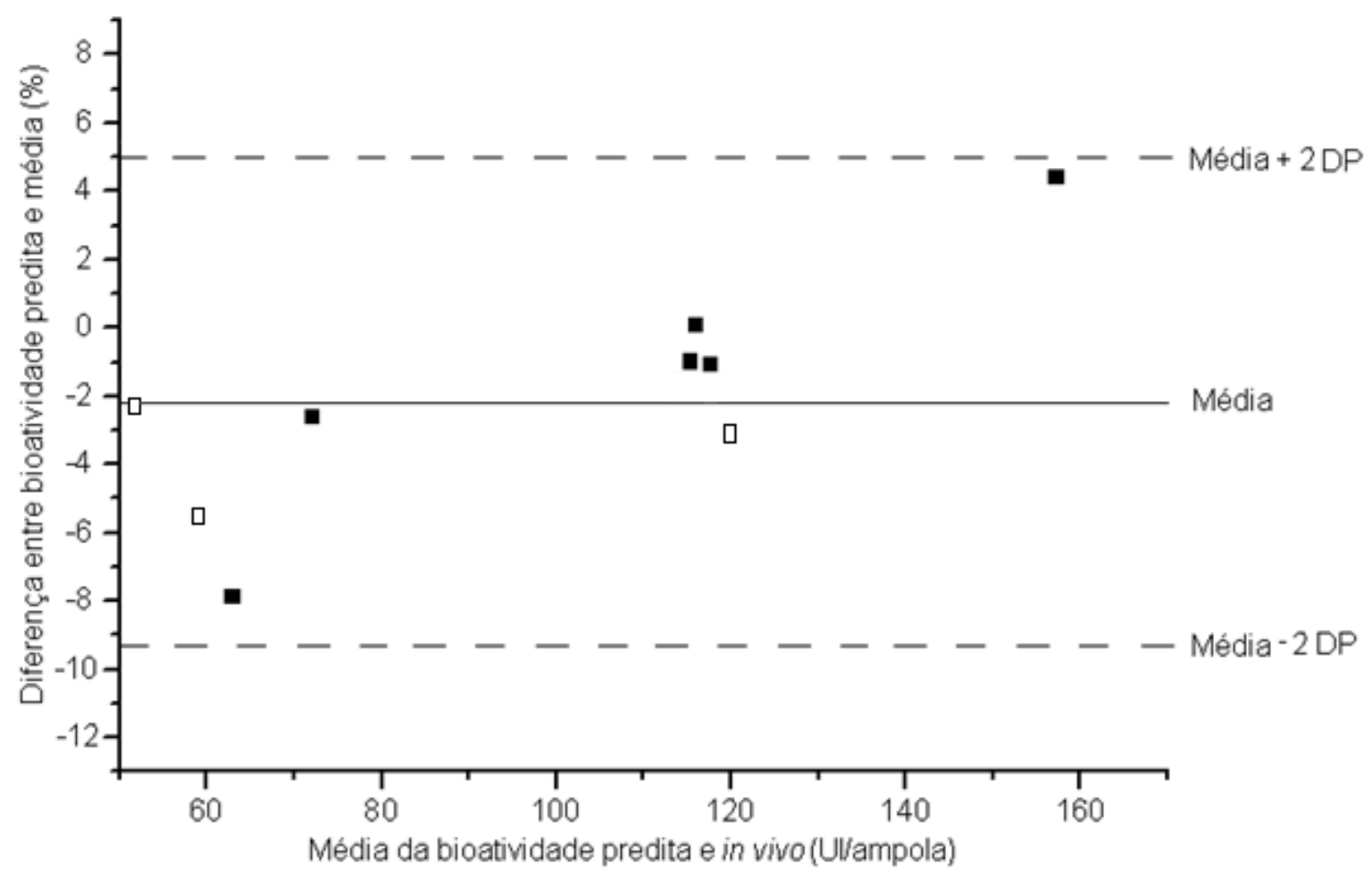

FIGURA 9 - Comparação entre a bioatividade predita-RP-HPLC e in vivo. $\square$ Amostras alteradas ; $\square$ Amostras íntegras

O teste "t-Student", realizado entre as determinações de atividade biológica do hFSH in vivo e predita pela equação, indica que o valor de tcalculado $(0,20)$ é muito menor do que o valor de t-teórico de 2,31, no limite de significância de 0,05, com 8 graus de liberdade, indicando que os resultados das duas metodologias não foram significativamente diferentes.

Para avaliar a precisão das determinações foram calculados o erro padrão de $\overline{\mathrm{d}}$, definido como $\left(\sqrt{\mathrm{DP}^{2} / \mathrm{n}}\right)$ e o erro padrão de $\overline{\mathrm{d}} \pm 2 \mathrm{DP}$, definido como $\left(\sqrt{3 \mathrm{DP}^{2} / \mathrm{n}}\right)$, sendo $1,16 \%$ e $2,01 \%$, respectivamente. O intervalo de $95 \%$ de 
confiança para o "bias" ( $\left.\overline{\mathrm{d}} \pm \mathrm{t} \sqrt{\mathrm{DP}^{2} / \mathrm{n}}\right)$, para o limite inferior de concordância (LI) e para o limite superior de concordância (LS) foram também calculados. Todos estes parâmetros estatísticos são apresentados na Tabela 8.

TABELA 8 - Parâmetros estatísticos, determinados de acordo com Bland e Altman, comparando o valor da bioatividade in vivo com aquela predita por RP- HPLC

Parâmetros

Valor Determinado

(\%)

Diferença Média $(\overline{\mathrm{d}})$ $-2,11$

Desvio Padrão (DP) 3,49

Intervalo $(\overline{\mathrm{d}} \pm 2 \mathrm{DP})$ $-9,1 a+4,9$ $\sqrt{\mathrm{DP}^{2} / \mathrm{n}}$ 1,16
$\sqrt{3 \mathrm{DP}^{2} / \mathrm{n}}$ 2,01
$-4,79 a+0,57$
Intervalo $\left(\overline{\mathrm{d}} \pm \mathrm{t} \sqrt{\mathrm{DP}^{2} / \mathrm{n}}\right)$
Intervalo $\left(\mathrm{LI} \pm \mathrm{t} \sqrt{3 \mathrm{DP}^{2} / \mathrm{n}}\right)$
$-13,73$ a $-4,45$
Intervalo $\left(\mathrm{LS} \pm \mathrm{t} \sqrt{3 \mathrm{DP}^{2} / \mathrm{n}}\right)$
$+0,23 a+9,51$

Os resultados obtidos permitem concluir que a RP-HPLC pode ser um ensaio alternativo ao Bioensaio in vivo para a determinação da potência de hFSH de amostras íntegras e alteradas. 


\section{1.e Análise das preparações potencialmente alteradas de hFSH}

As estimativas de potência de duas preparações recombinantes comerciais (M e N) de $75 \mathrm{UI}$ e $150 \mathrm{UI}$ respectivamente, que estavam fora do prazo de validade declarado pelo fabricante (10 meses após o vencimento), foram avaliadas por ensaio biológico e por RP-HPLC utilizando o padrão de referência internacional de hFSH recombinante WHO 92/642 (Tabela 9). Para ambas as amostras foi observada uma perda de atividade de hFSH com relação ao conteúdo nominal de $\sim 17 \%$ com base no bioensaio, enquanto com base na RP. HPLC, a perda de atividade detectada foi de $~ 22 \%$.

TABELA 9 - Comparação entre a quantificação por Bioensaio in vivo e por RP-HPLC de preparações de hFSH fora do prazo de validade

\begin{tabular}{cccc}
\hline Preparação & $\begin{array}{c}\text { Conteúdo } \\
\text { nominal de } \\
\text { hFSH }^{\text {(Ul/ampola) }}\end{array}$ & $\begin{array}{c}\text { Determinação de } \\
\text { hFSH por } \\
\text { Bioensaio in vivo } \\
\text { (Ul/ampola) }\end{array}$ & $\begin{array}{c}\text { Determinação de } \\
\text { hFSH por } \\
\text { RP-HPLC } \\
\text { (Ul/ampola) }\end{array}$ \\
\hline $\begin{array}{r}\text { rhFSH-M (10 meses após 0 } \\
\text { vencimento) }\end{array}$ & 75 & 62,9 & 57,9 \\
rhFSH-N (10 meses após o & & & 118,4 \\
vencimento) & 150 & 123,9 & \\
\hline a Declarado pelo fabricante & & &
\end{tabular}

Os perfis em RP-HPLC das preparações $M$ e $N$ são mostrados na Figura 10. Os tempos de retenção de hFSH recombinante rhFSH-M ( $t_{R}=26,28 \pm$ $0,05, n=3)$ e rhFSH-N $\left(t_{R}=26,22 \pm 0,03, n=3\right)$ foram similares aos das outras preparações recombinantes analisadas no presente estudo. Os picos com $t_{R}$ de 9 minutos correspondem aos diferentes excipientes presentes nas preparações analisadas. 

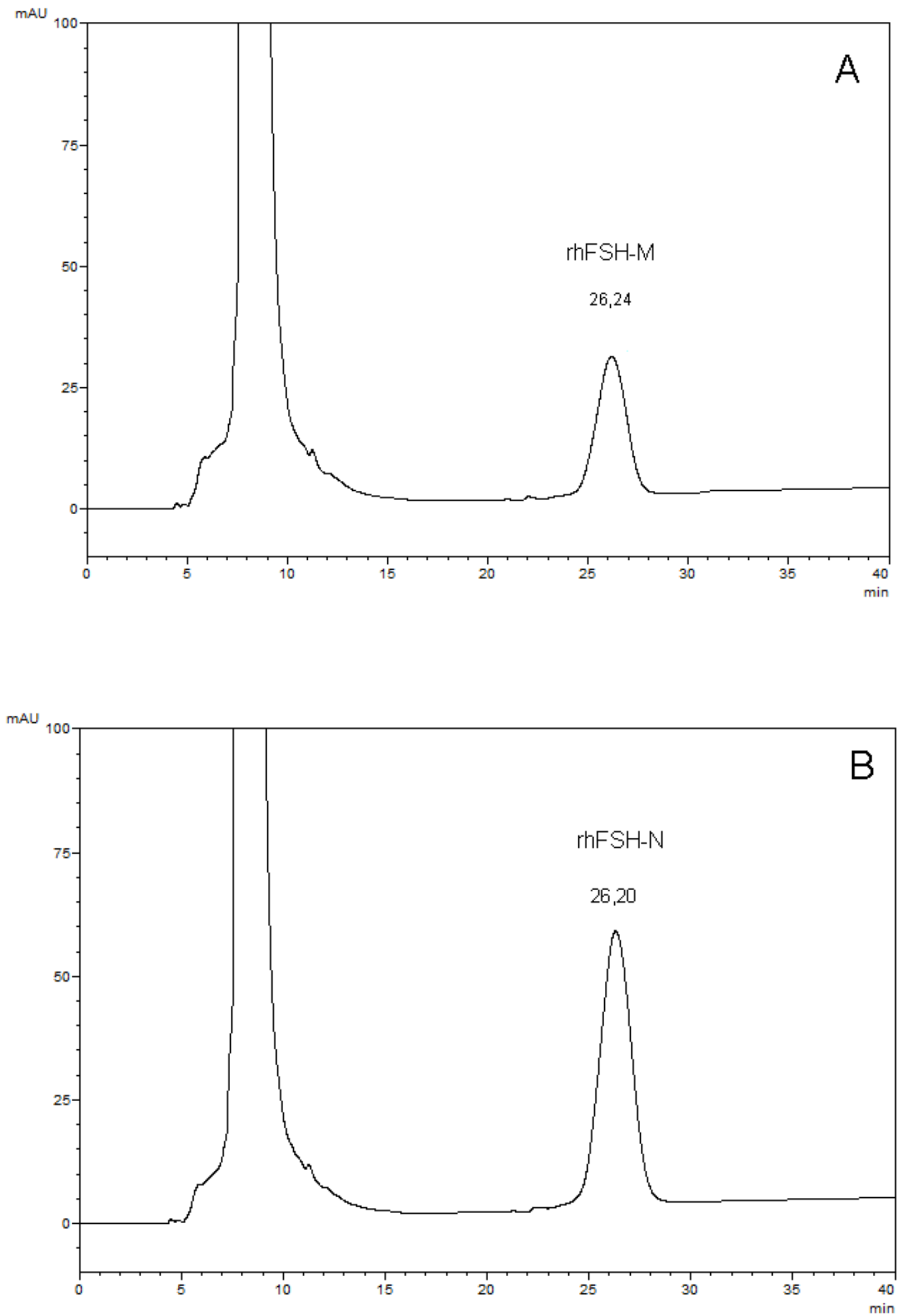

FIGURA 10 - Perfil em RP-HPLC de preparações de hFSH recombinante fora do prazo de validade. (A) rhFSH-M (B) rhFSH-N 
A potência de uma outra preparação de $\mathrm{FSH}$ (rhFSH-O), na qual induzimos uma alteração térmica, foi determinada por ensaio biológico e por RPHPLC. Esta preparação foi submetida a uma temperatura de $80{ }^{\circ} \mathrm{C}$, durante 5 minutos. O perfil em RP-HPLC da preparação de hFSH e do controle (mesma preparação sem sofrer tratamento térmico) é mostrado na Figura 11. Observa-se que após o aquecimento há formação de dois picos. Conforme trabalho anterior realizado em nosso laboratório por Carvalho e colaboradores (2009), a dissociação total do FSH heterodímero forma 46,7 \% de subunidade a e 53,3 \% de $\beta$, sendo a subunidade $\beta$ menos hidrofóbica que a subunidade $\alpha$ e com hidrofobicidade semelhante ao do heterodímero. Com base neste estudo, observa-se que no caso da presente amostra, (após o seu aquecimento) houve formação de $27,4 \%$ de subunidade a. Não é possível visualizar diretamente a subunidade $\beta$, pois ela elui em um tempo de retenção muito próximo ao do heterodímero, sobrepondo-se suas áreas. Entretanto, estequiometricamente é possível calcular a \% desta subunidade com base na \% do que se formou de $\alpha$. No caso da presente amostra houve formação de 31,3 \% da subunidade $\beta$. Logo, a fração correspondente ao heterodímero é de 41,3 \%. O conteúdo de FSH determinado por RP-HPLC foi de 4,13 $\mu \mathrm{g}$ /ampola ou 52 Ul/ampola. Foi, portanto, detectada via RP-HPLC, uma perda de atividade em relação à amostra controle de $59 \%$.

A estimativa de potência da preparação de FSH aquecida, através de ensaio biológico in vivo, em relação ao padrão de referência internacional de hFSH recombinante (WHO 08/282) foi de 52,4 Ul/ampola. A perda de atividade detectada em relação ao conteúdo nominal por este método foi de 58\%.

Salientamos que os dados referentes ao $\mathrm{hFSH}$ aqui apresentados foram publicados no Journal of Pharmaceutical and Biomedical Analysis, v.54, p.681-686, 2011; "A pilot study on potency determination of human folliclestimulating hormone: A comparison between reversed-phase high-performance liquid chromatography method and the in vivo bioassay". 

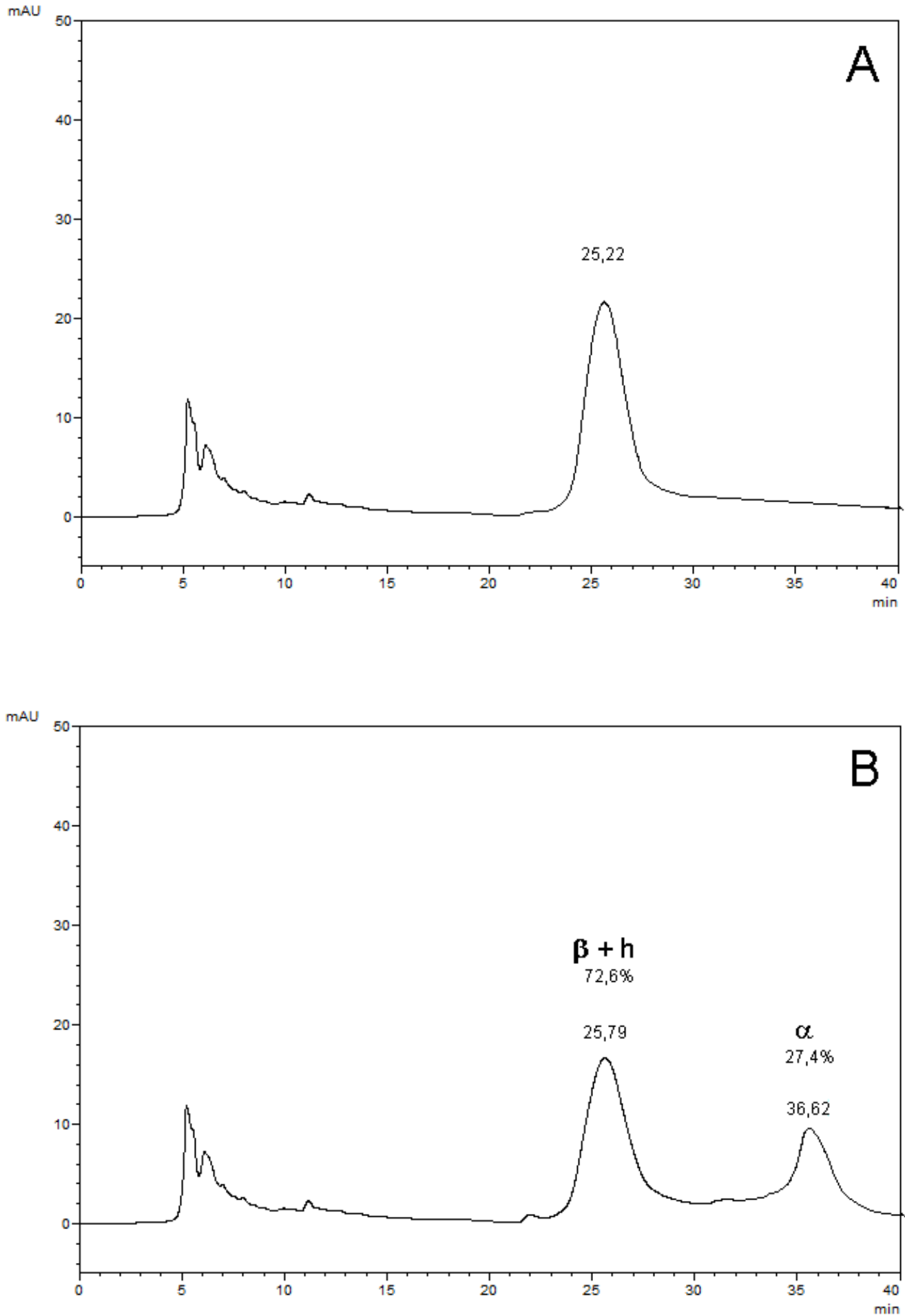

FIGURA 11 - Perfil em RP-HPLC da preparação de rhFSH-O. (A) rhFSH-O Controle (B) rhFSH-O submetida a aquecimento a $80 \stackrel{\circ}{ } \mathrm{C}$ 


\subsection{Determinação de potência de hTSH}

\section{2.a Comparação entre as determinações de hTSH por RP-HPLC e por Ensaio Biológico in vivo}

Na Tabela 10 é apresentado o conteúdo de hTSH ( $\mu \mathrm{g} / \mathrm{ampola})$ de 14 diferentes preparações, determinado por RP-HPLC utilizando técnica descrita em nosso laboratório por Oliveira e colaboradores (2003) e por ensaio biológico in vivo (East-Palmer,1995; Mattaliano,1995). Como padrão de referência para estas determinações foi utilizado o Padrão Internacional de TSH recombinante humano para bioensaio (rhTSH WHO 03/192), cujo perfil em RP-HPLC e em HPSEC são mostrados na Figura 12. Na Figura 13 são mostrados os perfis típicos em RPHPLC de hTSH recombinante (Figura $13 \mathrm{~A}$ ) e hipofisário (Figura $13 \mathrm{~B}$ ). Uma relação linear foi encontrada entre as determinações de hTSH por Bioensaio $\left(B_{\mu g}\right)$ e por RP-HPLC (RP-HPLC ${ }_{\mu g}$ ), com um coeficiente de correlação ( $r$ ) altamente significativo: $\mathrm{BA}_{\mu \mathrm{g}}=0,9790 \mathrm{RP}-\mathrm{HPLC} \mathrm{C}_{\mu \mathrm{g}}-0,052 ; \mathrm{r}=0,8725, \mathrm{p}<0,001$, $\mathrm{n}=14$. 
TABELA 10 - Comparação entre a quantificação de preparações de hTSH por Bioensaio in vivo e por RP-HPLC

\begin{tabular}{|c|c|c|}
\hline Preparação & $\begin{array}{c}\text { Determinação de hTSH por } \\
\text { Bioensaio in vivo } \\
\text { ( } \mu \text { g/ampola) }\end{array}$ & $\begin{array}{c}\text { Determinação de hTSH por } \\
\text { RP-HPLC } \\
\text { ( } \mu \text { g/ampola })\end{array}$ \\
\hline phTSH-A & 5,2 & 3,7 \\
\hline rhTSH-C & 11,3 & 10,0 \\
\hline rhTSH-D & 11,1 & 10,7 \\
\hline rhTSH-E & 9,0 & 9,3 \\
\hline rhTSH-F & 7,6 & 9,7 \\
\hline rhTSH-G & 4,4 & 5,8 \\
\hline rhTSH-H & 4,4 & 4,0 \\
\hline rhTSH-I & 8,8 & 8,6 \\
\hline rhTSH-J & 8,2 & 9,9 \\
\hline rhTSH-K & 7,9 & 8,8 \\
\hline rhTSH-L & 10,0 & 8,0 \\
\hline rhTSH-M & 3,6 & 5,4 \\
\hline rhTSH-N & 9,5 & 9,0 \\
\hline rhTSH-O & 4,0 & 5,1 \\
\hline
\end{tabular}



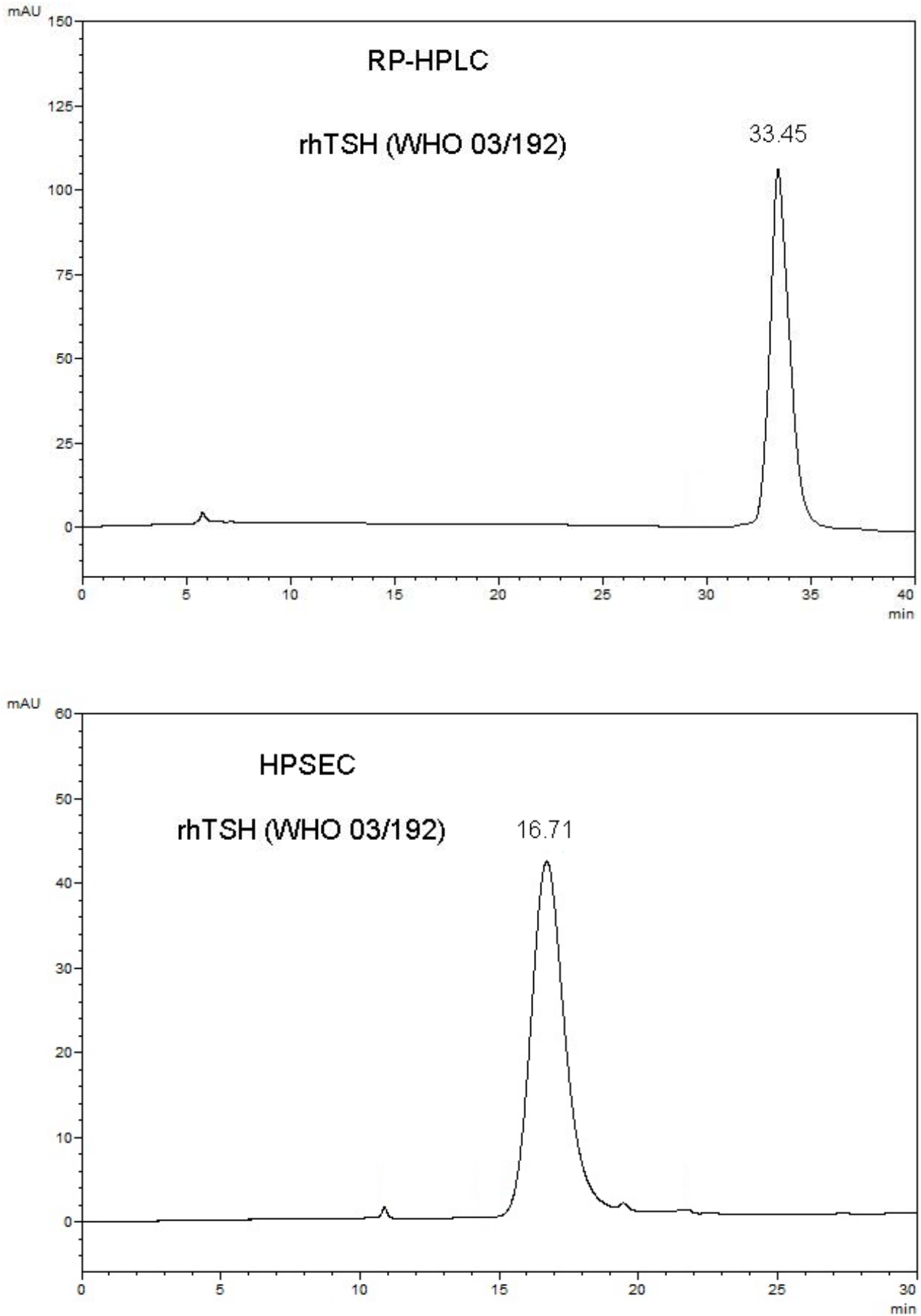

FIGURA 12 - Perfil em HPLC de $5 \mu \mathrm{g}$ do padrão de referência para ensaios biológicos hTSH recombinante (WHO 03/192). (A) RP-HPLC (B) HPSEC 

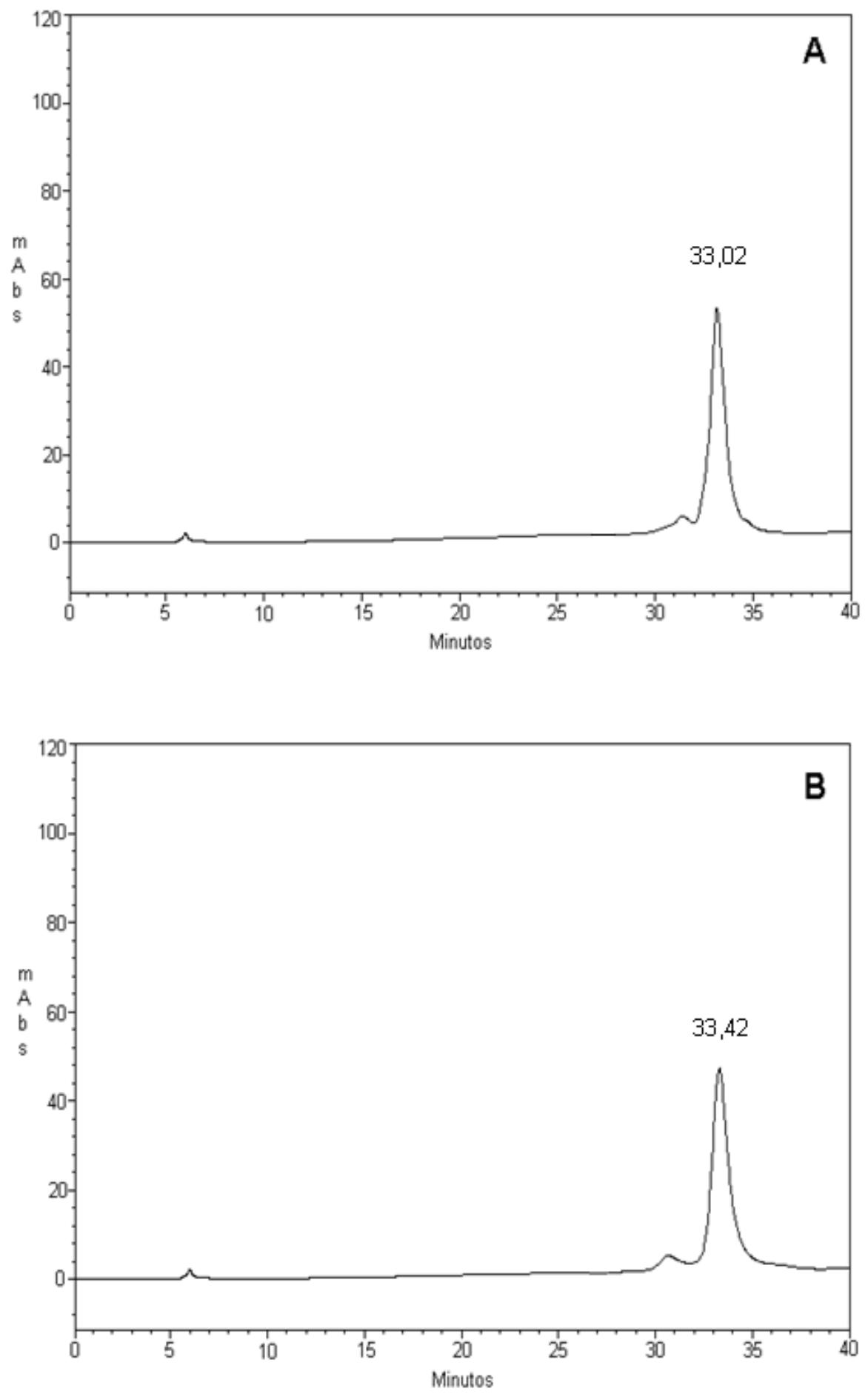

FIGURA 13 - Perfil em RP-HPLC de preparações de hTSH. (A) preparação rhTSH-O; (B) preparação phTSH-A. 


\section{2.b Validação da RP-HPLC para quantificação de hTSH}

Para avaliar o potencial da RP-HPLC de estimar com precisão a bioatividade in vivo, foi utilizada a análise estatística de Bland-Altman (1986), assim como anteriormente demonstrada para o estudo do hFSH. Neste estudo foram analisadas sete amostras íntegras de $\mathrm{TSH}$, sendo seis recombinantes (rhTSH- P a U), e uma hipofisária (phTSH-B). Também foram consideradas quatro outras amostras potencialmente alteradas: um lote comercial de hTSH com prazo de validade expirado ( 2 anos após o vencimento), uma amostra que sofreu ciclos de congelamento-descongelamento e duas amostras que sofreram aquecimento a diferentes temperaturas (Tabela 11). 
TABELA 11 - Comparação entre a atividade biológica do hTSH determinada por Bioensaio in vivo e predita pela equação por análise em RP-HPLC

\begin{tabular}{|c|c|c|c|c|c|c|}
\hline det & $\begin{array}{l}\text { Atividade } \\
\text { Biológica } \\
\text { eterminada por } \\
\text { RP-HPLC } \\
\text { ( } \mu \text { g/ampola) }\end{array}$ & $\begin{array}{l}\text { Atividade Biológica } \\
\text { predita por } \\
\text { RP-HPLC } \\
(1) \\
(\mu \mathrm{g} / \mathrm{ampola})\end{array}$ & $\begin{array}{c}\text { Atividade Biológica } \\
\text { determinada por } \\
\text { Bioensaio in vivo } \\
(2) \\
(\mu \mathrm{g} / \mathrm{ampola})\end{array}$ & $\begin{array}{l}\text { Média } \\
\text { Atividade } \\
\text { Biológica } \\
\text { (1) e (2) } \\
\text { ( } \mu \text { g/ampola) }\end{array}$ & $\begin{array}{l}\text { Diferença entre } \\
\text { Atividade Biológica } \\
\text { predita e média } \\
\text { d } \\
(\mu \mathrm{g})\end{array}$ & $\begin{array}{l}\text { Diferença entre } \\
\text { Atividade Biológica } \\
\text { predita e média } \\
\text { d } \\
(\%)\end{array}$ \\
\hline phTSH- B & 5,3 & 5,1 & 5,8 & 5,5 & $-0,4$ & $-7,3$ \\
\hline rhTSH- P & 11,3 & 11,0 & 9,7 & 10,4 & 0,6 & 5,8 \\
\hline rhTSH-Q & 8,8 & 8,6 & 7,5 & 8,1 & 0,5 & 6,2 \\
\hline rhTSH-R & 4,1 & 4,0 & 3,7 & 3,9 & 0,1 & 2,3 \\
\hline rhTSH-S & 7,9 & 7,7 & 8,2 & 8,0 & $-0,3$ & $-3,8$ \\
\hline rhTSH-T & 10,3 & 10,0 & 9,6 & 9,8 & 0,2 & 2,0 \\
\hline rhTSH-T (2 anos após o vencimento) & 9,7 & 9,4 & 10,1 & 9,8 & $-0,4$ & $-4,1$ \\
\hline rhTSH-T (5 ciclos de congela-descongela) & 10,2 & 9,9 & 10,4 & 10,2 & $-0,3$ & $-2,9$ \\
\hline rhTSH-U & 9,7 & 9,4 & 10,5 & 10,0 & $-0,6$ & $-6,0$ \\
\hline rhTSH-U $\left(50^{\circ} \mathrm{C}, 12 \mathrm{~h}\right)$ & 8,5 & 8,3 & 10,4 & 9,4 & $-1,1$ & $-11,7$ \\
\hline rhTSH-U $\left(65^{\circ} \mathrm{C}, 10 \mathrm{~min}\right)$ & 7,6 & 7,4 & 7,8 & 7,6 & $-0,2$ & $-2,6$ \\
\hline
\end{tabular}


Foi observada uma diferença percentual média $(\overline{\mathrm{d}})$, entre a bioatividade predita pela equação estabelecida e a média da bioatividade obtida pelos dois métodos de $-2,01 \pm 5,56 \%$, com limites de confiança de $95 \%(\bar{d} \pm 2 \mathrm{DP})$ de $-13,13$ a $+9,11 \%$ (Figura 14).

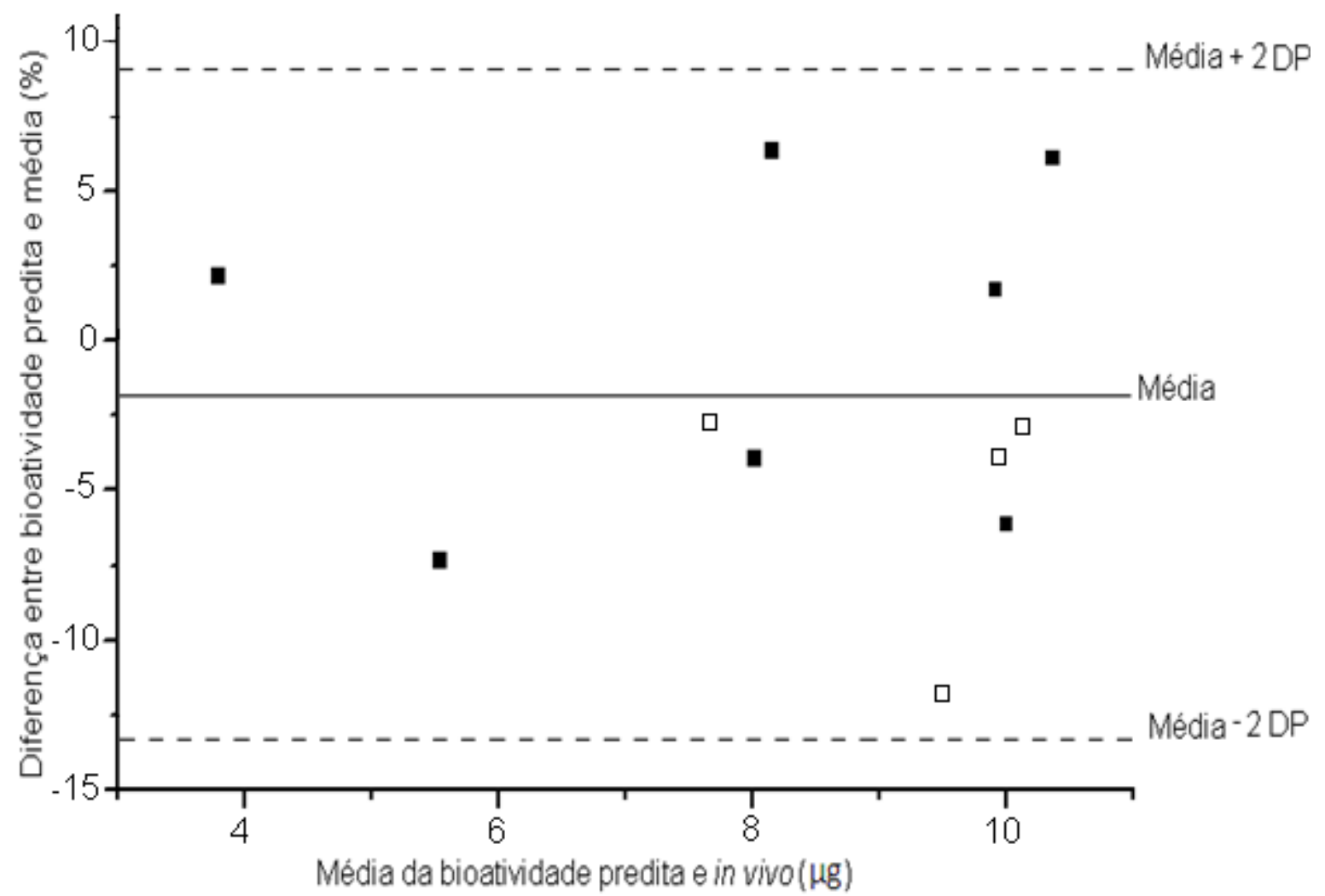

FIGURA 14 - Comparação entre a bioatividade predita e in vivo de preparações de hTSH. $\square$ Amostras alteradas ; Amostras íntegras

O teste "t-Student", realizado entre as determinações de atividade biológica do hTSH in vivo e predita pela equação, indica que o valor de tcalculado $(0,29)$ é muito menor do que o valor de t-teórico de 2,23 , no limite de significância de 0,05 , com 10 graus de liberdade, indicando que os resultados das duas metodologias não foram significativamente diferentes. 
Para avaliar a precisão das determinações foram calculados o erro padrão de $\overline{\mathrm{d}}$ e o erro padrão de $\overline{\mathrm{d}} \pm$ 2DP sendo $1,68 \%$ e 2,90 \%, respectivamente. O intervalo de $95 \%$ de confiança para o "bias" $\left(\bar{d} \pm t \sqrt{D^{2} / n}\right)$, para o limite inferior de concordância (LI) e para o limite superior de concordância (LS) foram também calculados (Tabela 12).

TABELA 12 - Parâmetros estatísticos, determinados de acordo com Bland e Altman, comparando o valor da bioatividade in vivo com aquela predita por RP-HPLC

Parâmetros

\begin{tabular}{|c|c|}
\hline Parâmetros & $\begin{array}{c}\text { Valor Determinado } \\
(\%)\end{array}$ \\
\hline Diferença Média $(\overline{\mathrm{d}})$ & $-2,01$ \\
\hline Desvio Padrão (DP) & 5,56 \\
\hline Intervalo $(\overline{\mathrm{d}} \pm 2 \mathrm{DP})$ & $-13,13 a+9,11$ \\
\hline$\sqrt{\mathrm{DP}^{2} / \mathrm{n}}$ & 1,68 \\
\hline$\sqrt{3 \mathrm{DP}^{2} / \mathrm{n}}$ & 2,90 \\
\hline Intervalo $\left(\overline{\mathrm{d}} \pm \mathrm{t} \sqrt{\mathrm{DP}^{2} / \mathrm{n}}\right)$ & $-5,76 a+1,4$ \\
\hline Intervalo $\left(\mathrm{LI} \pm \mathrm{t} \sqrt{3 \mathrm{DP}^{2} / \mathrm{n}}\right)$ & $-19,60$ a $-6,65$ \\
\hline Intervalo $\left(\mathrm{LS} \pm \mathrm{t} \sqrt{3 \mathrm{DP}^{2} / \mathrm{n}}\right)$ & $+2,64 a+15,58$ \\
\hline
\end{tabular}

Os resultados obtidos permitem concluir que a RP-HPLC pode ser um ensaio alternativo ao Bioensaio in vivo para a determinação da potência de hTSH de amostras íntegras e alteradas. 


\section{2.c Análise das preparações potencialmente alteradas de hTSH}

O método por nós proposto foi também utilizado para determinar a potência de amostras de hTSH potencialmente alteradas.

Um lote de hTSH-T recombinante comercial, com prazo de validade expirado há 2 anos, mostrou um perfil de RP-HPLC idêntico ao obtido para um lote dentro do prazo de validade (Figura 15 A e B). A quantificação do produto vencido, por ensaio biológico e por RP-HPLC, mostrou um conteúdo/potência de hTSH de $10,1 \mu \mathrm{g}$ e 9,7 $\mu \mathrm{g}$ respectivamente, equivalente ao obtido para o produto dentro do prazo de validade (Tabela 13).

Foi testada também uma amostra de rhTSH-T que sofreu 5 ciclos de congelamento-descongelamento. Neste caso também não foi detectada qualquer alteração (Figura 15 A e C). O conteúdo/potência de hTSH da amostra que sofreu congelamento e descongelamento foi de 10,2 $\mu \mathrm{g}$ por RP-HPLC e 10,4 $\mu \mathrm{g}$ por bioensaio, equivalente ao da amostra que não sofreu este processo (Tabela 13).

Outra preparação (rhTSH-U) foi aquecida a $100^{\circ} \mathrm{C}$, por um tempo de 5 minutos, a $50^{\circ} \mathrm{C}$, por 12 horas e a $65^{\circ} \mathrm{C}$, por 10 minutos. Os perfis em RP-HPLC destas preparações de hTSH submetidas a aquecimento e do controle (mesma preparação sem sofrer tratamento térmico) são mostrados nas Figuras 16, 17 e 18.

Observa-se que após o aquecimento a $100^{\circ} \mathrm{C}$ da preparação $\mathrm{rhTSH}-\mathrm{U}$ ocorreu dissociação total do heterodímero (Figura 16). Conforme trabalho anterior realizado em nosso laboratório por Carvalho e colaboradores (2009), quando ocorre dissociação total do hTSH heterodímero há formação de 47,4 \% e $52,6 \%$ de subunidade $\alpha$ e $\beta$ respectivamente, sendo a subunidade a menos hidrofóbica que a subunidade $\beta$ e com hidrofobicidade semelhante ao do heterodímero. No caso da presente amostra, as porcentagens obtidas para as subunidades a e $\beta$ confirmam a dissociação total do heterodímero. Ao analisar esta amostra no bioensaio in vivo não foi detectada qualquer bioatividade o que 
era de se esperar uma vez que o hormônio só é ativo quando está na forma heterodimérica (Tabela 13).

Quando a preparação rhTSH-U foi aquecida a $50^{\circ} \mathrm{C}$, ocorreu uma dissociação parcial sendo observada a formação de $6,5 \%$ de subunidade $\beta$ (Figura 17). Não é possível visualizar diretamente a subunidade $\alpha$, pois ela elui em um tempo de retenção muito próximo ao do heterodímero, sobrepondo-se suas áreas. Entretanto, estequiometricamente foi possível calcular a \% desta subunidade com base na \% do que se formou de $\beta$. No caso da presente amostra houve formação de $5,9 \%$ da subunidade $\alpha$. Logo, a fração correspondente ao heterodímero é de $87,6 \%$. Ao analisar esta amostra no bioensaio in vivo, não foi observada perda de atividade com relação ao controle, enquanto com base na RP-HPLC, a perda de atividade detectada foi de $12 \%$ (Tabela 13).

Quando a amostra rhTSH-U foi aquecida a $65^{\circ} \mathrm{C}$ ocorreu também uma dissociação parcial. Observa-se a formação de $11,5 \%$ de subunidade $\beta$ e de $10,4 \%$ de subunidade $\alpha$, sendo portanto a fração correspondente ao heterodímero de 78,1\% (Figura 18). Ao analisar esta amostra no bioensaio in vivo, foi observada uma perda de atividade de $26 \%$ com relação ao controle, enquanto com base na RP-HPLC, a perda de atividade detectada foi de $~ 22 \%$ (Tabela 13). 
TABELA 13 - Comparação entre a atividade de preparações alteradas de hTSH por Bioensaio in vivo e por RP-HPLC

\begin{tabular}{|c|c|c|c|c|}
\hline Preparação & $\begin{array}{r}\text { Determir } \\
\text { por } \\
(\mu \mathrm{g} / \mathrm{ampola})\end{array}$ & $\begin{array}{l}\text { nação de TSH } \\
\text { RP-HPLC } \\
\text { (\% recuperação) }\end{array}$ & $\begin{array}{r}\text { Determin } \\
\text { por Bioe } \\
\text { ( } \mu \text { g/ampola) }\end{array}$ & $\begin{array}{l}\text { lação de TSH } \\
\text { nsaio in vivo } \\
\text { (\% recuperação) }\end{array}$ \\
\hline rhTSH-T Controle & 10,3 & - & 9,6 & 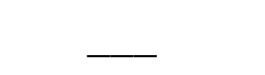 \\
\hline rhTSH-T (2 anos após o vencimento) & 9,7 & 94,2 & 10,1 & 105,2 \\
\hline rhTSH-T (5 ciclos de congela-descongela) & 10,2 & 99,0 & 10,4 & 108,3 \\
\hline rhTSH-U Controle & 9,7 & 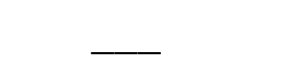 & 10,5 & $\underline{-}$ \\
\hline rhTSH-U $\left(50^{\circ} \mathrm{C}, 12 \mathrm{~h}\right)$ & 8,5 & 87,6 & 10,4 & 99,0 \\
\hline rhTSH-U $\left(65^{\circ} \mathrm{C}, 10 \mathrm{~min}\right)$ & 7,6 & 78,1 & 7,8 & 74,3 \\
\hline rhTSH-U $\left(100^{\circ} \mathrm{C}, 5 \mathrm{~min}\right)$ & N.D. ${ }^{a}$ & 0 & N.D. ${ }^{a}$ & 0 \\
\hline
\end{tabular}



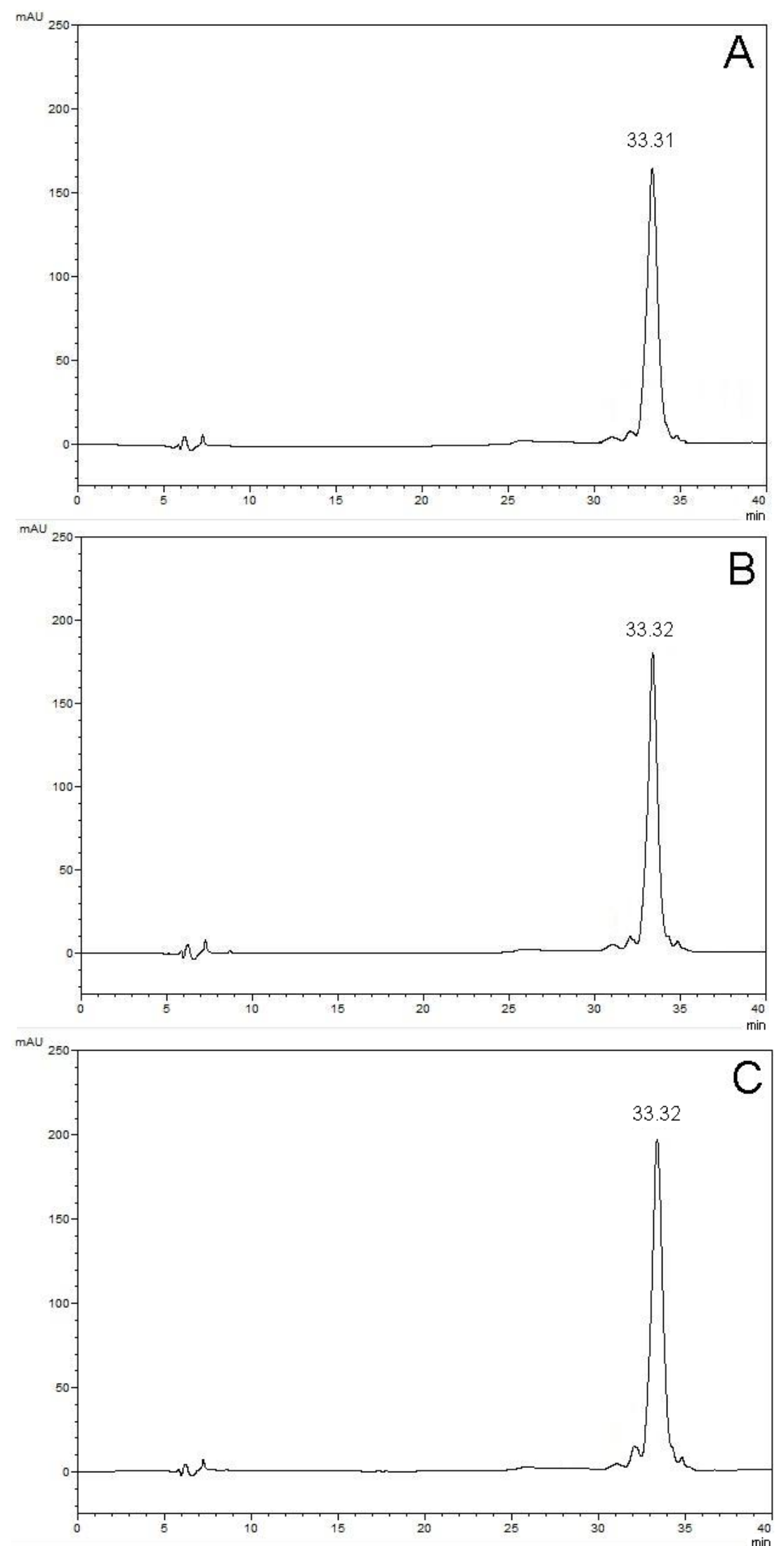

FIGURA 15 - Perfil em RP-HPLC da preparação rhTSH-T. (A) rhTSH-T Controle (B) rhTSH-T fora do prazo de validade (C) rhTSH-T submetida a 5 ciclos de congelamento-descongelamento. 

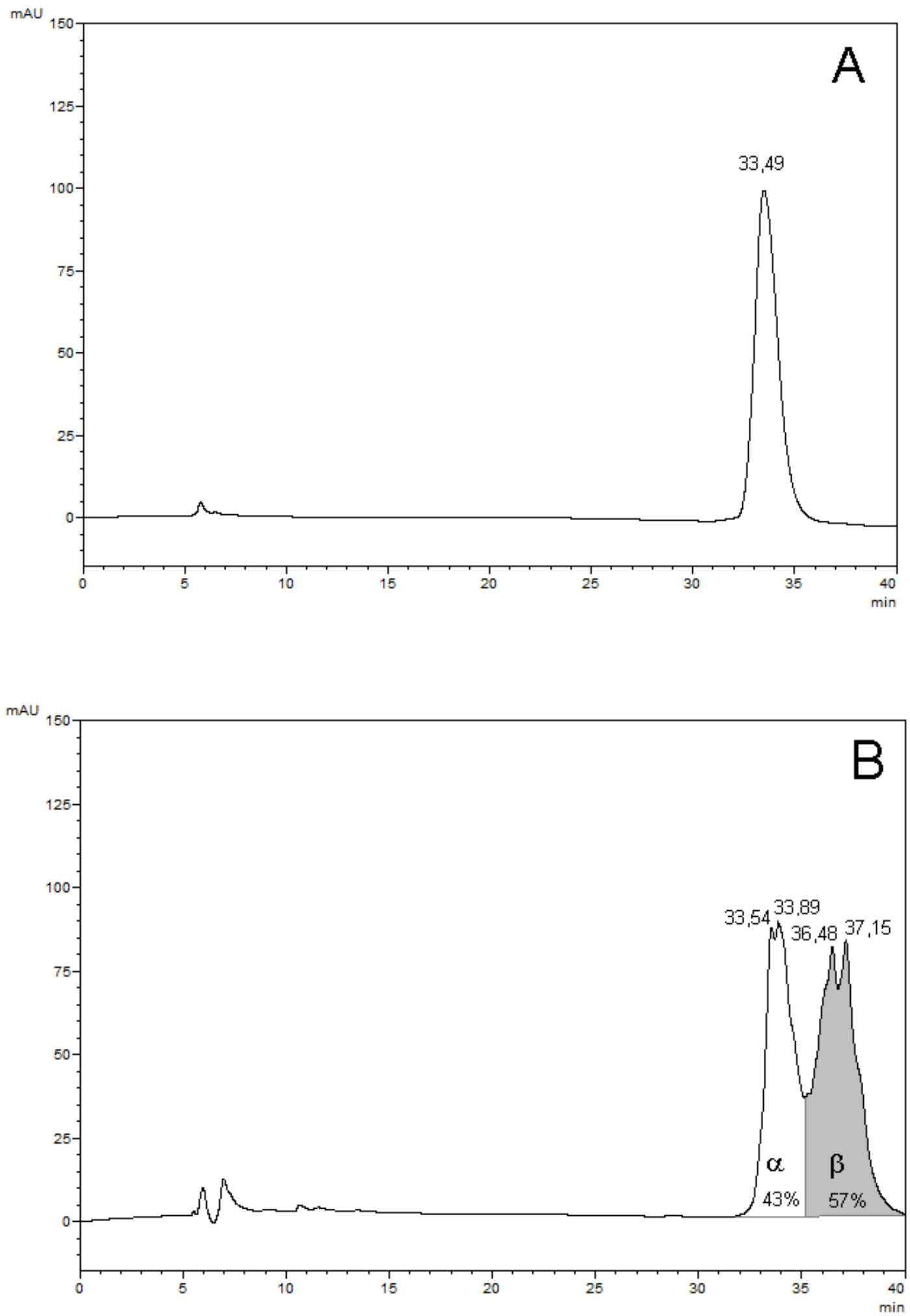

FIGURA 16 - Perfil em RP-HPLC da preparação rhTSH-U. (A) rhTSH-U Controle (B) rhTSH-U submetida a aquecimento a $100^{\circ} \mathrm{C}$ 

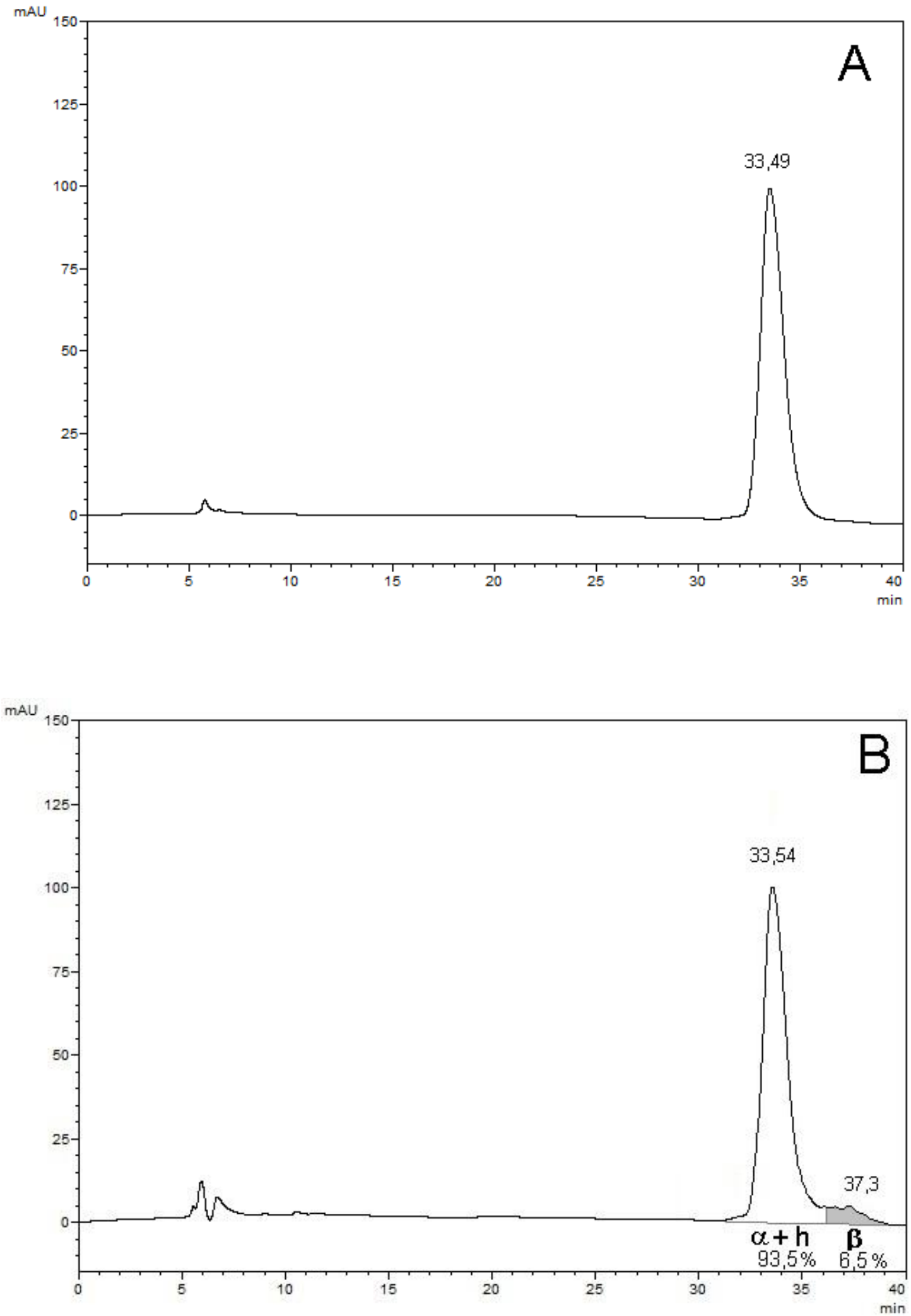

FIGURA 17 - Perfil em RP-HPLC da preparação de hTSH recombinante U. (A) rhTSH-U Controle (B) rhTSH-U submetida a aquecimento a $50^{\circ} \mathrm{C}$ 

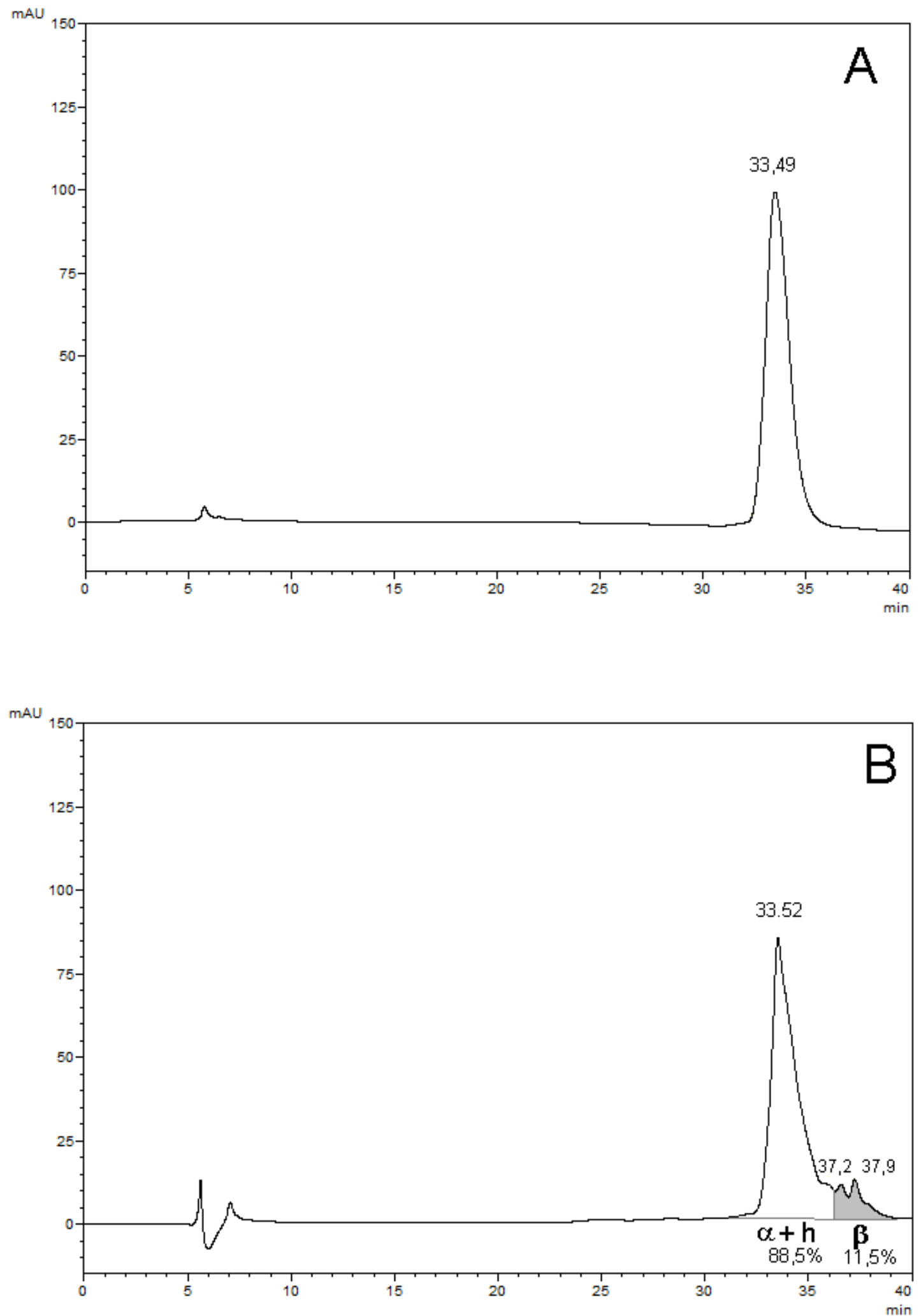

FIGURA 18 - Perfil em RP-HPLC da preparação de hTSH recombinante U. (A) rhTSH-U Controle (B) rhTSH-U submetida a aquecimento a $65^{\circ} \mathrm{C}$ 
Um manuscrito com os dados aqui apresentados para o hTSH está sendo preparado para ser submetido ao Journal of Pharmaceutical and Biomedical Analysis: "Potency determination of human thyrotropin via RP-HPLC in comparison with the in vivo bioassay: analysis of different and of partly-degraded preparations against the International Standard of Recombinant Thyrotropin (WHO-03/192)". 


\subsection{Determinação de potência de hLH}

\section{3.a Cromatografia líquida de alta eficiência em fase reversa (RP-HPLC)}

Devido a falta de padrões oficiais para ensaios físico-químicos, foi utilizado para as determinações da potência do hLH o padrão de referência internacional para ensaios biológicos $\mathrm{rhLH}(\mathrm{WHO}$ 96/602). Este padrão contém um alto conteúdo de Albumina de Soro Humano (HSA) a qual elui na condição de análise por RP-HPLC em tempo de retenção diferente do hLH. Entretanto, em cromatografia líquida de alta eficiência de exclusão molecular (HPSEC), o pico do HSA elui encobrindo o pico do $\mathrm{hLH}$, o que inviabiliza a análise por esta técnica (Figura 19).

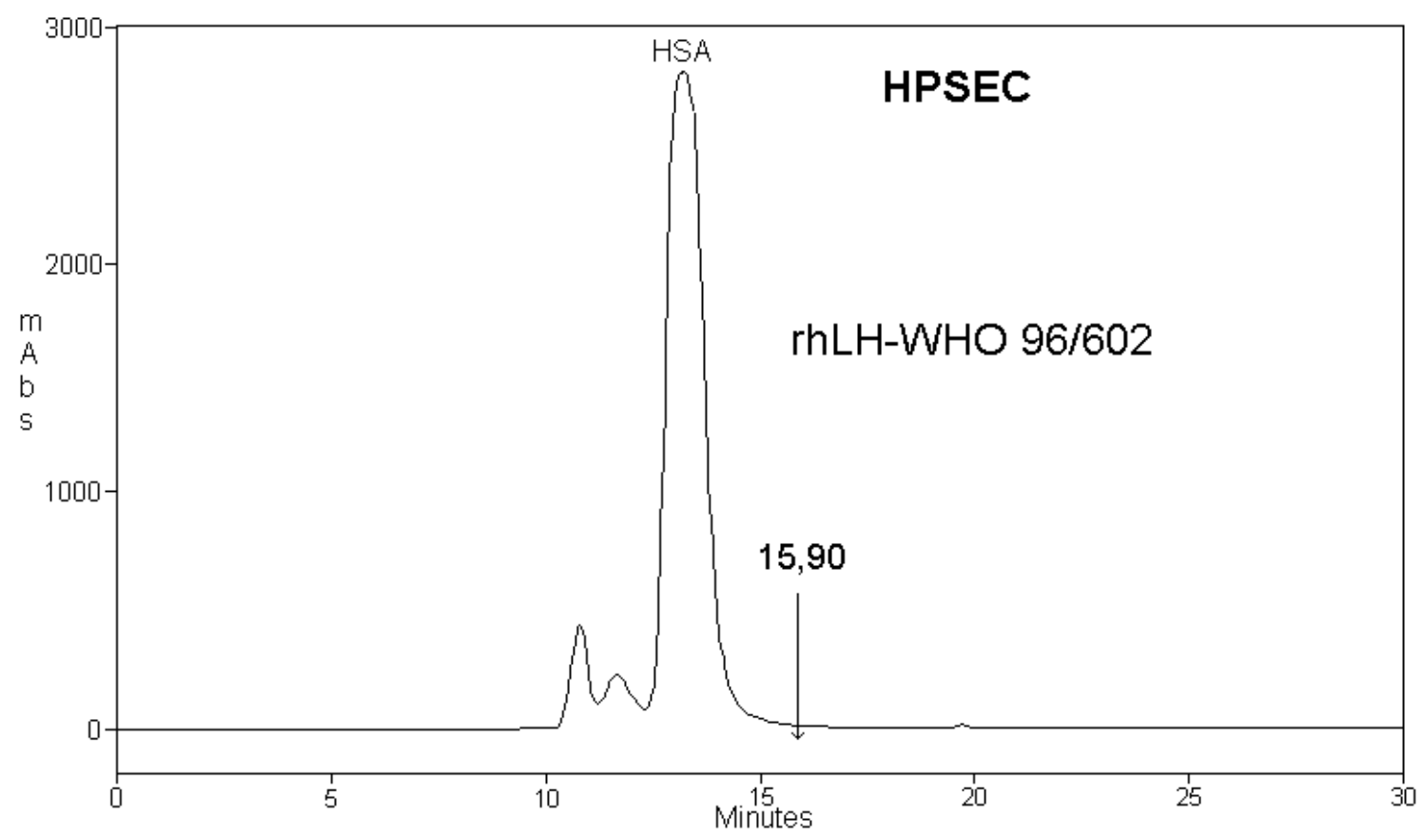

FIGURA 19 - Perfil em HPSEC de $2 \mu \mathrm{g}$ do padrão de referência para ensaios biológicos hLH recombinante (WHO 96/602). O tempo de retenção da preparação de rhLH sem HSA, analisada nas mesmas condições, é indicado pela seta. 
A técnica descrita em nosso laboratório por Almeida e colaboradores (2010) para determinar o conteúdo do hLH por RP-HPLC se mostrou inadequada para a análise quantitativa do padrão de referência de ensaio biológico (rhLH WHO 96/602), pois este padrão apresenta um alto conteúdo de HSA e as hidrofobicidades dessas moléculas são semelhantes, dificultando a separação entre elas (Figura 20). Um fator de correção foi então estabelecido levando em conta a perda de área correspondente ao LH que foi coberta pela HSA.

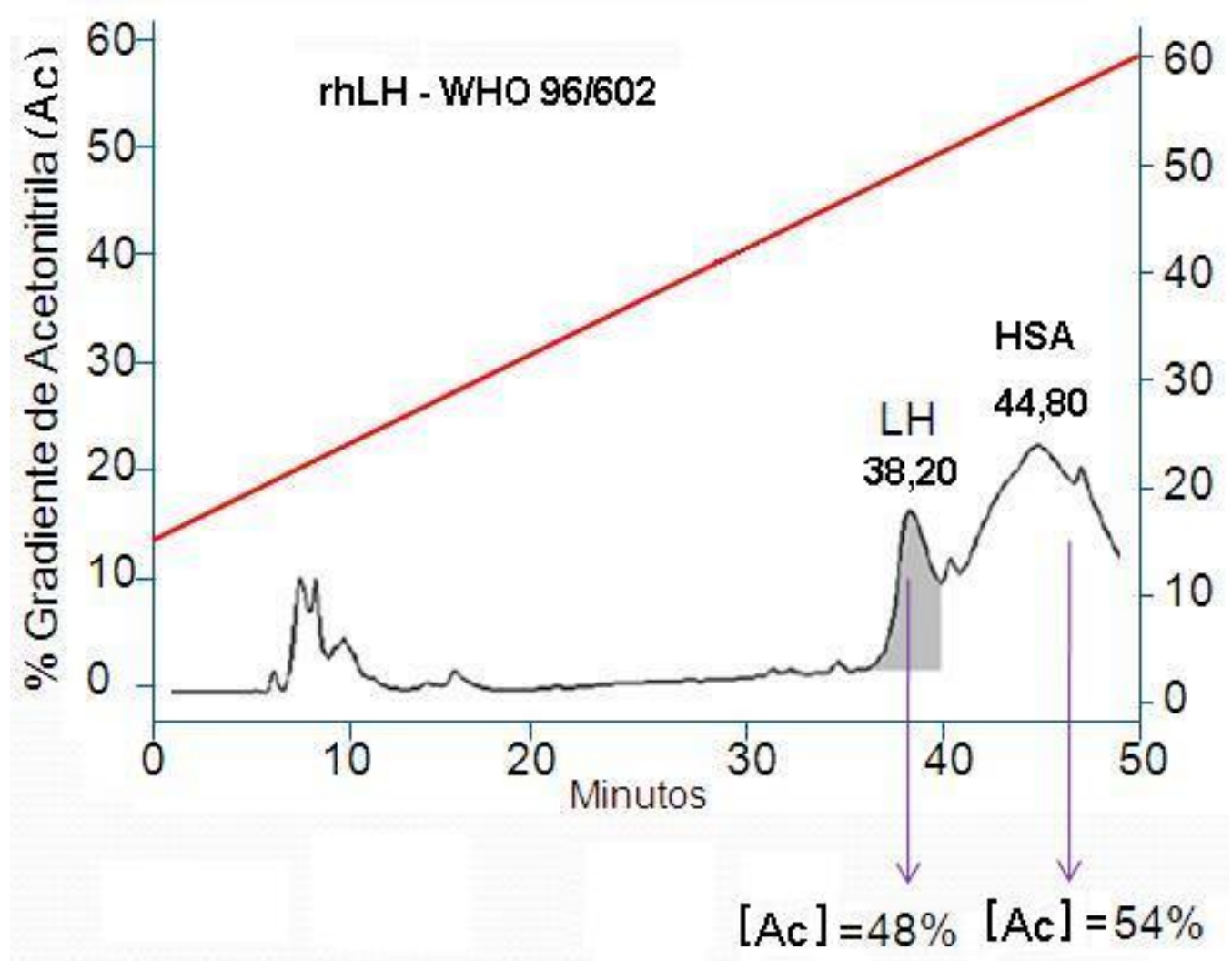

FIGURA 20 - Perfil em RP-HPLC do padrão de referência para ensaios biológicos hLH recombinante (WHO 96/602) nas condições experimentais descritas por Almeida e colaboradores (2010). 
Fez-se necessário então realizar estudos para adequação desta técnica às características do padrão. Mantendo-se a mesma fase móvel, modificaram-se os seguintes parâmetros: início e final do gradiente e duração da corrida (Tabela 14).

TABELA 14 - Condições estudadas para análise por RP-HPLC da preparação de LH

\begin{tabular}{|c|c|c|c|c|c|}
\hline \multicolumn{2}{|c|}{ Gradiente } & \multicolumn{4}{|c|}{ rhLH (WHO 96/602) } \\
\hline \multirow{2}{*}{$\begin{array}{c}\text { Acetonitrila } \\
\%\end{array}$} & \multirow{2}{*}{$\begin{array}{c}\text { Duração } \\
\text { Min. }\end{array}$} & \multicolumn{2}{|c|}{ Tempo de Retenção } & \multirow{2}{*}{$t_{R R}{ }^{a}$} & \multirow{2}{*}{$\begin{array}{c}\text { Fator de } \\
\text { Correção } \\
\%\end{array}$} \\
\hline & & LH & HSA & & \\
\hline $12,5-60$ & 50 & 38,20 & 44,80 & 1,2 & 18 \\
\hline $15-60$ & 50 & 36,00 & 46,80 & 1,3 & - \\
\hline $20-60$ & 50 & 31,10 & 44,10 & 1,4 & - \\
\hline $25-60$ & 50 & 25,28 & 40,63 & 1,6 & - \\
\hline $27-60$ & 50 & 22,43 & 38,23 & 1,7 & 13 \\
\hline $28-60$ & 50 & 21,10 & 38,47 & 1,8 & - \\
\hline $27-50$ & 50 & 21,84 & 43,76 & 2,0 & 8 \\
\hline $27-45$ & 60 & 28,65 & 62,27 & 2,2 & 2 \\
\hline $27-42$ & 60 & 30,82 & 70,68 & 2,3 & 0 \\
\hline
\end{tabular}

a Tempo de retenção relativo

Com base nestes estudos estabeleceu-se que a análise do hLH em RP-HPLC deveria ser realizada nas condições experimentais mostradas na Tabela 15, que mostraram a menor interferência do pico da albumina na quantificação do hormônio. 
TABELA 15 - Condições experimentais a serem empregadas na RP-HPLC para análise de hLH

\begin{tabular}{|c|c|}
\hline Características & Descrição \\
\hline Coluna & $\mathrm{C}_{4}$ Grace Vydac 214 TP $54(5 \mu \mathrm{m}, 25 \mathrm{~cm}$ X 4,6mm D.I. $)$ \\
\hline Pré-coluna & $\mathrm{C}_{4}$ Grace Vydac 214 FSK $54(5 \mu \mathrm{m}, 1 \mathrm{~cm} \times$ 4,6mm D.I. $)$ \\
\hline Temperatura da coluna & $25^{\circ} \mathrm{C}$ \\
\hline \multirow{2}{*}{ Fase Móvel } & Solução A: Fosfato de Sódio 0,05M pH 7,0 \\
\hline & Solução B: Acetonitrila \\
\hline Modo de eluição & Gradiente Linear: $1^{\circ}=27-42 \%$ B; $2^{\circ}=42-65 \%$ B \\
\hline Duração da corrida & $1^{\circ}=60$ minutos $; 2^{\circ}=20$ minutos \\
\hline Fluxo da fase móvel & $0,5 \mathrm{~mL} / \mathrm{min}$ \\
\hline Sistema de detecção & Absorbância em luz ultravioleta UV \\
\hline Comprimento de onda & $220 \mathrm{~nm}$ \\
\hline Volume injetado & $\begin{array}{l}\text { Alíquotas de } 5-10 \mu \mathrm{L} \text { de phLH e } \\
20-100 \mu \mathrm{L} \text { de } \mathrm{rhLH}\end{array}$ \\
\hline
\end{tabular}

Os perfis cromatográficos do padrão de referência para ensaio biológico rhLH(WHO 96/602) nas condições experimentais, descritas por Almeida e colaboradores (2010) e nas novas condições estabelecidas, bem como os parâmetros de separação nestas condições são mostrados na Figura 21 e na Tabela 16. 

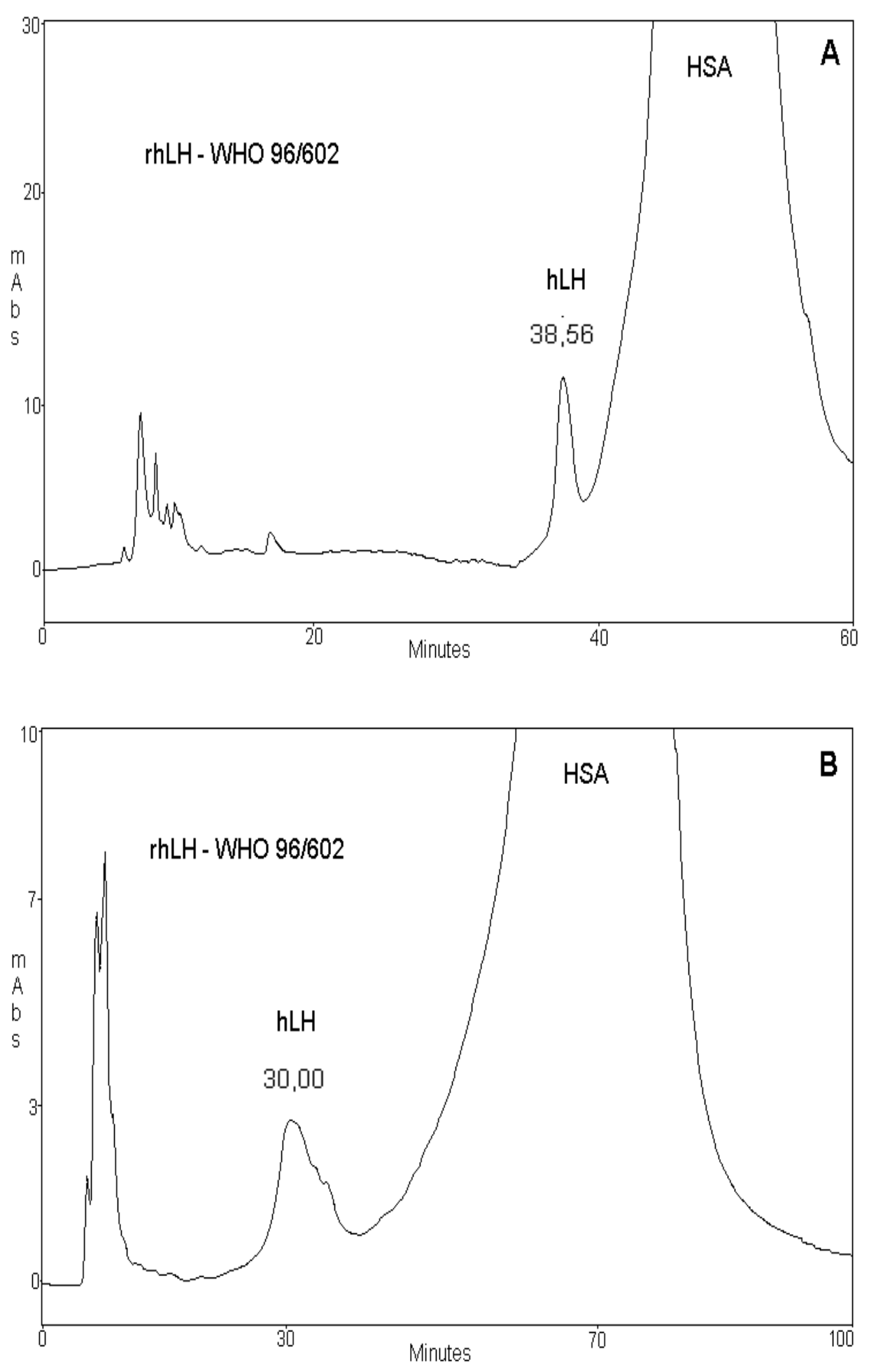

FIGURA 21 - Perfil em RP-HPLC do padrão de referência para ensaios biológicos hLH recombinante (WHO 96/602). (A) condições experimentais descritas por Almeida e colaboradores (2010); (B) novas condições estabelecidas. 
TABELA 16 - Parâmetros de desempenho de separação HSA-LH em diferentes condições de RP-HPLC

\begin{tabular}{|c|c|c|c|c|c|c|}
\hline \multirow{2}{*}{$\begin{array}{l}\text { PREPARAÇÃO } \\
\text { rhLH (WHO 96/602) }\end{array}$} & \multicolumn{3}{|c|}{ LH } & \multicolumn{3}{|c|}{ HSA } \\
\hline & $\begin{array}{c}t_{R 1}^{a} \\
(\min )\end{array}$ & $\begin{array}{l}\mathrm{w}_{1}^{\mathrm{b}} \\
(\mathrm{min})\end{array}$ & $\mathrm{Tf}_{1}{ }^{\mathrm{C}}$ & $\begin{array}{c}t_{\mathrm{R} 2}^{\mathrm{a}} \\
(\mathrm{min})\end{array}$ & $\begin{array}{l}\mathbf{w}_{2}^{\mathrm{b}} \\
(\mathrm{min})\end{array}$ & $\mathrm{Tf}_{2}{ }^{\mathrm{c}}$ \\
\hline Condição Nova & 30,00 & 11,40 & 1,60 & 72,12 & 18,28 & 1,1 \\
\hline Condição Almeida, 2010 & 38,56 & 2,45 & 1,14 & 47,92 & 6,40 & 1,4 \\
\hline
\end{tabular}

A qualidade da separação entre HSA e hLH foi avaliada, nas duas condições, pelo tempo de retenção relativo $\left(t_{R R}\right)$ e pelo fator de resolução (Rf) (Tabela 17). Nas novas condições, uma melhor separação entre os picos de HSA e hLH foi alcançada.

TABELA 17 - Parâmetros de qualidade da separação HSA-LH

\begin{tabular}{lcc}
\hline Condições de RP-HPLC & $\mathbf{t}_{\mathbf{R R}}{ }^{\mathbf{a}}$ & $\mathbf{R f}^{\mathbf{b}}$ \\
\hline Nova & 2,40 & 2,72 \\
Almeida, 2010 & 1,24 & 2,28 \\
\hline $\begin{array}{l}\text { a Tempo de retenção relativo } \\
\text { b Fator de resolução }\end{array}$ & \\
\hline
\end{tabular}

Salientamos que os dados aqui apresentados com relação à separação entre HSA e hLH foram publicados em Journal of Pharmaceutical and Biomedical Analysis, v.63, p.160-164, 2012; "Qualitative and quantitative reversed-phase high performance liquid chromatographic analysis of glycoprotein hormones in the presence of a large excess of human serum albumin." 


\section{3.b Quantificação de amostras íntegras e alteradas por RP-HPLC e por Ensaio Biológico in vivo}

Na Tabela 18 é apresentado o conteúdo/potência de hLH (Ul/ampola) de preparações hipofisárias (phLH-A e phLH-B) e recombinante (rhLH-C) determinados por RP-HPLC utilizando a técnica anteriormente estabelecida e por ensaio biológico in vivo (Van Hell, 1964). A determinação da preparação recombinante foi realizada em relação ao padrão de referência internacional de hLH recombinante (WHO 96/602), enquanto as preparações hipofisárias foram determinadas em relação ao padrão de referência internacional de $\mathrm{hLH}$ hipofisário (WHO 80/552). A recuperação média destas determinações, relativa ao conteúdo nominal, foi de $94,6 \pm 7,88 \%$ para as estimativas por RP-HPLC e 102,6 $\pm 2,80 \%$ para as estimativas por bioensaio.

TABELA 18 - Comparação entre a quantificação de preparações de hLH íntegras por Bioensaio in vivo e por RP-HPLC

\begin{tabular}{lccc}
\hline Preparação & $\begin{array}{c}\text { Conteúdo } \\
\text { Nominal }^{\text {a }}\end{array}$ & $\begin{array}{c}\text { Determinação de hLH } \\
\text { (Ul/ampola) }\end{array}$ & $\begin{array}{c}\text { Determinação de hLH } \\
\text { (Ul/ampola) }\end{array}$ \\
\hline phLH-A & 60,3 & 53,0 & $\begin{array}{c}\text { por Bioensaio in vivo } \\
\text { (Ul/ampola) }\end{array}$ \\
phLH-B & 60,3 & 62,3 & 61,9 \\
rhLH-C & 75,0 & 69,5 & 74,8 \\
\hline
\end{tabular}

a Declarado pelo fabricante

Amostras alteradas de $\mathrm{hLH}$ também foram analisadas. Para obter estas amostras as preparações rhLH-C e phLH-B foram aquecidas a $70{ }^{\circ} \mathrm{C}$, por um tempo de 10 minutos. Os perfis em RP-HPLC destas preparações de hLH submetidas a tratamento térmico e do controle (mesma preparação sem sofrer aquecimento) são mostrados nas Figuras 22 e 23. Observa-se que após o aquecimento, em ambas as preparações testadas, foi obtido um pico bastante deslocado com relação à porção do heterodímero com um tempo de retenção relativo ao heterodímero de 1,73 e 1,55 respectivamente para o hLH-C 
recombinante e hLH-B hipofisário. Esta posição não corresponde ao tempo de eluição das subunidades $\alpha$ e $\beta$ (assinalado na Figura por setas), tratando-se de um produto com hidrofobicidade maior que a do heterodímero, que pode apresentar alguma atividade biológica. De fato a atividade biológica destes produtos alterados, determinados por bioensaio ou por RP-HPLC, mostraram uma perda de atividade média com relação à preparação que não sofreu aquecimento de $47 \%$ e $58 \%$, respectivamente (Tabela 19 ).

TABELA 19 - Comparação entre a perda de atividade de preparações alteradas de hLH por Bioensaio in vivo e por RP-HPLC

\begin{tabular}{lllll}
\hline Preparação & $\begin{array}{c}\text { Determinação de LH } \\
\text { por RP-HPLC } \\
\text { (Ul/ampola) (\% recuperação) }\end{array}$ & $\begin{array}{c}\text { Determinação de LH por } \\
\text { Bioensaio in vivo } \\
\text { (Ul/ampola) }\end{array}$ \\
\hline rhLH-C (cocuperação)
\end{tabular}

Uma relação linear foi encontrada quando a determinação da potência pelo Bioensaio $\left(B A_{\cup I}\right)$ das preparações íntegras e alteradas de $h L H$ foi comparada com a determinação pela RP-HPLC (RP-HPLC $\left.C_{U I}\right): B_{U I}=0,8771$ RP-HPLC $C_{U I}+$ 12,$41 ; r=0,9786, p<0,01, n=5$. Para $\circ h L H$, não foi possível realizar outros estudos tais como os realizados para o hFSH e o hTSH em virtude das poucas amostras disponíveis. 

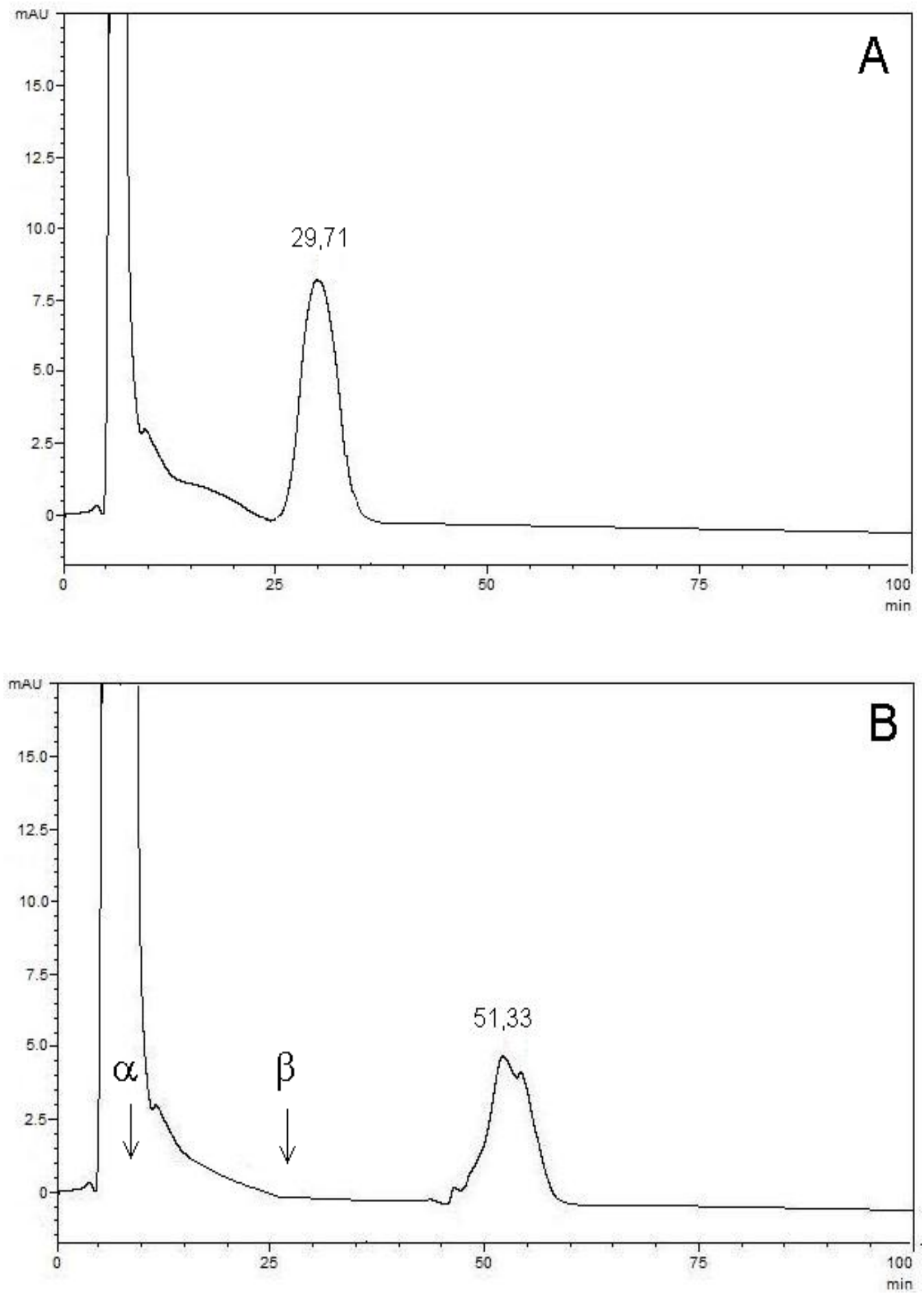

FIGURA 22 - Perfil em RP-HPLC da preparação rhLH-C (A) rhLH-C Controle (B) rhLH-C após aquecimento a $70^{\circ} \mathrm{C}$ 

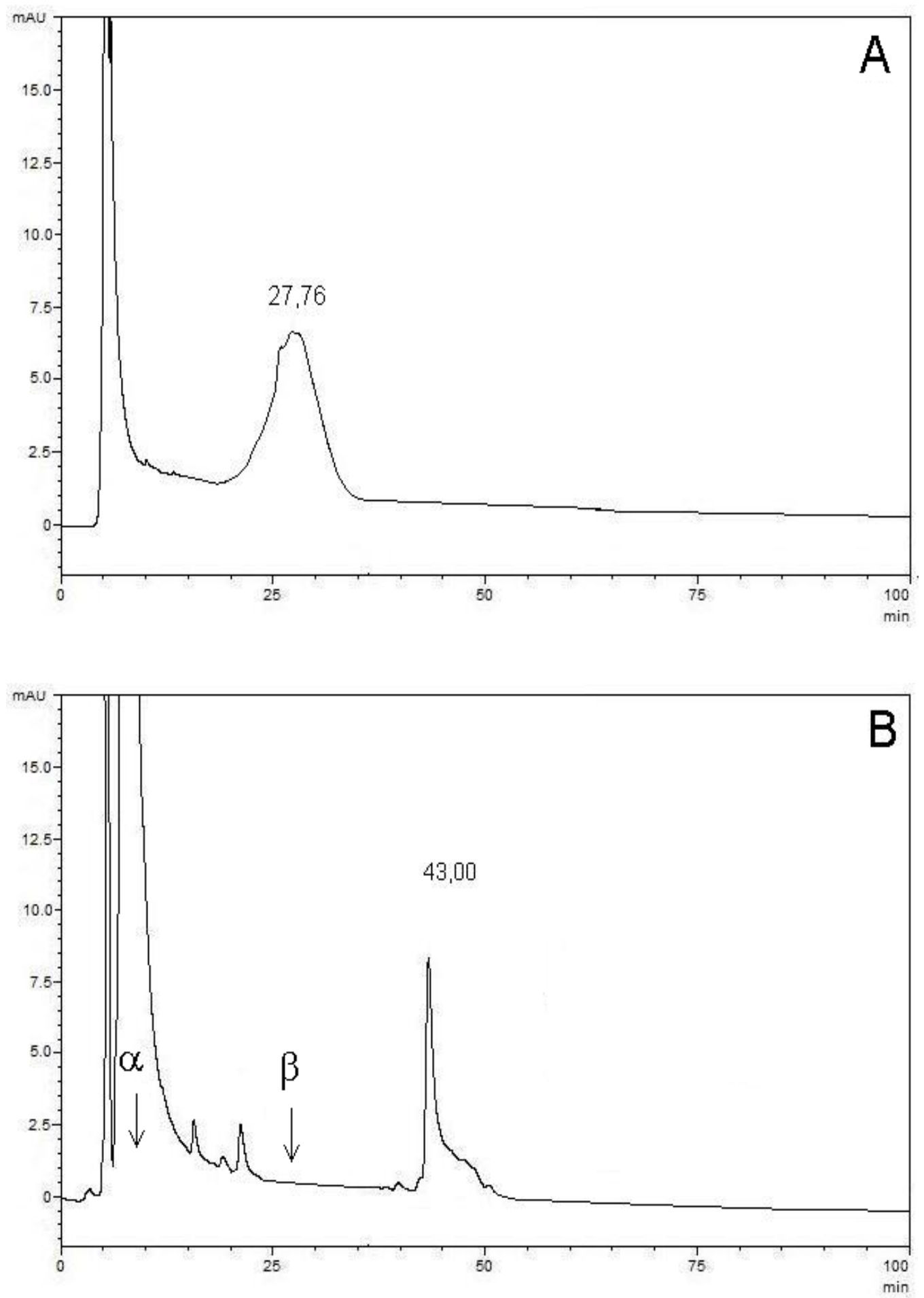

FIGURA 23 - Perfil em RP-HPLC da preparação phLH-B

(A) phLH-B Controle (B) phLH-B após aquecimento a $70^{\circ} \mathrm{C}$ 


\section{DISCUSSÃO}

Com base nos resultados obtidos no presente trabalho foi possível concluir que a metodologia físico-química por RP-HPLC é certamente uma alternativa viável ao bioensaio in vivo para a determinação quantitativa da atividade biológica de hFSH e hTSH.

Mesmo considerando que um método analítico físico-químico não reflete completamente a complexidade estrutural de uma glicoproteína e sua heterogeneidade inerente, sendo o enfoque biológico mais apropriado para a quantificação das mesmas (Bristow, 2011), ainda assim não é menor a importância de ensaios alternativos que possam complementar o clássico bioensaio in vivo, diminuindo a dependência do uso de animais para a sua quantificação. Um único tipo de análise físico-química obviamente não pode refletir todos os aspectos da atividade biológica in vivo de um hormônio. De acordo com o enfoque de consistência ("consistency approach") (Garthoff, 1995; Hendriksen, 2008 e 2009), que implica na utilização de testes específicos para demonstrar a equivalência de um produto com outro de comprovada eficácia, existe uma tendência de aceitar ensaios alternativos para determinações de rotina, após a validação inicial do processo com o bioensaio in vivo.

A metodologia proposta, baseada simplesmente na massa das substâncias administradas, forneceu um indicador útil do seu efeito, sendo capaz de prever as atividades biológicas com precisão razoável. Isto pode ser devido ao fato dos glicanos ou da distribuição das isoformas em geral, não serem notavelmente diferentes entre as preparações testadas ou, alternativamente, que as isoformas com maior influência na bioatividade estarem presentes apenas em quantidades muito pequenas. Isto pode também explicar outros estudos 
reportados na literatura em que a avaliação da bioatividade do hFSH também foi com base em determinação de massa, tais como os de Drieberger e Baer (2003) e Basset (2005).

Dentro do contexto de produtos para uso farmacêutico, a quantificação dos mesmos é muito importante, pois a falta de precisão e exatidão nas medidas pode comprometer a eficácia de um tratamento e ter consequências que tanto podem ser discretas como fatais. Ao analisar amostras de hFSH (ver Tabela 6), hTSH (ver Tabela 10) e hLH (ver Tabela18 e 19), foram encontradas correlações altamente significativas entre as quantificações obtidas por RP-HPLC e por bioensaios in vivo.

A validação do modelo de regressão, realizada segundo a estatística de Bland-Altman (1986), utilizando amostras íntegras e alteradas de preparações de hFSH e de hTSH que não tinham sido utilizadas para construir a curva de correlação, mostrou um acordo aceitável entre os dois métodos. No caso do $\mathrm{hFSH}$, a potência estimada pelo método proposto (físico-químico) não foi inferior a $85 \%$ e superior a $110 \%$ da potência estimada pelo método in vivo e no caso do hTSH, não foi inferior a $80 \%$ e superior a $115 \%$, estando portanto dentro dos limites de $80-125 \%$, preconizados pela Farmacopeia Europeia para o ensaio biológico referente a estes produtos. Para o $\mathrm{hLH}$, a validação do modelo de regressão não foi possível de ser realizado em virtude das poucas amostras disponíveis.

O "bias" entre as determinações efetuadas pelos dois métodos foi da mesma ordem tanto para o hFSH $(-2,11 \%)$ quanto para o hTSH $(-2,01 \%)$. Já a precisão calculada para o hFSH (ver Tabela 8) foi melhor que a encontrada para 0 hTSH (ver Tabela 12). A maioria dos parâmetros estatísticos calculados para o $\mathrm{hFSH}$ e para o hTSH foram da mesma ordem ou mesmo melhores do que os encontrados na literatura para estudos análogos (Mulders, 1997 e 1999). É importante enfatizar que este tipo de validação está em conformidade com as diretrizes do "Centro Europeu de Validação de Métodos Alternativos" (ECVAM) da Comissão Européia. Recomenda-se que este procedimento seja utilizado, sempre que possível, para a comparação de dados obtidos a partir de diferentes métodos (Garthoff, 1995; Mulders,1999; Storring, 2002). 
A análise de amostras alteradas de hFSH (fora do prazo de validade e termicamente alterada) mostrou uma perda de atividade semelhante, seja estimada via bioensaio in vivo que pelo método alternativo por RP-HPLC. Em amostras de $\mathrm{hTSH}$ termicamente alteradas $\left(100^{\circ} \mathrm{C}\right.$ e $\left.65^{\circ} \mathrm{C}\right)$ também foram detectadas perda de atividade por ambas as metodologias. Entretanto, na amostra de $\mathrm{hTSH}$ aquecida a $50^{\circ} \mathrm{C}$ somente foi possível identificar perda de atividade pelo método alternativo ( 12\%), enquanto pelo método biológico esta alteração não foi detectada, evidenciando desta forma a sensibilidade superior do método alternativo com relação ao bioensaio in vivo. $\mathrm{O}$ estudo realizado anteriormente em nosso laboratório por Carvalho e colaboradores, identificando e caracterizando as subunidades $\alpha$ e $\beta$ dos hormônios hipofisários hFSH, hTSH e hLH por RP-HPLC, foi de grande importância para a análise das amostras alteradas, permitindo a quantificação da porção inalterada após as amostras sofrerem aquecimento (Carvalho, 2009). Salientamos ainda a alta estabilidade encontrada para a amostra comercial de hTSH, que estocada a $4^{\circ} \mathrm{C}$ e analisada 2 anos após sua data de expiração não mostrou qualquer diferença detectável, seja pela metodologia físico-química que pelo bioensaio. Esta mesma amostra também permaneceu inalterada após sofrer 5 ciclos de congelamentodescongelamento, avaliada pelas duas metodologias.

Em trabalhos anteriores realizados em nosso laboratório, foram estabelecidas e validadas quanto à exatidão, precisão, linearidade e sensibilidade, as metodologias de RP-HPLC utilizadas no presente trabalho para o hFSH (Loureiro, 2006), hTSH (Oliveira, 2003) e hLH (Almeida, 2010), na forma heterodimérica ou dissociada (Carvalho, 2009). No caso do hFSH, este método é, tanto quanto sabemos, o único na literatura capaz de analisar o hFSH intacto, isto é, na sua forma heterodimérica (Loureiro, 2006), o que é fundamental para se estabelecer a potência/conteúdo deste hormônio por RP-HPLC, como proposto neste trabalho.

Cabe ainda comentar sobre a grande dificuldade no que se refere à disponibilidade de padrões de referência para estudos físico-químicos. Preparações com pureza adequada, homogeneidade e quantidade de material suficiente são necessárias para o desenvolvimento e a aplicação destes estudos, 
que cada vez mais estão sendo introduzidos por Agências Reguladoras e pelas Farmacopeias para a substituição dos ensaios biológicos in vivo, cujo custo e imprecisão são bem conhecidos (Miethe, 2002; Longstaff, 2009).

No presente trabalho foram utilizados nos ensaios físico-químicos os Padrões Internacionais recombinantes para ensaio biológico de hTSH (WHO 03/192), hFSH (WHO 92/642 e 08/282) e de hLH (WHO 96/602). Geralmente, os padrões para ensaio biológico apresentam um conteúdo do excipiente Albumina de Soro Humano (HSA) e no presente trabalho apenas o padrão de hTSH não contém este excipiente. A análise do padrão de hFSH, através da RP-HPLC por nós desenvolvida, mostrou que a grande quantidade de HSA presente nas ampolas deste padrão não elui nas condições estabelecidas para esta metodologia, não interferindo assim na determinação do $\mathrm{hFSH}$, numa preparação em que o hormônio representa menos de $1 \%$ da massa total. Ao contrário, para a determinação do hLH em RP-HPLC, a técnica anteriormente estabelecida em nosso laboratório mostrou-se inadequada para a análise quantitativa do Padrão Internacional de hLH recombinante para ensaio biológico (WHO 96/602), pois a HSA presente neste padrão elui interferindo no pico do hLH (Almeida, 2010).

Uma nova metodologia para análise quantitativa e qualitativa do $\mathrm{hLH}$ na presença de grande quantidade de HSA foi então estabelecida e uma melhor resolução entre os picos de HSA e hLH foi alcançada. Pela primeira vez, o hLH pode ser analisado simplesmente alterando e otimizando as condições cromatográficas, sem a necessidade de adição de um sal, extração ou remoção de proteína, típicas de outras abordagens na literatura (Bietlot, 1997; LaraQuitanar, 2007; Liu, 2011), proporcionando assim um poderoso instrumento para identificação e controle de qualidade desta preparação. Nas condições otimizadas foi alcançada uma melhora com relação ao método anteriormente padronizado para o hLH (Almeida, 2010) de aproximadamente 2 vezes no tempo de retenção relativo e de $\sim 20 \%$ na resolução. A quantificação das amostras de hLH mostrou uma tendência da RP-HPLC de subestimar as determinações de hLH. Para realizar uma análise estatística semelhante à feita para o hFSH e hTSH e comprovar esta tendência, seria necessário dispor de um número maior de amostras de hLH. 
Salientamos ainda que foram observadas diferenças altamente significativas no tempo de retenção das preparações recombinantes, pituitárias e urinárias de $\mathrm{hFSH}$, refletindo provavelmente o efeito de diferenças estruturais na composição de carboidratos e na hidrofobicidade desta glicoproteina. Observações análogas foram obtidas para os outros dois hormônios glicoproteicos hTSH (Oliveira, 2003; Mendonça, 2005; Damiani, 2013) e hLH (Almeida, 2010).

Considerando a obtenção de fármacos pela Internet, um fenômeno que vem crescendo muito na última década, a possibilidade de distribuição de um produto inadequado e inseguro para o consumidor deve ser evitado ao máximo (Baert, 2010). O método alternativo proposto no presente trabalho para avaliar a potência dos glicohormônios, hFSH e hTSH, pode ser uma aplicação viável para avaliar a qualidade destes produtos.

Enfatizamos ainda a importância do presente estudo no controle de qualidade dos hormônios aqui estudados, especialmente os recombinantes, muito utilizados na prática clínica, seja em diagnóstico ou terapia. O estrito controle da potência destes produtos é um pré-requisito para assegurar a sua identidade e eficácia e o presente trabalho está contribuindo nesta direção.

A metodologia alternativa aqui apresentada para a quantificação de hFSH e hTSH claramente contempla os elementos "Refinement e Reduction" dos 3 Rs para um uso responsável de animais de experimentação no desenvolvimento e controle de qualidade de produtos bioativos.

Por último ressaltamos que o presente estudo é inétido, não tendo sido encontrados relatos na literatura de métodos alternativos ao bioensaio in vivo para o hTSH. Para o hFSH, embora haja alternativas descritas na literatura, estas não se referem à cromatografia líquida em fase reversa (RP-HPLC) como aqui desenvolvido. Inédita também é a técnica desenvolvida de determinação quantitativa e qualitativa de hLH na presença de altas quantidades de HSA. 


\section{CONCLUSÕES}

Em conclusão, este trabalho demonstra que a análise físico-química por RP-HPLC é uma alternativa potencialmente viável aos bioensaios in vivo para a quantificação do hFSH e do hTSH em preparações íntegras e alteradas.

O emprego destes métodos alternativos, utilizados para assegurar a qualidade e a eficácia de um produto farmacêutico, pode reduzir enormemente 0 número de animais ou mesmo evitar o seu uso. A este respeito, os resultados do presente trabalho caminham para o uso em combinação ou eventual substituição dos bioensaios in vivo em protocolos de controle de qualidade para a avaliação da potência do hFSH e do hTSH. 


\section{REFERÊNCIAS BIBLIOGRÁFICAS}

AHUJA, S. Assuring quality of drugs by monitoring impurities. Adv. Drug Deliv. Rev., v.59, n.1, p.3-11, 2007.

ALMEIDA, B.E.; OLIVEIRA, J.E.; CARVALHO, C.M.; DALMORA, S.L.; BARTOLINI, P.; RIBELA, M.T.C.P. Analysis of human luteinizing hormone and human chorionic gonadotropin preparations of different origins by reversed-phase highperformance liquid chromatography. J. Pharm. Biomed. Anal., v.53, p.90-97, 2010.

ALMEIDA, B.E.; OLIVEIRA, J.E.; DAMIANI, R.; DALMORA, S.L.; BARTOLINI, P.; RIBELA, M.T.C.P. A pilot study on potency determination of human folliclestimulating hormone: A comparison between reversed-phase high-performance liquid chromatography method and the in vivo bioassay. J. Pharm. Biomed. Anal., v.54, p.681-686, 2011.

ALMEIDA, B.E.; OLIVEIRA, J.E.; DAMIANI, R.; DALMORA, S.L.; BARTOLINI, P.; RIBELA, M.T.C.P. Qualitative and quantitative reversed-phase high performance liquid chromatographic analysis of glycoprotein hormones in the presence of a large excess of human serum albumin. J. Pharm. Biomed. Anal., v.63, p.160164, 2012.

AMORESANO, A.; SICILIANO, R.; ORRU, S.; NAPOLEONI, R.; ALTAROCCA, V.; DE LUCA, E.; SIRNA, A.; PUCCI, P. Structural characterization of human recombinant glycohormones follitropin, lutropin and choriogonadotropin expressed in Chinese hamster ovary cells. Eur. J. Biochem., v.242, n.3, p.608-618, 1996.

ARORA, T.; MEHTA, A.K.; JOSHI, V.; MEHTA, K.D.; RATHOR, N.; MEDIRATTA, P.K.; SHARMA, K.K. Substitute of animals in drug research: An approach towards fulfillment of 4R's. Indian J. Pharm. Sci., v.73, n.1, p.1-6, 2011.

BAERT, B.DE; SPIEGELEER, B. Quality analytics of internet pharmaceuticals. Anal. Bioanal. Chem., v.398, n.1, p.125-136, 2010. 
BARTH, T.; SANGOI, M.D.; DA SILVA, L.M.; FERRETTO, R.M.; DALMORA, S.L. Assessment of rhEPO in pharmaceutical formulations by a reversed-phase liquid chromatography method and bioassay. J. Liquid Chromatogr. Relat. Technol., v.30, p.1277-1288, 2007.

BASAK, A.K.; RAW, A.S.; AL HAKIM, A.H.; FURNESS, S.; SAMAAN, N.I.; GILL, D.S.; PATEL, H.B.; POWERS, R.F.; YU, L. Pharmaceutical impurities: Regulatory perspective for Abbreviated New Drug Applications. Adv. Drug Deliv. Rev., v.59, n.1, p.64-72, 2007.

BASSET, R. Continued improvements in the quality and consistency of follitropin alfa, recombinant human FSH. Reprod. Biomed. Online, v.10, p.169-177, 2005.

BELLINI , M.H.; BARTOLINI, P. In vivo bioassay for the potency determination of human growth hormone in dwarf "little" mice. Endocrinology, v.132, p.2051-2055, 1993.

BIETLOT, H.P.; GIRARD, M., Analysis of recombinant human erythropoietin in drug formulations by high-performance capillary electrophoresis, J. Chromatogr. A, v. 759, p.177-184, 1997.

BLAND, J.M.; ALTMAN, D.G. Statistical methods for assessing agreement between two methods of clinical measurement, Lancet, v.1, p.307-310, 1986.

BONNEMA, S.J.; HEGEDUS, L. Radioiodine therapy in benign thyroid diseases: Effects, side effects, and factors affecting therapeutic outcome. Endocr Rev., v.33, n.6, p.920-980, 2012.

BOUSFIELD, G.R.; BUTNEV, V.Y.; WALTON, W.J.; NGUYEN, V.T.; HUNEIDI, J.; SINGH, V.; KOLLI, V.S.K.; HARVEY, D.J.; RANCE, N.E. All-or-none Nglycosylation in primate follicle-stimulating hormone $\beta$ subunits. Mol. Cel. Endocrinol., v.260, p.40-48, 2007. 
BRISTOW, A.F.; WILSON, C.; SUTCLIFFE, N. Reversed-phase high-performance liquid chromatography of human thyroid-stimulating hormone. J. Chromatogr., v.270, p.285-92, 1983.

BRISTOW, A.F.; JEFFCOATE, S.L. Analysis of therapeutic growth hormone preparations: report of an interlaboratory collaborative study on growth hormone assay methodologies, Biologicals, v.20, p.221-231, 1992.

BRISTOW, A.F. Assignment of quantities to biological medicines: An old problem re-discovered. Phil. Trans. R. Soc., v.369, n.1953, p.4004-4013, 2011.

CANONNE, C.; PAPANDREOU, M.J.; MEDRI, G.; VARRIER, B.; RONIN, C. Biological and immunochemical characterization of recombinant human thyrotrophin. Glycobiology, v.5, p.473-481, 1995.

CARVALHO, C.M.; OLIVEIRA, J.E.; ALMEIDA, B.E.; UEDA, E.K.M.; TORJESEN, P.A.; BARTOLINI, P.; RIBELA, M.T.C.P. Efficient isolation of the subunits of recombinant and pituitary glycoprotein hormones. J. Chromatogr. A, v.1216, n.9, p.1431-1438, 2009.

CHLENOV, M.A.; KANDYBA, E.I.; NAGORNAYA, L.V.; ORLOVA, I.L.; VOLGIN, Y.V. High-Performance Liquid-Chromatography of Human Glycoprotein Hormones. J. Chromatogr., v.631, n.1-2, p.261-267, 1993.

CHOI, J.H.; WONG, A.S.T.; HUANG H.F.; LEUNG P.C.K. Gonadotropins and ovarian cancer. End. Rew., v.28, p.440-461, 2007.

CHRISTIN-MAITRE, S.; TAYLOR, A.E.; KHOURY, R.H.; HALL, J.E.; MARTIN, K. A.; SMITH, P.C.; ALBANESE, C.; JAMESON, J.L.; CROWLEY, W.F.; JRSLUSS, P. M. Homologous in vitro bioassay for follicle-stimulating hormone $(\mathrm{FSH})$ reveals increased FSH biological signal during the mid- to late luteal phase of the human menstrual cycle. J Clin Endocrinol Metab., v.81, n.6, p.2080-2088, 1996. 
DALMORA, S.; OLIVEIRA, J.E.; AFFONSO, R.; GIMBO, E.; RIBELA, M.T.C.P.; BARTOLINI, P. Analysis of recombinant human growth hormone directly in osmotic shock fluids. J. Chromatogr. A, v.782, p.199-210, 1997.

DALMORA, S.L.; MASIERO, S.M.K.; OLIVEIRA, P.R.; SANGOI, M.D.; BRUM, L. Validation of an RP-LC method and assessment of rhG-CSF in pharmaceutical formulations by liquid chromatography and biological assay. J. Liq. Chromatogr. Rel. Technol., v.29, p.1753-1767, 2006.

DAMIANI, R.; OLIVEIRA, J.E.; VORAUER-UHL, K.; PERONI, C.N.; VIANNA, E.G.; BARTOLINI, P.; RIBELA, M.T.C.P. Stable expression of a human-like sialylated recombinant thyrotropin in a Chinese hamster ovary cell line expressing alpha 2,6sialyltransferase. Protein Expr. Purif., v.67, p.7-14, 2009.

DAMIANI, R.; ALMEIDA, B.E.; OLIVEIRA, J.E.; BARTOLINI, P.; RIBELA, M.T.C.P. Enhancement of human thyrotropin synthesis by sodium butyrate addition to serum-free CHO cell culture. Appl. Biochem. Biotechnol., v.171, p.1658-1672, 2013.

DE LEO, V.; MUSACCHIO, M.C.; DI SABATINO, A.; TOSTI, C.; MORGANTE, G.; PETRAGLIA, F. Present and future of recombinant gonadotropins in reproductive medicine. Curr. Pharm. Biotechnol., v.13, n.3, p.379-391, 2012.

DRIEBERGEN, R.; BAER, G. Quantification of follicle stimulating hormone (folitropin alfa): is in vivo bioassay still relevant in the recombinant age? Curr. Med. Res. Opin., v.19, p.41-46, 2003.

DUFAU, M.L.; MENDELSON, C.R.; CATT, K.J. A highly sensitive in vitro bioassay for luteinizing hormone and chorionic gonadotropin: Testosterone production by dispersed leydig cells. J. Clin. Endocrinol. Metab., v. 39, n.3, p.610-613, 1974. 
EAST-PALMER, J.; SZKUDLINSKI, M.W.; LEE, J.; THOTAKURA, N.R.; WEINTRAUB, B.D. A novel, nonradioactive in vivo bioassay of thyrotropin (TSH). Thyroid, v.5, p.5-9, 1995.

EUROPEAN PHARMACOPOEIA. 7. ed. Estrasburgo: EDQM, 2011.

FABRE, I. Alternative methods to animal experimentation: regulatory aspects, state of the art, and prospects. Bull. Academ. Veter. France, v.161, p.403-407, 2008.

FEKETE, S.; VEUTHEY, J.L.; GUILLARME, D. New trends in reversed-phase liquid chromatographic separations of therapeutic peptides and proteins: Theory and applications. J. Pharm. Biomed. Anal., v.69, p.9-27, 2012.

FENWICK, N.P.; FRASER, D. The three Rs in the pharmaceutical industry: perspectives of scientist and regulators. Anim. Welfare, v.14, p.367-377, 2005.

FERRETTO, R.M.; LEAL, D.P.; DA SILVA, L.M.; NOGUEIRA, D.R.; DALMORA, S.L. Validation of a size-exclusion LC method and assessment of rhEPO in pharmaceutical formulations by liquid chromatography and biological assay. $J$. Liquid Chromatogr. Relat. Technol., v.32, n.10, p.1392-1406, 2009.

FRAIETTA, R.; ZYLBERSTEJN, D.S.; ESTEVES, S.C. Hypogonadotropic hypogonadism revisited. Clinics., v.68, p.81-88, 2013.

GALET, C.; LECOMPTE, F.; COMBARNOUS, Y. Association/dissociation of gonadotropin subunits involves disulfide bridge disruption which is influenced by carbohydrate moiety. Biochem. Biophys. Res. Comm., v.324, p.868-873, 2004.

GARTHOFF, B.; HENDRIKSEN, C.F.M; BAYOL, A.; GONCALVES, D.; GRAUER, A.; DELEEUW, R.; VANNOORDWIJK, J.; PARES, M.; PIROVANO, R.; RIETH, M.; RONNEBERGER, H.; SPIESER, J.M.; STORRING, P.; VOSBECK, K.; WEICHERT, H. Safety and efficacy testing of hormones and related products - the 
report and recommendations of ECVAM workshop-9, ATLA-Altern. Lab. Anim., v.23, p.699-712, 1995.

GROOME, N.P.; ILLINGWORTH, P.J.; O'BRIEN, M.; PAI, R.; RODGER, F.E.; MATHER, J.P.; MCNEILLY, A.S. Measurement of dimeric inhibin $b$ throughout the human menstrual cycle. J. Clin. Endocrinol. Metab., v.81, n.4, p.1401-1405, 1996.

HALDER, M.; HENDRIKSEN, C.F.M.; CUSSLER, K.; BALLS, M. ECVAM's contributions to the implementation of the Three Rs in the production and quality control of biologicals, ATLA-Altern. Lab. Anim., v.30, p.93-108, 2002.

HARA, K.; RATHNAM, P.; SAXENA, B.B. Structure of carbohydrate moieties of alpha-subunits of human follitropin, Lutropin, and Thyrotropin. J. Biological Chem., v.253, n.5, p.1582-1591, 1978.

HARTREE, A.S.; RENWICK, A.G.C. Molecular-structures of glycoprotein hormones and functions of their carbohydrate components. Biochem. J., v.287, p.665-679, 1992.

HARTUNG, T.; HOFFMANN, S.; STEPHENS, M. Mechanistic validation. ALTEX., v.30, n.2, p.119-130, 2013.

HENDRIKSEN, C.F.M. Reduction of numbers of animals used in the quality control of biologicals, ATLA-Altern. Lab. Anim., v.32, p.53-58, 2004.

HENDRIKSEN, C.F.M. Replacement, reduction and refinement alternatives to animal use in vaccine potency measurement, Expert Rev. Vaccines, v.8, p.313322, 2009.

HENDRIKSEN, C.F.M.; ARCINIEGA, J.L.; BRUCKNER, L.; CHEVALIER, M.; COPPENS, E.; DESCAMPS, J.; DUCHENE, M.; DUSEK, D.M.; HALDER, M.; KREEFTENBERG, H.; MAES, A.; REDHEAD, K.; RAVETKAR, S.D.; SPIESER, 
J.M.; SWAM, H. The consistency approach for the quality control of vaccines, Biologicals, v.36, p.73-77, 2008.

HIYAMA, J.; RENWICK, A.G.C. Separation of human glycoprotein hormones and their subunits by reversed-phase liquid-chromatography. J. Chromatogr., v.529, n.1, p.33-41, 1990.

HORSMAN, G.; TALBOT, J.A.; McLOUGHLIN, J.D.; LAMBERT, A.; ROBERTSON, W.R. A biological, immunological and physico-chemical comparison of the current clinical batches of the recombinant FSH preparations Gonal-F and Puregon. Hum. Reprod., v.15, p.1898-1902, 2000.

HOWLES, C.M. Role of LH and FSH in ovarian function. Mol. Cell. Endocrinol., v.161, p.25-30, 2000.

JIA, X.C.; KESSEL, B.; YEN, S.S.; TUCKER, E. M.; HSUEH, A.J. Serum bioactive follicle-stimulating hormone during the human menstrual cycle and in hyper- and hypogonadotropic states: Application of a sensitive granulosa cell aromatase bioassay. J. Clin. Endocrinol. Metab., v.62, n.6, p.1243-1249, 1986.

JIA, X.C.; HSUEH, A.J. Granulosa cell aromatase bioassay for follicle-stimulating hormone: Validation and application of the method. Endocrinology., v.119, n.4, p.1570-1577, 1986.

JUNG, C.; LEE, Y.; JEONG, Y.R.; KIM, J.Y.; KIM, Y.H.; KIM, H.S. Characterization of $\mathrm{N}$ alpha-acetyl methionyl human growth hormone formed during expression in Saccharomyces cerevisiae with liquid chromatography and mass spectrometry. $\boldsymbol{J}$. Chromatogr. B, v.814, p.53-59, 2005.

KOVALESKI, J.; KRAUT, B.; MATTIUZ, A.; GIANGIULIO, M.; BROBST, G.; CAGNO, W.; KULKARNI, P.; RAUCH, T. Impurities in generic pharmaceutical development. Adv. Drug Deliv. Rev., v.59, n.1, p.56-63, 2007. 
LARA-QUINTANAR, P.; LACUNZA, I.; SANZ, J.; DIEZ-MASA, J.C.; FRUTOS, M. Immunochromatographic removal of albumin in erythropoietin biopharmaceutical formulations for its analysis by capillary electrophoresis, J. Chromatogr. A, v.1153, p.227-234, 2007.

LEIST, M.; HASIWA, N.; DANESHIAN, M.; HARTUNG, T. Validation and quality control of replacement alternatives - current status and future challenges. Toxicol. Res., v.1, n.1, p.8-22, 2012.

LI, L.; TIAN, D.D.; CHEN, F.; YANG, J.L.; YU, K.; SUN, Y. Strategies for improving the quantitative bioanalytical performance of LC-MS in pharmacokinetic studies. Curr. Drug Metabol., v.13, n.9, p.1206-1212, 2012.

LISI, F. Gonadotropin therapies in assisted reproduction: safety, efficacy and costs evaluation. In: 17th WORLD CONGRESS ON CONTROVERSIES IN OBSTETRICS, GYNECOLOGY \& INFERTILITY (COGI), Nov 08-11, 2012, Portugal, Proceedings, p.61-65, 2013.

LIU, C.; DONG, S.; XU, X.; YIN, Y.; SHRIVER, Z.; CAPILA, I.; MYETTE, J.; VENKATARAMAN, G. Assessment of the quality and structural integrity of a complex glycoprotein mixture following extraction from the formulated biopharmaceutical drug product. J. Pharm. Biomed. Anal., v.54, p.27-36, 2011.

LONGSTAFF, C.; WHITTON, C.M.; STEBBINGS, R.; GRAY, E. How do we assure the quality of biological medicines? Drug Discov. Today, v.14, n.1-2, p.50-55, 2009.

LOUMAYE, E.; DREANO, M.; GALAZKA, A.; HOWLES, C.; HAM, L.; MUNAFO, A.; ESHKOL, A.; GIUDICE, E.; DE LUCA, E.; SIRNA, A.; ANTONETTI, F.; GIARTOSIO, C.E.; SCAGLIA, L.; KELTON, C.; CAMPBELL, R.; CHAPPEL, S.; DUTHU, B.; CYMBALISTA, S.; LEPAGE, P. Recombinant follicle stimulating hormone: development of the first biotechnology product for the treatment of infertility. Hum. Reprod. Update, v.4, p.862-881, 1998. 
LOUREIRO, R.F.; OLIVEIRA, J.E.; TORJESEN, P.A.; BARTOLINI, P.; RIBELA, M.T.C.P. Analysis of intact human follicle-stimulating hormone preparations by reversed-phase high-performance liquid chromatography. J. Chromatogr. A, v.1136, p.10-18, 2006.

LUSTER, M. Present status of the use of recombinant human TSH in thyroid cancer management. Acta Oncol., v.45, p.1018-1030, 2006.

MADDEN, J.C.; HEWITT, M.; PRZYBYLAK, K.; VANDEBRIEL, R.J.; PIERSMA, A.H.; CRONIN, M.T. Strategies for the optimisation of in vivo experiments in accordance with the 3Rs philosophy. Regul Toxicol Pharmacol., v.63, n.1, p.140154, 2012.

MATTALIANO, R.J.; WHITTAKER, B.G.; LOSAPIO, N.M.; CHENEY, L.; COLE, E.S.; PRATT, B.M. Analysis of bioactivity of recombinant human thyroid stimulating hormone in T4 supressed mice. Thyroid, v.5, p.S1-S225, 1995.

McKENZIE, J.M. The bioassay of thyrotropin in serum. Endocrinology, v.63, p.372-382, 1958.

MENDONÇA, F.; OLIVEIRA, J.E.; BARTOLINI, P.; RIBELA, M.T.C.P. Two-step chromatographic purification of recombinant human thyrotropin and its immunological, biological, physico-chemical and mass spectral characterization. $\boldsymbol{J}$. Chromatogr. A, v.1062, p.103-112, 2005.

METZ, B.; BRUNEL, F.; CHAMBERLIN, C.; VAN DER GUN, J.; HALDER, M.; JISKOOT, W.; KERSTEN, G.; VAN OPSTAL, O.; PETERSEN, J.W.; RAVETKAR, S.D.; REDHEAD, K.; SCHWANIG, M.; WILHELMSEN, E.S.; VANN, W.F.; HENDRIKSEN, C. The potential of physicochemical and immunochemical assays to replace animal tests in the quality control of toxoid vaccines. The report and recommendations of ECVAM workshop 61. ATLA-Altern. Lab. Anim., v.35, p. 323-331, 2007. 
MIETHE, G. Possibilities of replacing and reducing animal tests in the pharmacopoeias: an evaluation of unused methods and proposals for change. Atla-Altern. Lab. Anim., v.30, p.229-240, 2002.

MINEGISHI, T.; NAKAMURA, K.; TAKAKURA, Y.; IBUKI, Y.; IGARASHI, M.; MINEGISH, T. Cloning and sequencing of human FSH receptor cDNA. Biochem Biophys Res Commun., v.175, n.3, p.1125-1130, 1991.

MULDERS, J.W.M.; DERKSEN, M.; SWOLFS, A.; MARIS, F. Prediction of the in vivo biological activity of human recombinant follicle stimulating hormone using quantitative isoelectric focusing. Biologicals, v.25, p.269-281, 1997.

MULDERS, J.W.M.; WIJN, H.; THEUNISSEN, F.; MACHIELSEN, P.; JANSSEN, P. Prediction of the in vivo biological activity of human recombinant follicle stimulating hormone using quantitative isoelectric focusing. Optimization of the model. Pharm. Pharmacol. Commun., v.5, p.51-55, 1999.

MURALIDHAR, K.; CHAUDHARY, R. Assessment of current protocols for the production of therapeutic gonadotropins. Proc. Natl. Acad. Sci. India B, v.78, p.189-210, 2008.

NIKITAS, P.; PAPPA-LOUISI, A. Retention models for isocratic and gradient elution in reversed-phase liquid chromatography. J. Chromatogr. A, v.1216, n.10, p.1737-1755, 2009.

OBORA, S.; KUROSAWA, T. Implementation of the Three Rs in biomedical research - has the turn of the century turned the tide? ATLA-Altern. Lab. Anim., v.37, p.197-207, 2009.

OLIVEIRA, J.E.; SOARES, C.R.J.; PERONI, C.N.; GIMBO, E.; CAMARGO, I.M.C.; MORGANTI, L.; BELLINI, M.H.; AFFONSO, R. ; ARKATEN, R.R.; BARTOLINI, P.; RIBELA, M.T.C.P. High-yield purification of biosynthetic human growth hormone 
secreted in Escherichia coli periplasmic space, J. Chromatogr. A, v. 852, p. 441450, 1999.

OLIVEIRA, J.E.; MENDONCA, F.; PERONI, C.N.; BARTOLINI, P.; RIBELA, M.T.C.P. Determination of Chinese hamster ovary cell-derived recombinant thyrotropin by reversed-phase liquid chromatography. J. Chromatogr. B, v.787, p.345-355, 2003.

OLIVEIRA, J.E.; DAMIANI, R.; BARTOLINI, P.; RIBELA, M.T.C.P. Practical reversed-phase high-performance liquid chromatography method for laboratoryscale purification of recombinant human thyrotropin. J. Chromatogr. A, v.1164, p.206-211, 2007.

OLIVEIRA, J.E.; DAMIANI, R.; VORAUER-UHL, K.; BARTOLINI, P.; RIBELA, M.T.C.P. Influence of a reduced $\mathrm{CO}_{2}$ environment on the secretion yield, potency and N-glycan structures of recombinant thyrotropin from $\mathrm{CHO}$ cells. Mol. Biotechnol., v.39, p.159-166, 2008.

PARSONS, T.F.; STRICKLAND, T.W.; PIERCE, J.G. Rapid and easy separation of the subunits of bovine and human glycoprotein hormones by use of highperformance liquid-chromatography. Endocrinology, v.114, n.6, p.2223-2227, 1984.

PERERA-MARIN, G.; MURCIA, C.; GONZALEZ-PADILLA, E. Luteinizing hormone (LH) isoforms in ruminants: Characterization and physiological relevance. Anim. Reprod. Sci., v.101, n.3-4, p.187-207, 2007.

PERONI, C.N.; SOARES, C.R.J.; GIMBO, E.; MORGANTI, L.; RIBELA, M.T.C.P.; BARTOLINI, P. High-level expression of human thyroid-stimulating hormone in Chinese hamster ovary cells by co-transfection of dicistronic expression vectors followed by a dual-marker amplification strategy. Biotechnol. Appl. Biochem., v.35, p.19-26, 2002. 
RAO, C.V. Multiple novel roles of luteinizing hormone. Fertil. Steril., v.76, n.6, p.1097-1100, 2001.

RIBELA, M.T.C.P.; GOUT, P.W.; BARTOLINI, P. Synthesis and chromatographic purification of recombinant human pituitary hormones. J. Chromatogr. B, v.790, p.285-316, 2003.

RIBELA, M.T.C.P.; GOUT, P.W.; OLIVEIRA, J.E.; BARTOLINI, P. HPLC analysis of human pituitary hormones for pharmaceutical applications. A review. Curr. Pharm. Anal., v.2, p.103-126, 2006.

RIGGIN, R.M.; SHAAR, C.J.; DORULLA, G.K.; LAFEBER, D.S.; MINER, D.J. High-performance size-exclusion chromatography determination of the potency of biosynthetic human growth hormones products. J. Chromatogr., v.435, p.307$318,1988$.

RUSSELL, W.M.S.; BURCH, R.I. The principles of humane experimental technique, London, UK: Methuen, 1959.

SCHUTKOSKI, R.; SOUTO, R.B.; CALEGARI, G.Z.; ELSENBACH, L.I.; PORTO, L.P.; SCHRAMM, V.; STAMM, F.P.; DALMORA, S.L. Assessment of recombinant human erythropoietin by alternative bioassay and its correlation with liquid chromatography methods. Anal. Method., v.5, n.16, p.4238-4243, 2013.

SENDAK, R.A.; WANG, F.; GEAGAN, L.B.; ARMSTRONG, L.A.; THYNE, C.D.; COLE, E.S.; MATTALIANO, R.J. Comparison of two in vitro methods for the measurement of recombinant human TSH bioactivity. Biologicals, v.30, p.245$254,2002$.

SHOHAM, Z.; SMITH, H.; YEKO, T.; O'BRIEN, F.; HEMSEY, G.; O'DEA, L. Recombinant LH (lutropin alpha) for the treatment of hypogonadotrophic women with profound LH deficiency: a randomized, double-blind, placebo-controlled, proof-of-efficacy study. Clin. Endocrinol., v.69, p.471-478, 2008. 
SOARES, C.R.J, CAMARGO, I.M.C.; MORGANTI, L.; GIMBO, E.; OLIVEIRA, J.E.; LEGOUX, R.; FERRARA, P.; BARTOLINI, P. Reversed-phase highperformance liquid chromatography method for the determination of prolactin in bacterial extracts and in its purified form. J. Chromatogr. A, v.955, p.229-236, 2002.

SONG, D; WANG, J. Modified resolution factor for asymmetrical peaks in chromatographic separation, J. Pharm. Biomed. Anal., v.32, p.1105-1112, 2003.

SPIESER, J.M. Alternatives to Animal Testing: New Approaches in the Development and Control of Biologicals, in: Proceedings of International Symposium organized by the European Directorate for the Quality of Medicines \& HealthCare (EDQM), Council of Europe in close co-operation with the Ministry of Health and Social Welfare of Croatia, Dubrovnik, Croatia, p.37-38, 2008.

STAMM, F.P.; CALEGARI, G.Z.; DE FREITAS, G.W.; SOUTO, R.B.; PORTO, L.P.; CARDOSO Jr, C.D.A.; DALMORA, S.L. Assessment of recombinant human parathyroid hormone: Correlation of LC methods with bioassays. Analyst, v.138, n.5, p.1419-1426, 2013.

STAUB, A.; GUILLARME, D.; SCHAPPLER, J.; VEUTHEY, J.L.; RUDAZ, S. Intact protein analysis in the biopharmaceutical field. J. Pharm. Biomed. Anal., v.55, n. 4, p.810-822, 2011.

STEELMAN, S.L.; POHLEY, F.M. Assay of the follicle stimulating hormone based on the augmentation with human chorionic gonadotropin. Endocrinology, v.53, p.604-616, 1953.

STORRING, P.L.; DAS, R.E.G.; MULDERS, J.M.W.; HALDER, M. Physicochemical methods for predicting the biological potency of recombinant follicle stimulating hormone: an international collaborative study of isoeletric focusing and capillary zone electrophoresis. Biologicals, v.30, p.217-234, 2002. 
SZKUDLINSKI, M.W.; GROSSMANN, M.; LEITOLF, H.; WEINTRAUB, B.D. Human thyroid-stimulating hormone: structure-function analysis. Methods, v.21, p.67-81, 2000.

SZKUDLINSKI, M.W.; FREMONT, V.; RONIN, C.; WEINTRAUB, B.D. Thyroidstimulating hormone and thyroid-stimulating hormone receptor structure - Function relationships. Physiol. Rev., v.82, p.473-502, 2002.

UEDA, E.K.M.; GOUT, P.W.; MORGANTI, L. Ni(II)-based immobilized metal ion affinity chromatography of recombinant human prolactin from periplasmic Escherichia coli extracts. J. Chromatogr. A, v.922, p.165-175, 2001.

ULLOA-AGUIRRE, A.; TIMOSSI, C.; BARRIOS-DE-TOMASI, J.; MALDONADO, A.; NAYUDU, P. Impact of carbohydrate heterogeneity in function of folliclestimulating hormone: studies derived from in vitro and in vivo models. Biol. Reprod., v.69, p.379-389, 2003.

VAN DAMME, M.P.; ROBERTSON, D.M.; MARANA, R.; RITZEN, E.M.; DICZFALUSY, E. A sensitive and specific in vitro bioassay method for the measurement of follicle-stimulating hormone activity. Acta Endocrinol. (Copenh), v.91, n.2, p.224-237, 1979.

VAN DAMME, M.P.; ROBERTSON, D.M.; DICZFALUSY, E. An improved in vitro bioassay method for measuring luteinizing hormone ( $\mathrm{LH}$ ) activity using mouse leydig cell preparations. Acta Endocrinol. (Copenh), v.77, n.4, p.655-671, 1974.

VAN HELL, H.; OVERBEEK, G.A.; MATTHIJSEN, R. Effects of human menopausal gonadotrophin preparations in different bioassay methods. Acta Endocrinol., v.47, n.3, p.409-418, 1964.

WILHELMI, A.E.; Growth hormone bioassay. In: Berson S.A., Yalow R.S. (Ed.). Methods in Investigative and Diagnostic Endocrinology, North Holland, Amsterdam, 1973. p.296-302. 
WORTH, A.P.; BALLS, M. The principles of validation and the ECVAM validation process. Altern. Lab. Anim., v.32 Supl 1B, p.623-629, 2004.

ZACHARIS, C.K. Accelerating the quality control of pharmaceuticals using monolithic stationary phases: a review of recent HPLC applications. J. Chromatogr. Sci., v.47, n.6, p.443-51, 2009.

ZHAO, Y.L.; BREZINA, P.; HSU, C.C.; GARCIA, J.; BRINSDEN, P.R.; WALLACH, E. In vitro fertilization: Four decades of reflections and promises. Biochim. Biophys. Acta Gen. Subj., v.1810, n.9, p.843-852, 2011. 